Purdue University

Purdue e-Pubs

Open Access Theses

Theses and Dissertations

$12-2016$

\title{
Multimedia techniques for construction education and training
}

Wayne A. Bunnell

Purdue University

Follow this and additional works at: https://docs.lib.purdue.edu/open_access_theses

Part of the Civil Engineering Commons

\section{Recommended Citation}

Bunnell, Wayne A., "Multimedia techniques for construction education and training" (2016). Open Access Theses. 836.

https://docs.lib.purdue.edu/open_access_theses/836

This document has been made available through Purdue e-Pubs, a service of the Purdue University Libraries. Please contact epubs@purdue.edu for additional information. 


\section{PURDUE UNIVERSITY \\ GRADUATE SCHOOL \\ Thesis/Dissertation Acceptance}

This is to certify that the thesis/dissertation prepared

By Wayne Andrew Bunnell

Entitled

MULTIMEDIA TECHNIQUES FOR CONSTRUCTION EDUCATION AND TRAINING

For the degree of Master of Science in Civil Engineering

Is approved by the final examining committee:

Darcy Bullock

Chair

James V. Krogmeier

四

Jon D. Fricker

$\nabla$

To the best of my knowledge and as understood by the student in the Thesis/Dissertation Agreement, Publication Delay, and Certification Disclaimer (Graduate School Form 32), this thesis/dissertation adheres to the provisions of Purdue University's "Policy of Integrity in Research” and the use of copyright material.

Approved by Major Professor(s): Darcy Bullock

Approved by:

Dulcy Abraham

$11 / 21 / 2016$

Head of the Departmental Graduate Program

Date 

MULTIMEDIA TECHNIQUES FOR CONSTRUCTION EDUCATION AND TRAINING

\author{
A Thesis \\ Submitted to the Faculty \\ of \\ Purdue University \\ by \\ Wayne A. Bunnell \\ In Partial Fulfillment of the \\ Requirements for the Degree \\ of \\ Master of Science in Civil Engineering
}

December 2016

Purdue University

West Lafayette, Indiana 
This work is dedicated to those who have been paramount in supporting me in my educational endeavor from the beginning to the end. Mom and Dad, you've been there since the beginning and this work is dedicated to you. Dad, you have always encouraged me to do my best. Although you've told me to, put me in Boy Scouts, and basically pounded it into my brain from day 1 , that's not the reason I do my best. I am inspired to reach my fullest potential and to do my best in everything I do because I see that your actions match your words, and I believe that actions speak much louder than words. You're living the example of the kind of professional that I've striven to become. I always have and always look up to you, as a father, as a mentor, as a role model, and as a friend. Mom, you're the one who's kept me going with your love and your support. If there's ever a question I have about anything, you are first on my list. You've been my moral compass, my chef's assistant, my idea bouncer, my emotional tap, my everything I've ever needed it when I needed it. Mom and Dad, you've always been there for me, and supported me, and believed in me through it all. It is because of your initial belief in me that I had the courage to believe in myself.

This work is also dedicated to Aunt Beccie and Uncle Will Tidmore without whom I'd not have been able to keep going. Aunt Beccie, your love and belief in me is unwavering. You've been there and helped me through everything from keeping my car freshman year to having me over for dinner for some serious conversations. I know that you're always just a phone call away and that I'm never truly on my own because I have you. Uncle Will, you too have always trusted and believed in me. You're inspiration to me because you've shown me that no matter how bad life gets, you can turn it around and make it good again. Aunt Beccie and Uncle Will, you guys have been the standby support and have served as my peace of mind because I knew that if I ever needed anything, even just a break from it all, you were and are just a phone call away.

Finally, I'd like to dedicate this work to the love of my life, Amber Millikan. We attribute this research as the reason we first met. Thus, it is only fitting that this work be dedicated to you also. Since the day that we've met, you've been my sunshine, my hope, my happiness, and my only thought. You have helped me through my writing, my presentations, and much of my other work. You've helped me through my anger, my upset, my anguish, and my stress. You're always there for me and willing to help, but most of all, you believe in me more than I believe in myself. It's your deep belief in me that keeps me going every day. 


\section{ACKNOWLEDGEMENTS}

I like to first express my deepest gratitude to my advisor, Dr. Bullock, for his direction, advice and guidance, and willingness to help. He has always shown great respect to his students, emphasizing that we are colleagues. I firmly believe that in order to get respect, one must give respect, and Darcy has my utmost respect. My research at the Traffic Lab has been safe, educational, productive, and fun. I am confident that without Darcy's enthusiasm and support, it would not have been quite so educational, productive, or fun. In addition, I would like to thank Dr. Fricker and Dr. Krogmeier for serving on my committee and reviewing this document. Their thoughts and opinions have helped me make this document as good as it possibly could be.

I would like to offer my appreciation to the many members of INDOT who have

helped me in my research in the field. Specifically, Rob Goldner, Elsadig Ibrahim, Cliff Walker, Tim Wells, and Ben Smith have been always ready to help and deserve special mention. I would also like to thank all the contractors and construction personnel, who are too many to name, that allowed us to deploy cameras on their construction sites. Without their support, this research would not be possible. 
Thanks to all of my colleagues at the Traffic Lab whose friendship and support made the lab a work environment that I wanted to come back to every day. Special thanks to Drake Krohn and Steve Remias for your help in the field work of this research. I would be remiss to not mention Lou Rymarcsuk's work in creating the all-inclusive program to produce time-lapse videos, which saved many hours of work in the lab, and is greatly appreciated.

I would like to thank all the staff at the JTRP office for really just taking care of us, whatever we needed. Bridget Brunton, Kym Pelfree, Terea (Morris) Walker, and Katie Hendryx have all been immensely helpful with anything and everything I've needed help on. A special thanks to Debbie Horton for all your support and kindness.

Finally, I would like to thank all my friends who have helped me through this entire process from my undergraduate colleagues including but not limited to Payden Johnson, Chris O'Brien and Dovydas Kackys, to my graduate colleagues such as Christos Gkartzonikas. And of course, I could not have accomplished anything without the support of my best friends and family. Debra Burrow has been in support of me $150 \%$ and deserves special mention, as do Zack and Tess Cassels, who have been with me through it all. 


\section{TABLE OF CONTENTS}

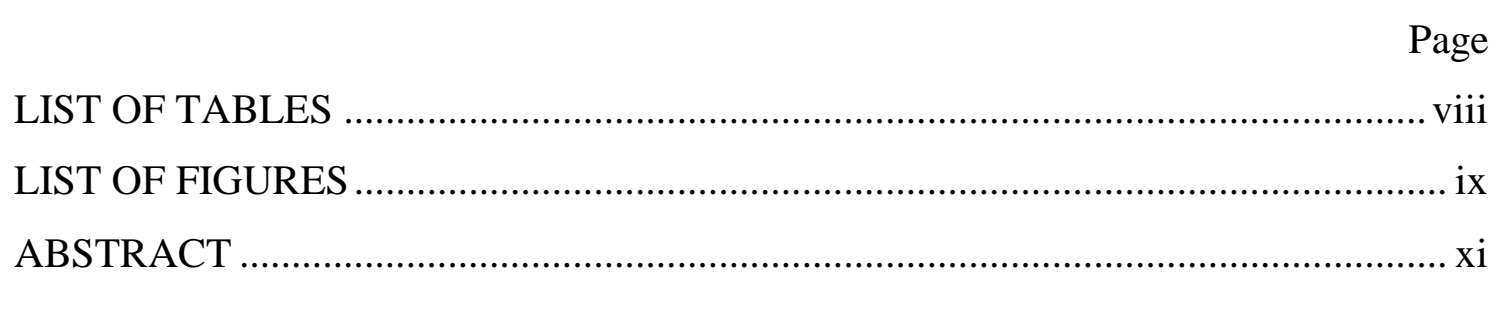

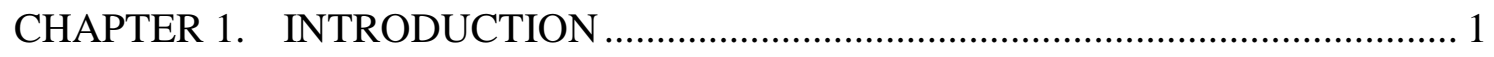

1.1 Introduction to Time-Lapse and Other Multimedia.............................................. 1

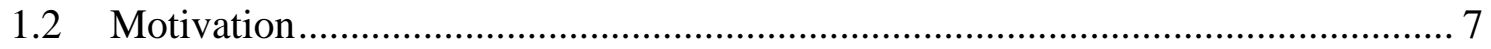

1.3 Time-Lapse Cameras and Considerations for Deployment .................................... 8

1.3.1 Wingscapes TimelapseCam Pro .............................................................. 8

1.3.2 Brinno TLC200 Pro................................................................................. 10

1.3.3 General Considerations .......................................................................... 12

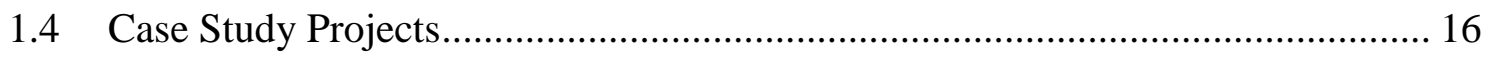

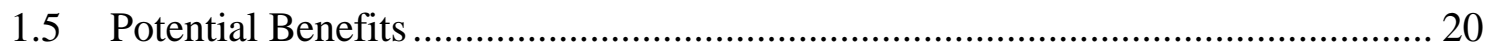

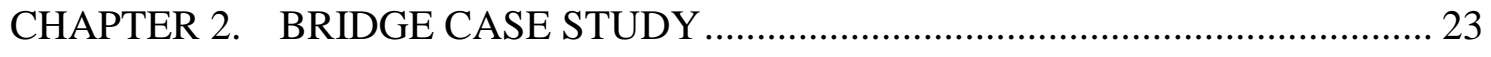

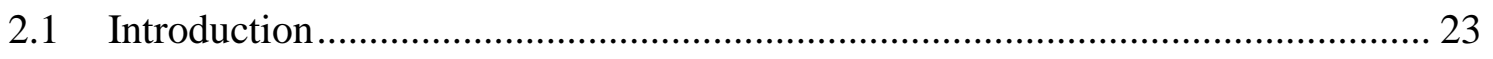

2.2 Bridge Support: Steel H-Piles ...................................................................... 24

2.3 Mechanically Stabilized Earth Retaining Wall .................................................... 31

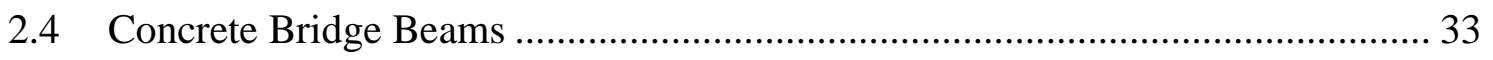

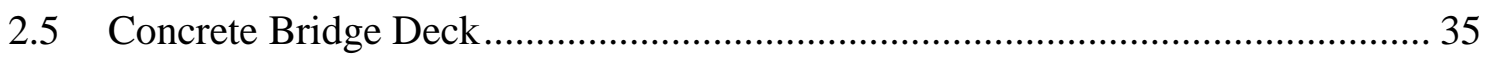

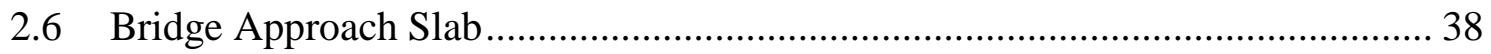

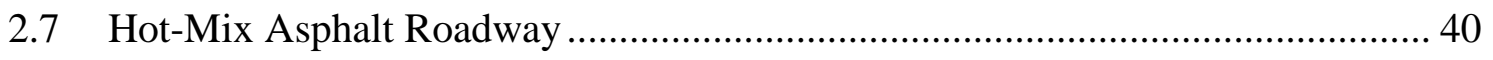

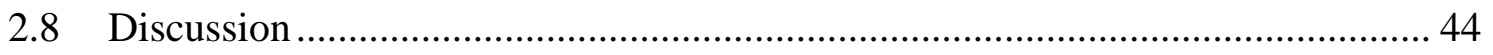

CHAPTER 3. MSE WALL CONSTRUCTION....................................................... 45

3.1 Introduction to Mechanically Stabilized Earth Walls .............................................. 45 
3.2 Leveling Pad Preparation and Construction .................................................... 49

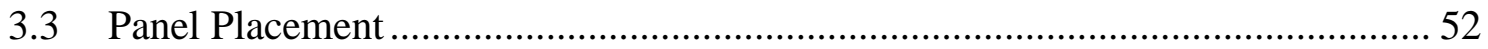

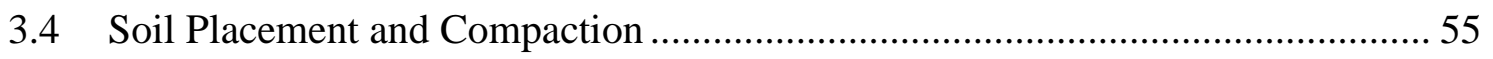

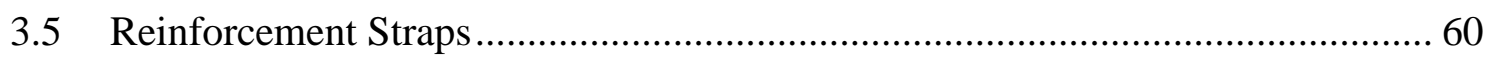

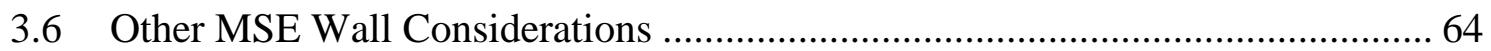

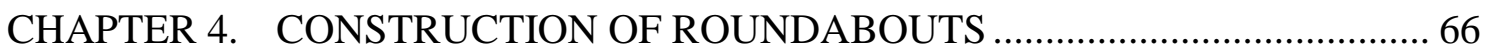

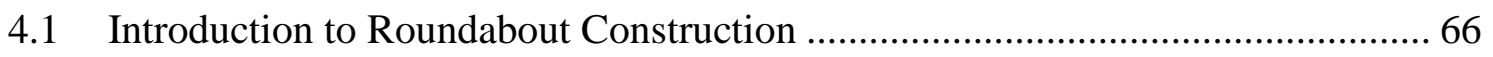

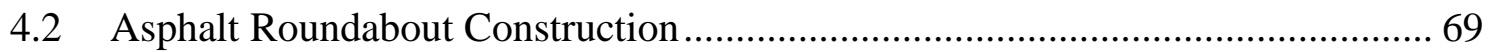

4.3 Concrete Roundabout Construction.................................................................... 72

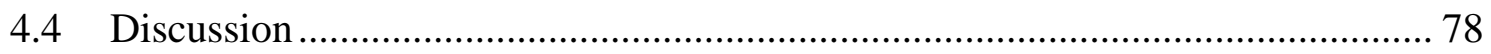

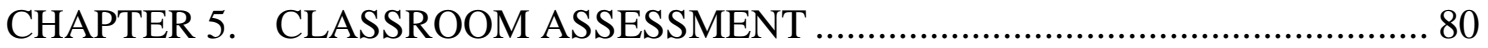

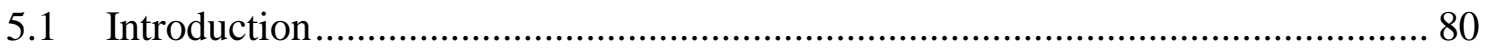

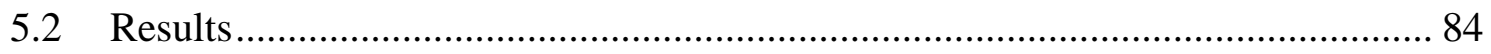

CHAPTER 6. BRIDGE DEMOLITION AND MEDIA CONTENT ………............... 91

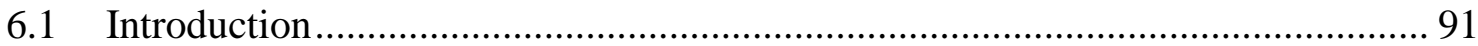

6.2 Sagamore Parkway US 52 Bridge Demolition …………………..................... 95

6.3 Whitewater River Bridge Demolition ................................................................ 99

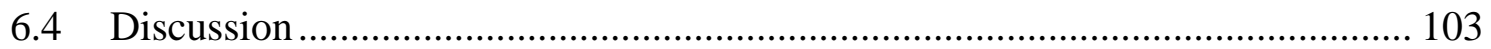

CHAPTER 7. TRAINING MATERIALS UTILIZED BY INDOT ............................ 104

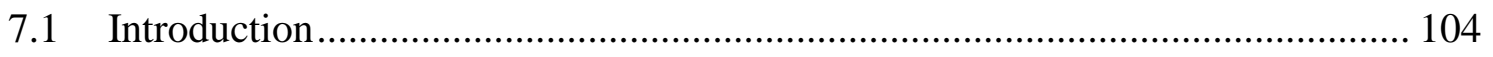

7.2 MSE Wall Construction Guidelines............................................................. 105

7.3 Underdrain Construction Guidelines …………............................................... 108

7.4 Implementation of Training Modules by INDOT .............................................. 111

CHAPTER 8. CONCLUSIONS …………………............................................. 113

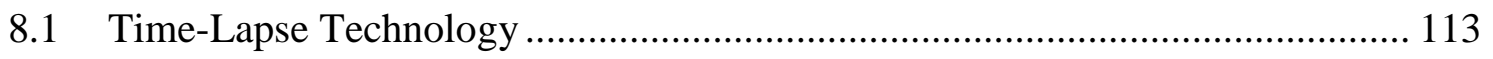

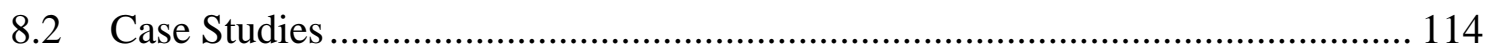

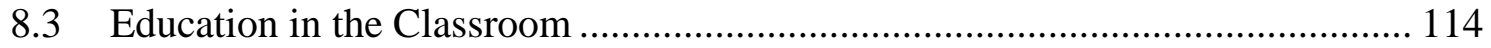

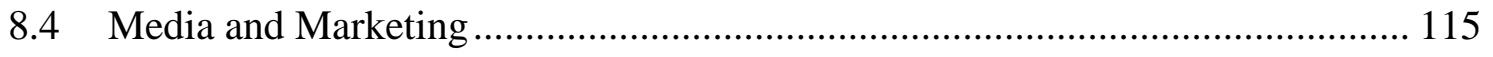

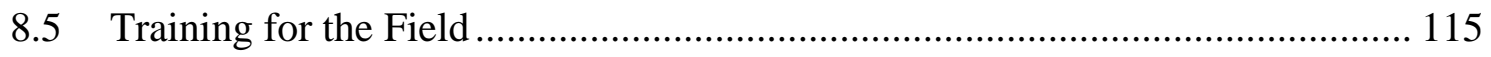

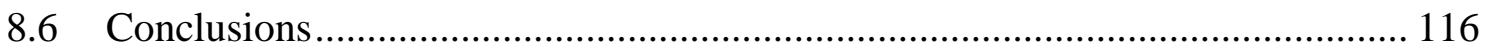




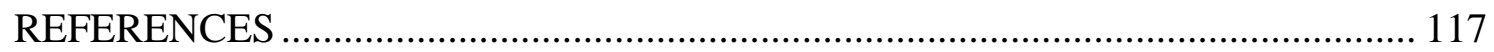

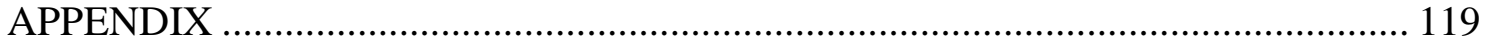




\section{LIST OF TABLES}

Table Page

Table 2.1 YouTube Video Demonstrating Time-Lapse Project Progress ..................... 28

Table 2.2 YouTube Time-Lapse Video Links For Case Study ................................... 29

Table 4.1 South Bend Roundabout Construction Schedule ...................................... 75

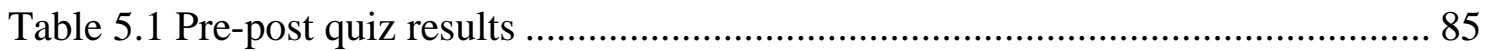




\section{LIST OF FIGURES}

Figure Page

Figure 1.1 INDOT Standard Specifications manual sample pages ............................ 4

Figure 1.2 Wingscapes time-lapse camera details............................................... 9

Figure 1.3 Brinno time-lapse camera details .................................................... 11

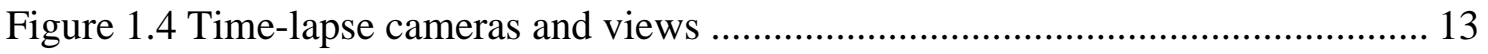

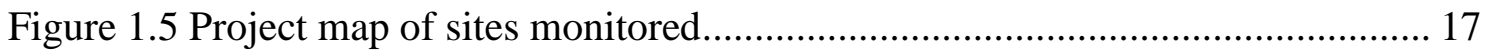

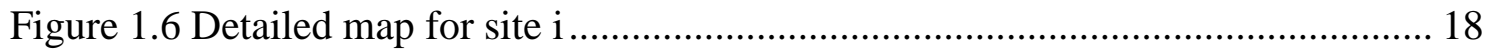

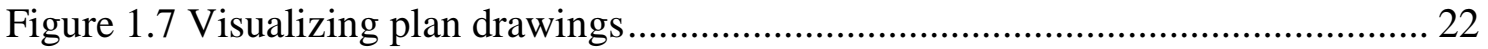

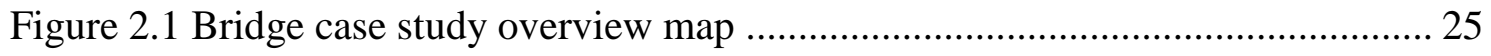

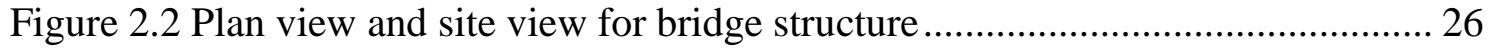

Figure 2.3 Construction of an overpass: Retaining wall and bridge construction......... 27

Figure $2.4 \mathrm{H}$-piles for mechanically stabilized earth wall and for bridge support ......... 30

Figure 2.5 Mechanically stabilized earth wall construction process on 5/7/2015 ......... 32

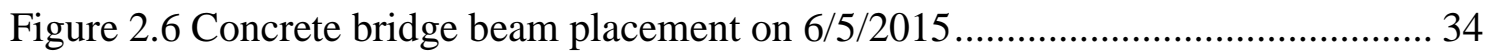

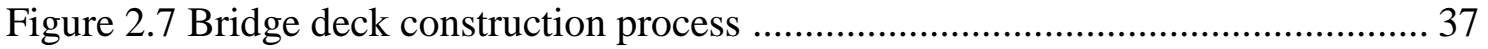

Figure 2.8 Bridge abutment construction process ........................................... 39

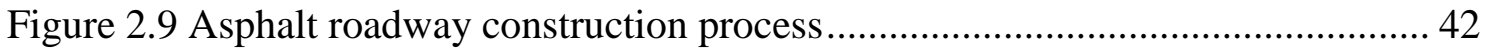

Figure 2.10 Underdrain installation process .................................................... 43

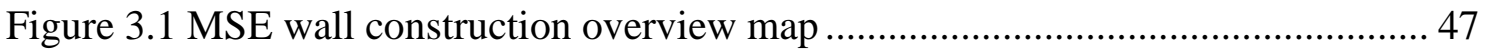


Figure 3.2 Construction process of a mechanically stabilized earth wall ..................... 48

Figure 3.3 Leveling pad construction process .................................................... 51

Figure 3.4 Erecting the first row of MSE wall panels ............................................. 53

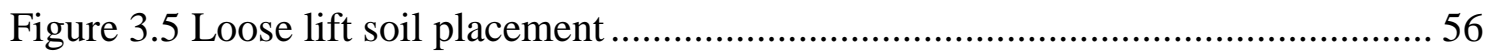

Figure 3.6 Proper/improper compaction methods ............................................... 59

Figure 3.7 Reinforcement strap placement and considerations .............................. 61

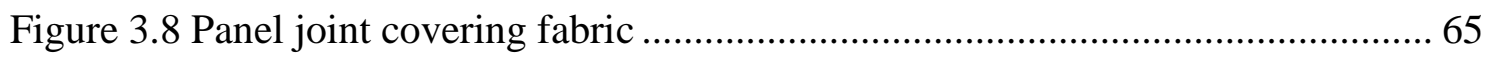

Figure 4.1 Flexible pavement roundabout overview and map ................................. 68

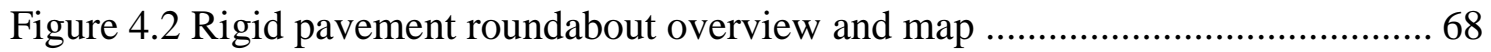

Figure 4.3 Asphalt roundabout construction process ......................................... 70

Figure 4.4 Concrete roundabout construction ................................................. 74

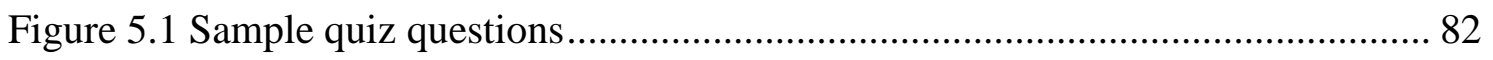

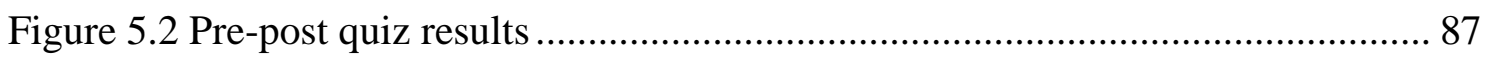

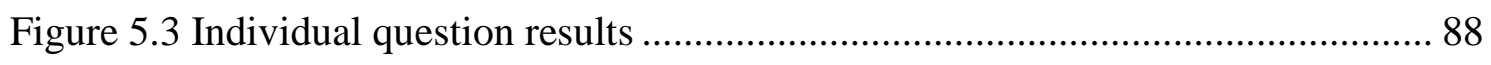

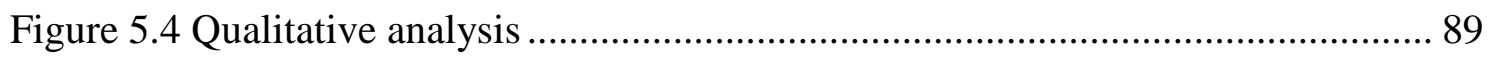

Figure 6.1 Sagamore Parkway bridge demolition overview .................................. 92

Figure 6.2 Old State Road 1 bridge demolition overview ...................................... 94

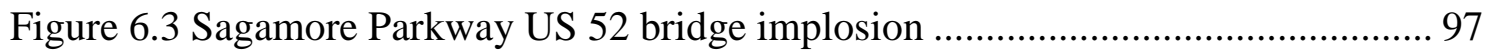

Figure 6.4 News Channel 18 interview on bridge demolition................................. 98

Figure 6.5 Demolition of Old State Road 1 Bridge over the Whitewater River .......... 102

Figure 7.1 MSE wall construction guidelines for inspectors and contractors ............. 106

Figure 7.2 Underdrain construction guidelines for inspectors and contractors ........... 110 


\begin{abstract}
Bunnell, Wayne A. M.S.C.E., Purdue University, December 2016. Multimedia Techniques for Construction Education and Training. Major Professor: Darcy Bullock.
\end{abstract}

The current profession of civil engineering often focuses education and training on code compliance rather than constructability and construction techniques. Also, it is well accepted that it takes a decade or more for engineers to develop a high-level project construction understanding and many state departments of transportation rely on in-field training for entry-level inspectors, with little or no education provisions for contractors. This research investigated the use of time-lapse photography to develop training and education material that will improve the understanding of project construction and crucial quality control specifications of an entry-level engineer, contractor, or inspector. Overall, the project team has deployed more than 160 timelapse cameras to capture and document various construction activities since the project inception in May 2015 on over 25 construction sites throughout the state of Indiana.

This document uses time-lapse photography and other media forms to monitor construction projects such as roadway construction on US 31 in Carmel and Westfield, construction of mechanically stabilized earth walls, roundabout construction, and bridge demolition in West Lafayette and Cedar Grove in order to develop educational and training materials for engineering students, construction inspectors, and contractors. 
This is accomplished in this document through construction case studies, time-lapse images, YouTube videos, and references to relevant INDOT Standard Specifications. Additionally, the project team has acquired quantitative data on the effectiveness of utilizing time-lapse photography to better educate in a classroom setting. The project team discovered that time-lapse photography did indeed enhance the lecture and following its use, students showed improvement. 


\section{CHAPTER 1. INTRODUCTION}

\subsection{Introduction to Time-Lapse and Other Multimedia}

The current profession of civil engineering often focuses education and training on code compliance rather than constructability and construction techniques. Also, it is well accepted that it takes a decade or more for engineers to develop a high-level project construction understanding, and many state departments of transportation rely on in-field training for entry-level inspectors, with little or no education provisions for contractors. This research investigated the use of time-lapse photography to develop training and education material that will improve the understanding of project construction and crucial quality control specifications of an entry-level engineer, contractor, or inspector. This document is organized as follows:

- Chapter 1.

This chapter provides an introduction to time-lapse photography and how it can be utilized for education and training in the field of Civil Engineering. The motivation for this research is described and specifics on time-lapse cameras are discussed. Sections of this chapter introduce the case studies that will be utilized in further chapters of this document and discuss the potential benefits that can be gained from this research. 
- Chapter 2: Bridge Case Study

Time-lapse images and videos from the US 31 construction project are used in conjunction with relevant passages from the INDOT Standard Specifications manual to demonstrate proper techniques relevant to constructing a bridge overpass.

- Chapter 3: MSE Wall Construction

Time-lapse images and videos also obtained from the US 31 construction project are used in this chapter to provide an overview of construction techniques for mechanically stabilized earth retaining walls. Relevant specifications from INDOT Standard Specifications manual are also referenced in this chapter.

- Chapter 4: Construction of Roundabouts

Time-lapse photography was utilized to document the construction of one asphalt roundabout along the US 31 corridor in Westfield and one concrete roundabout in South Bend. This chapter highlights the general processes related to constructing both roundabouts and compares the construction techniques. 
- Chapter 5: Classroom Assessment

In April of 2016, an experiment was conducted in Purdue Civil Engineering's CE361 class, "Introduction to Transportation Engineering," incorporating time-lapse images and videos into the teaching style. A before-and-after analysis was accomplished through the administration of two identical quizzes prior to and following the lecture.

\section{- Chapter 6: Bridge Demolition and Media Content}

In 2016, INDOT implemented the use of controlled explosive demolition to retire two separate bridges listed on the National Historic Bridge Registry. These bridges were located in West Lafayette and Cedar Grove. This chapter investigates the processes involved in bridge destruction and outlines specific points within the video footage of educational value.

- Chapter 7: Training Materials Utilized by INDOT

The project team has created training modules for INDOT and contractor inspectors, which have been implemented by INDOT in standard procedures. Two training modules featured in this chapter are the construction of mechanically stabilized earth retaining walls and underdrain construction.

Major infrastructure construction projects are often designed and constructed to last many decades. In order to ensure that this design life is met, multiple quality control mechanisms and practices are established to certify the proper completion of a project through all facets of construction. These quality control mechanisms include detailed design plans, thorough construction specifications, and the use of construction inspectors. However, there are often disconnects between the designers and the 
contractors. Inspectors and project managers often have to resolve these issues, which often results in costly change orders. It is highly desirable for designers, inspectors and project managers to have a shared vision on how various elements are constructed and the critical quality control check points.

Traditionally, this holistic knowledge is acquired through education and field experience. Obtaining such field experience for a single large-scale construction project can take nearly a decade from design to completion. The objective of this research is to provide designers, contractors, and inspectors with short comprehensive digital modules that can expedite the training and education process that typically can only be attained with years of field experience.

Currently, the Indiana Department of Transportation (INDOT) requires newlyhired inspectors to take inspection qualification tests for each inspection area. All guidelines for proper construction of field infrastructure are set out in the INDOT Standard Specifications book, a nearly 1200 page document sampled in Figure 1.1 (1). The Standard Specifications book is not written with the intent of education and training, but rather is oriented toward enforceable definitions. As a result, the INDOT Standard Specifications manual is not an effective training tool. This is a common characteristic of all DOT specification manuals. To supplement this inspection training, INDOT inspectors are also given the General Instructions to Field Employees (GIFE) as a reference guide (2). The INDOT GIFE manual is intended to serve as a set of general guidelines for employees in the field on INDOT construction projects. The GIFE manual is constantly being updated and is intended to promote procedural continuity among Indiana state inspectors on all state-owned construction projects. 


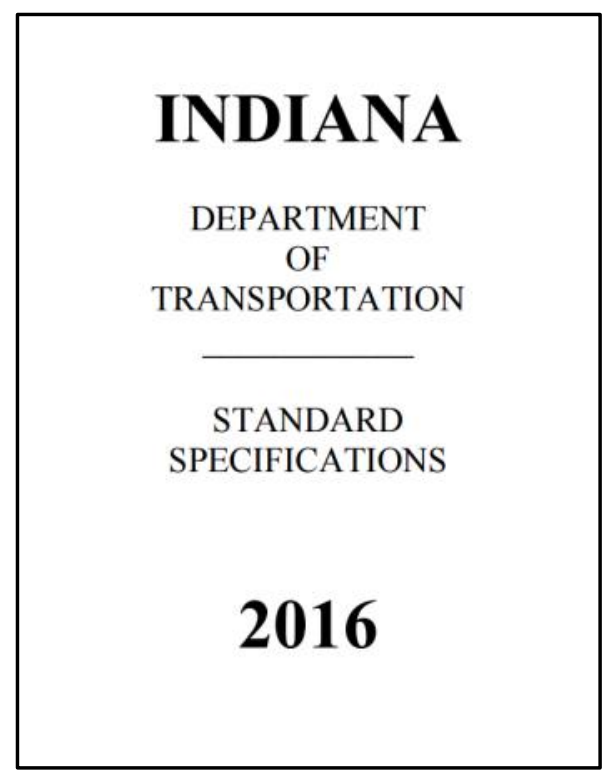

(a) Title page

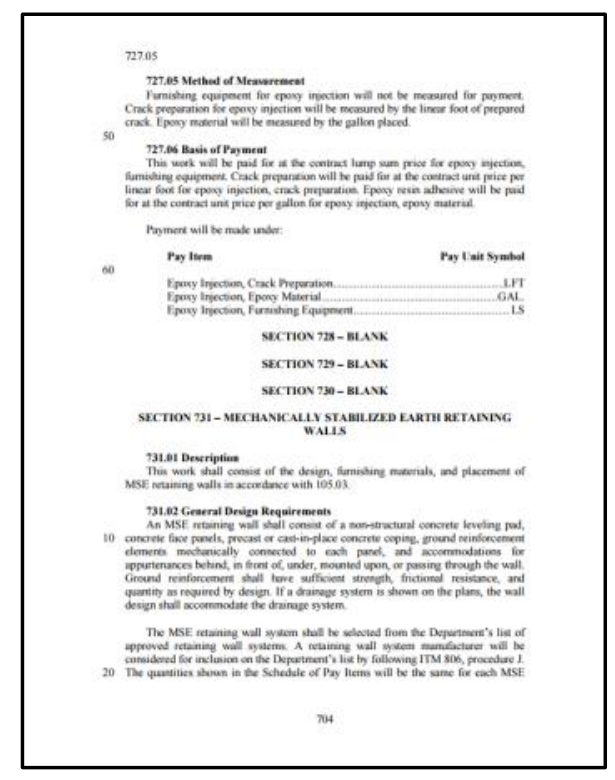

(c) MSE wall construction

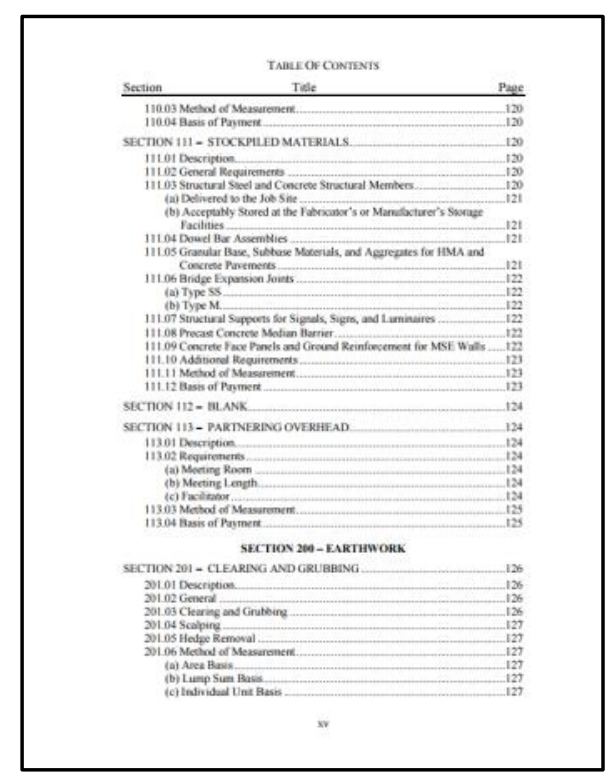

(b) Table of contents

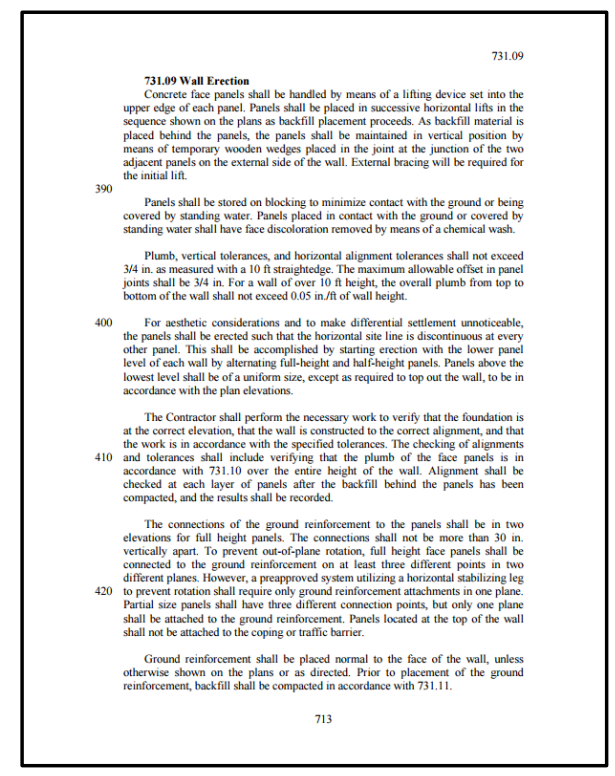

(d) MSE wall construction continued

Figure 1.1 INDOT Standard Specifications manual sample pages 
As with any position, new employees in the field experience a significant learning curve. It is difficult to absorb all of the proper construction practices on the construction site, as conditions are rapidly changing and new construction processes are occurring each week. A valuable quality control assessment can only be attained by having general knowledge of the construction activity prior to the assessment. As previously mentioned it is very difficult to achieve this knowledge without several years of field experience. The mental transition from plan drawings to construction completion can be a difficult skill to master. However, without this skill, the quality of the final construction project is affected.

Construction inspectors are expected to oversee multiple activities, sites, and inspection items. In addition, scheduling to be on site during critical quality control points can be challenging. Understanding that it is not feasible to have a construction inspector at every site at all times, it would be beneficial for an inspector to be able to replay the construction that took place at each site. This would allow an inspector to understand the work that had occurred in the previous day and determine if any construction issues had arisen.

Using time-lapse photography and other multimedia to document and virtually inspect large-scale infrastructure projects has the potential to significantly leverage an inspector's time. Time-lapse videos can provide weeks or even months of construction progress in minutes. Other multimedia, such as footage from a camcorder or a GoPro, is especially useful for capturing quicker processes such as the implosion of a bridge or very specific portions of a project. With multimedia footage from time-lapse cameras, images from digital single-image reflex cameras, and video content from camcorders, 
the project team has created several training modules for various field infrastructures. It is through these video modules that inspectors, engineers, and contractors may be able to gain on-site "experience" before ever stepping foot on the construction site. Individuals who have viewed the videos of documented construction projects will have a greater advantage when working on a project for the first time. Ideally, this advantage will ease and expedite a new-hire's transition and knowledge of the position. This could have a significant impact on both the construction and inspection industry.

Since 2013, INDOT has been utilizing time-lapse photography to document various construction projects (3), to identify and measure vehicle queue lengths (4), and to create public awareness videos for high-profile construction projects $(5,6)$. For the purposes of construction time-lapse, the project team has utilized several small, inexpensive, weather-proof, battery-operated time-lapse cameras. These cameras have the ability to take a photo of various image qualities at a specified time interval. Several image qualities were utilized throughout the duration of this project at one-minute intervals to balance image fidelity and data storage. 


\subsection{Motivation}

The pseudo-field experience gained by viewing training videos of relevant construction projects will provide a higher quality and longer lasting product that will save both time and money in the long term. To realize this goal, it is necessary to impart "big picture" understanding of large-scale construction projects to entry-level engineers, inspectors, and contractors. A major step in becoming a professional in the construction industry is developing the ability to visualize the final product in order to anticipate the construction process from a set of construction plans or specifications. Further chapters of this document will describe the step-by-step construction process of a bridge overpass, a mechanically stabilized earth wall, and asphalt and concrete roundabouts as case studies to illustrate the process of creating learning modules. These learning modules are intended to provide engineers, designers, and inspectors the opportunity to visualize the correlation between plan drawings and real-life structures. In order to boost the educational learning curve of future inspectors and engineers, images and learning modules can be utilized to enhance current training procedures. Subsequent chapters of this document describe the time-lapse videos used to illustrate construction practices. 


\subsection{Time-Lapse Cameras and Considerations for Deployment}

\subsubsection{Wingscapes TimelapseCam Pro}

The first time-lapse cameras used by the project team can be seen in Figure 1.2. These cameras are portable, waterproof, and battery-operated. The Wingscapes cameras have the ability to take photos of various image qualities, ranging from 0.7 megapixels (low quality) to 10 megapixels (high definition quality). The Wingscapes cameras require $6 \mathrm{C}$-cell batteries, shown in Figure $1.2 e$ and battery life of the cameras depends primarily upon the selected picture frequency. However, cameras capturing images at one-minute frequency were found to last up to three weeks without service.

These cameras output images sequentially named in a series of folders. Converting these images into a time-lapse video can be an arduous process, but the individual images are easily accessible. Figure $1.2 b$ shows the inside of the camera, where the liquid crystal display (LCD) screen is located. Note that the screen is in the front of the camera. This camera model allows the user to take and display test photographs for easier positioning. However, because the screen does not actively show a view from the camera, positioning the TimelapseCam is a tedious and iterative process involving many slight adjustments. Due to its odd shape, the general public may not know what it is or its worth. For this reason, these cameras are much less likely to be stolen from the construction site than a more recognizable camera such as the GoPro. 


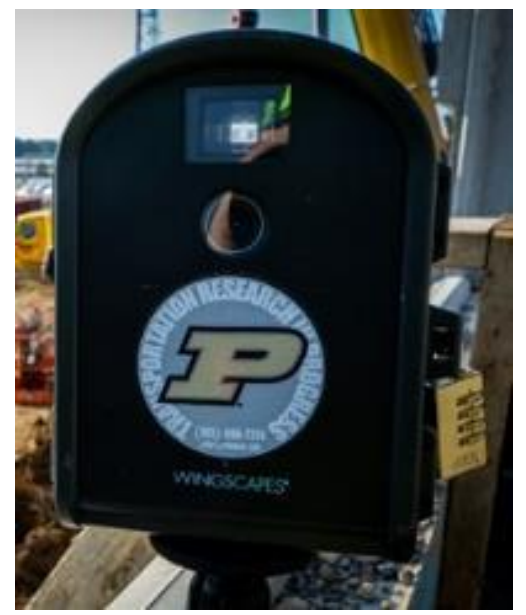

(a) Front of camera

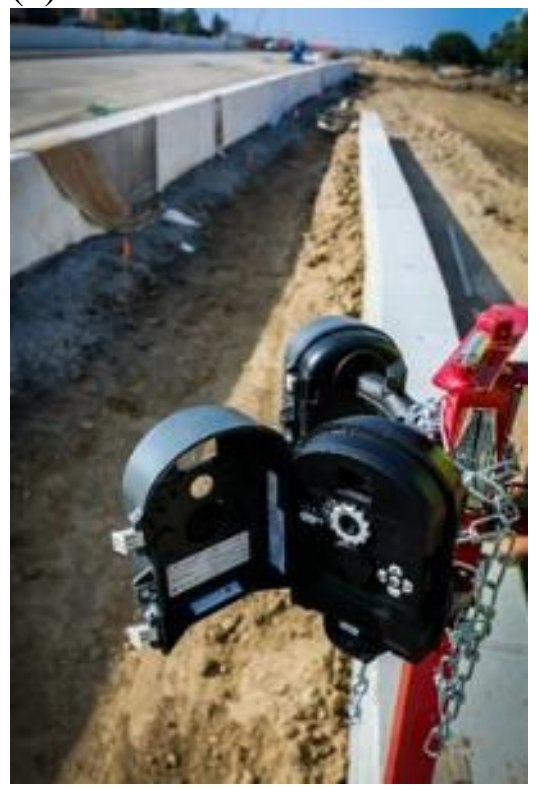

(c) Two mounting options

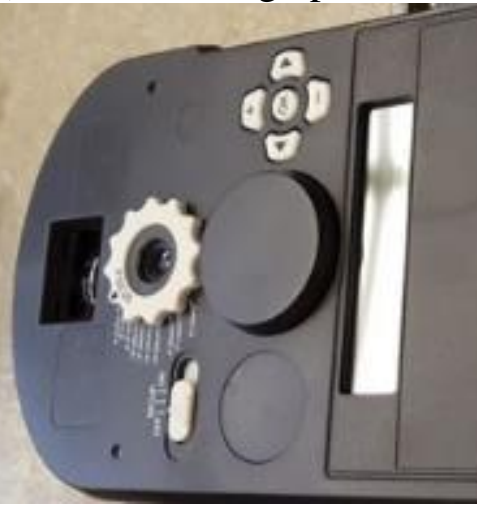

(e) Time-lapse camera takes $\mathrm{C}$-cell batteries

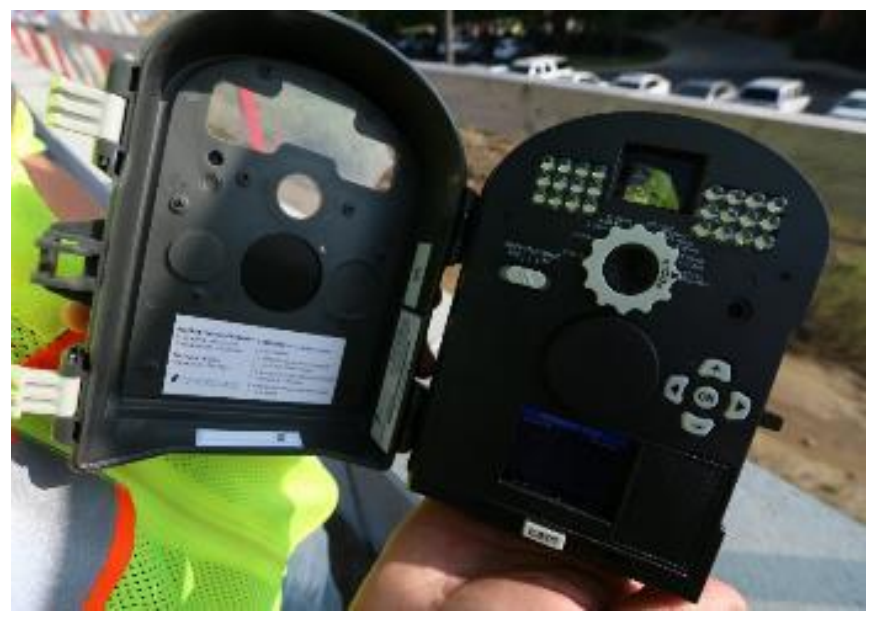

(b) Inside of camera and controls

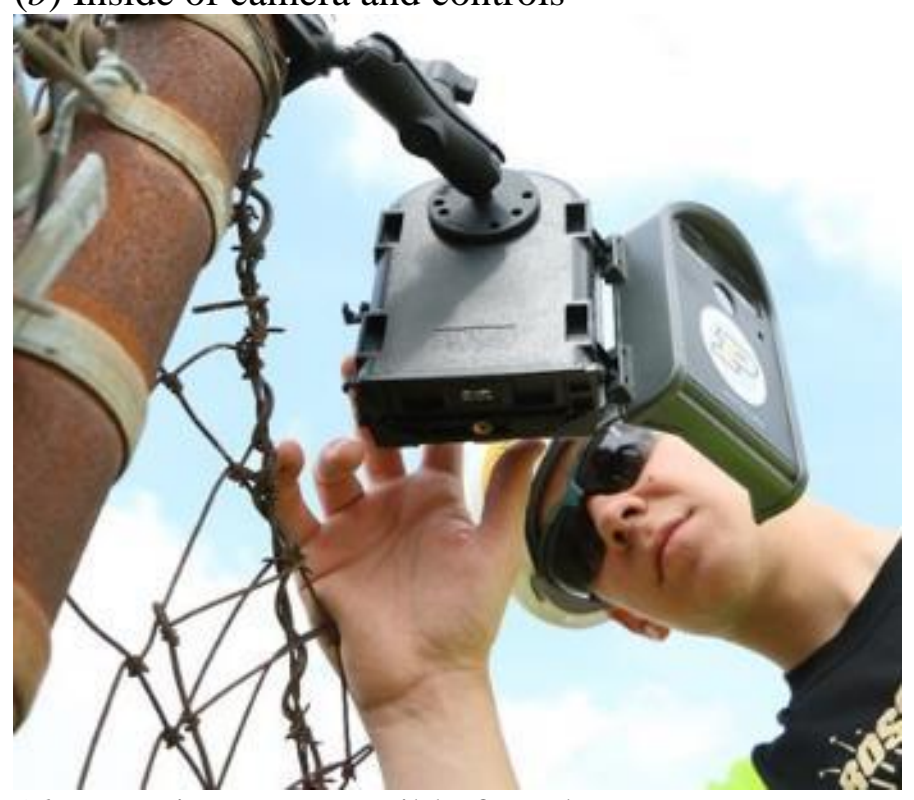

(d) Batteries are accessible from bottom

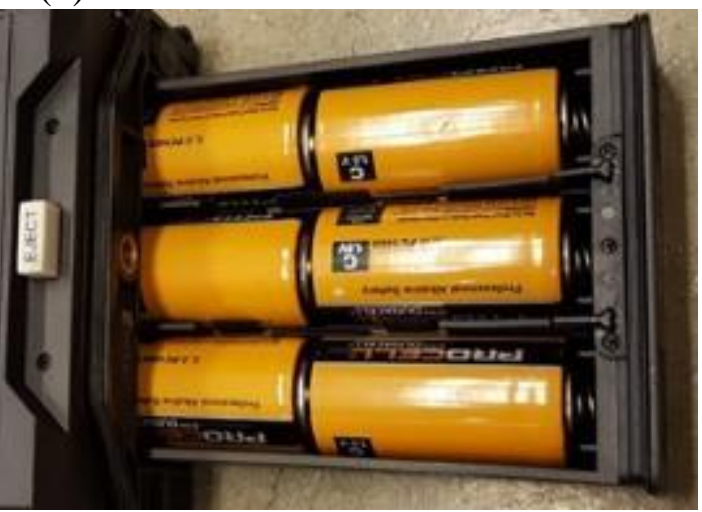




\subsubsection{Brinno TLC200 Pro}

Other time-lapse cameras explored by the project team can be seen in Figure 1.3 and are produced by Brinno. These cameras are smaller and easier to position than the Wingscapes cameras and also are battery-operated. The Brinno cameras also have the ability to take photos of various image qualities, but these cameras can also take images much more frequently than the Wingscapes cameras. The Brinno cameras require 4 AA-cell batteries, as seen in Figure 1.3e. Although battery life of the cameras depends primarily upon the selected picture frequency, cameras capturing images at the thirtysecond frequency were found to last well over one month without service. In fact, it was found that memory storage, rather than battery capacity was the limiting factor for the Brinno cameras.

These cameras produce time-lapse videos sequentially named. Unlike Wingscapes cameras, the Brinno cameras do not allow easy access to the individual pictures taken by the camera. However, using outside software, these images can be separated out of the video if necessary. Figure $1.3 b$ shows the back of the camera, where the liquid crystal display (LCD) screen is located. This camera model allows the user to actively see the view of the camera for easy positioning. Unfortunately, these cameras are not waterproof by themselves. Therefore, they require special all-weather cases, seen in Figure $1.3 c$ and Figure 1.3d. Perhaps the most important difference between the Brinno and Wingscapes cameras is that the Brinno cameras have a much wider field of view than the Wingscapes cameras. This makes the Brinnos much more useful in situations where the cameras must be placed close to a large object. Although 
the Brinno cameras tend to have a slight fish-eye effect, image quality is not generally affected.

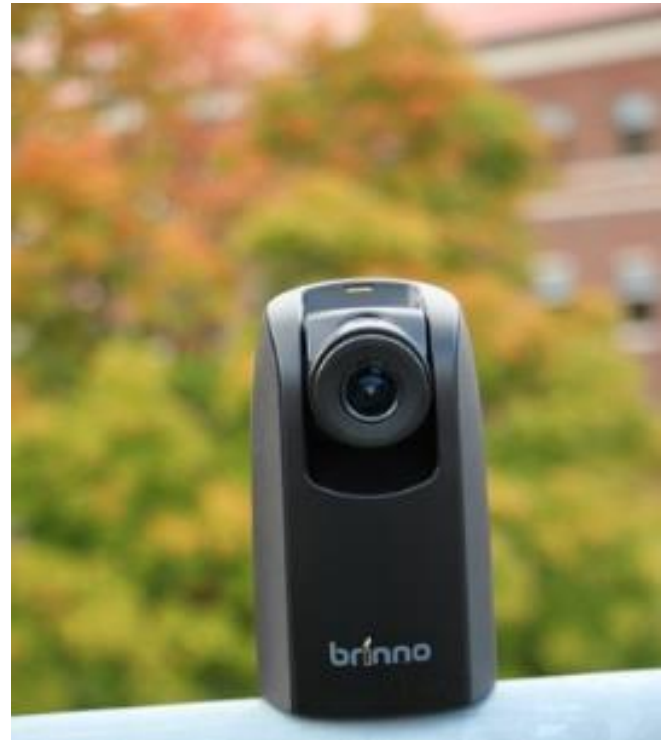

(a) Front of camera

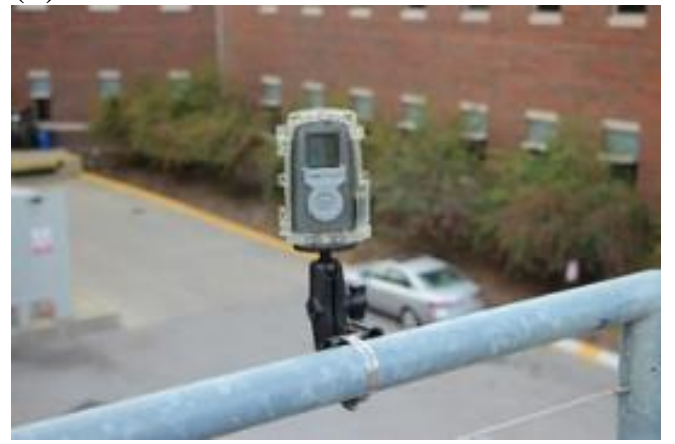

(c) Single mounting scheme

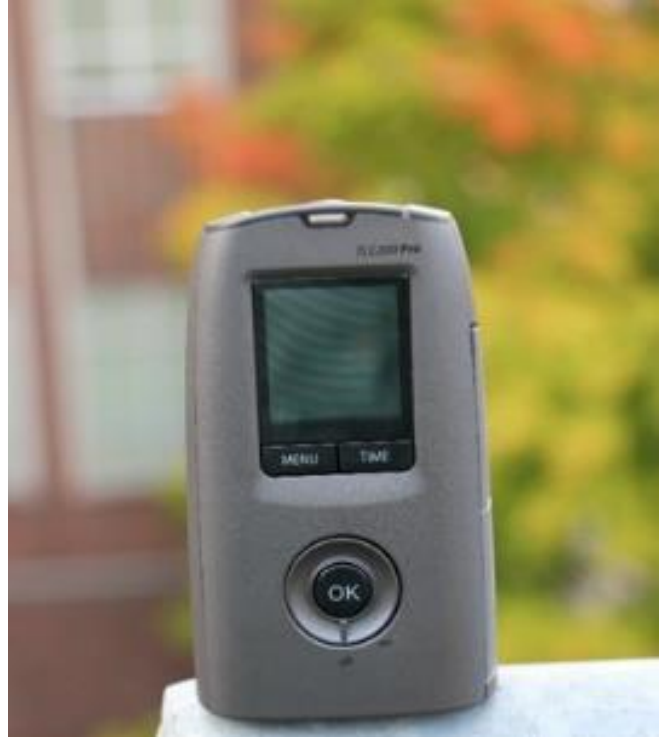

(b) Back of camera and controls

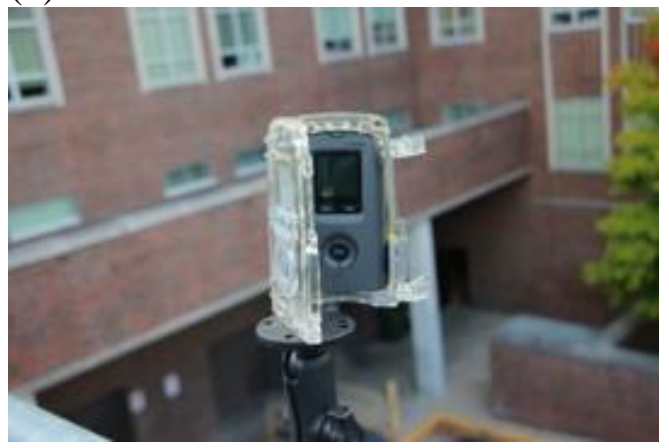

(d) Case preserves original view

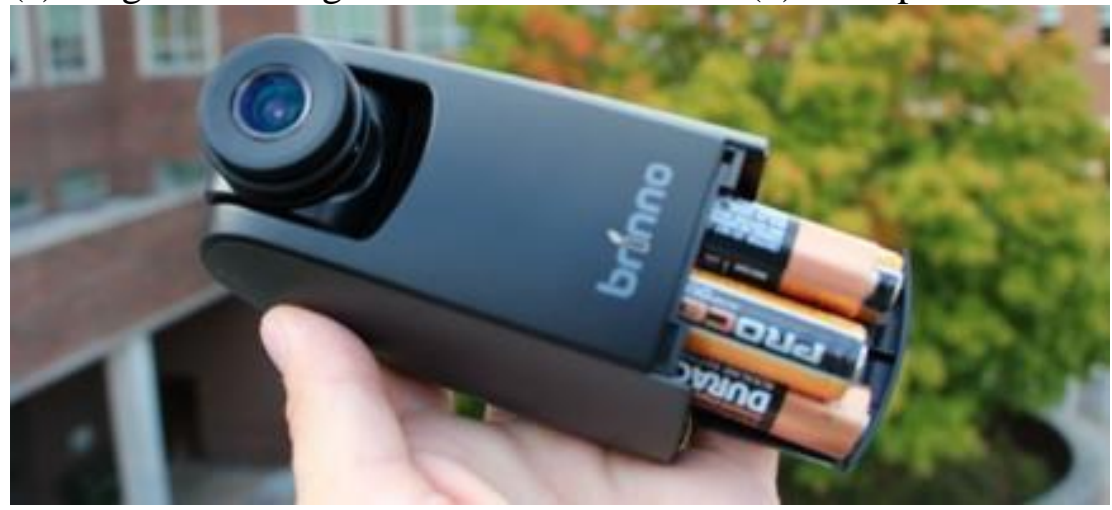

(e) Time-lapse camera takes AA-cell batteries, accessible from bottom

Figure 1.3 Brinno time-lapse camera details 


\subsubsection{General Considerations}

The time-lapse cameras were mounted to stationary objects such as utility poles, guardrails, and other permanent structures using metal camera mounts with hose clamps or ratchet straps. For security purposes, the time-lapse cameras were chained and locked in the field. Figure 1.2a and Figure $1.2 c$ demonstrate an example of how cameras may be placed and chained at the project site. Two examples of time-lapse camera placements can be seen in Figure 1.4. The Wingscapes time-lapse camera, mount, and chain can be seen in Figure 1.4a, while the view from that camera is shown in Figure 1.4b. This camera was used to observe the construction process of the overpass bridge described in greater detail in Chapter 2. Figure 1.4c, and Figure 1.4d show the Brinno camera and its view of roundabout construction in South Bend. The cameras in Figure $1.4 a$ and Figure $1.4 c$ correspond to videos listed further in this document. One video link in Chapter 2 shows the three-month construction process of the US 31 overpass bridge in one minute. 


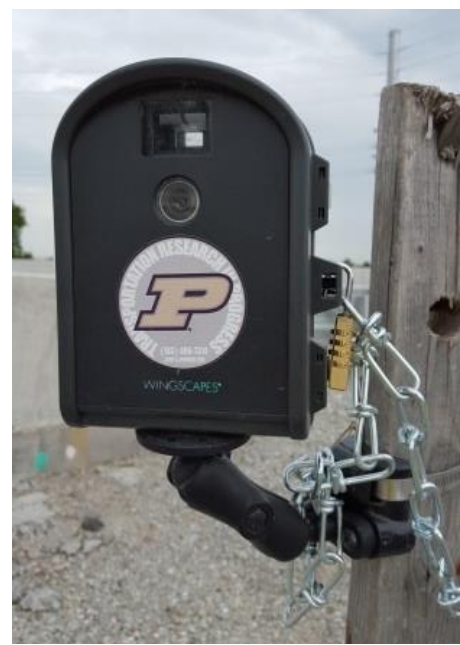

(a) Time-lapse camera 1a

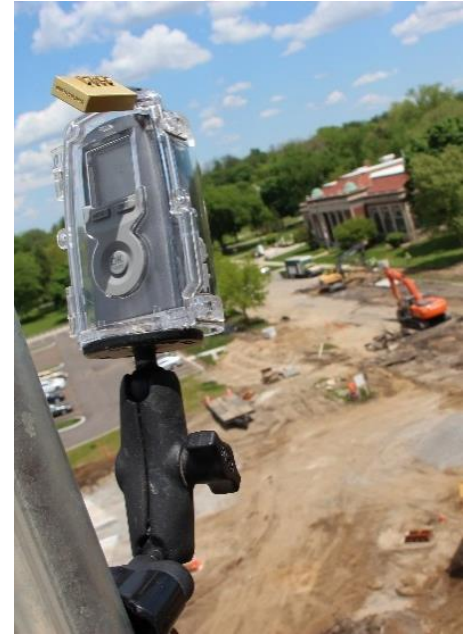

(c) Time-lapse camera 1b

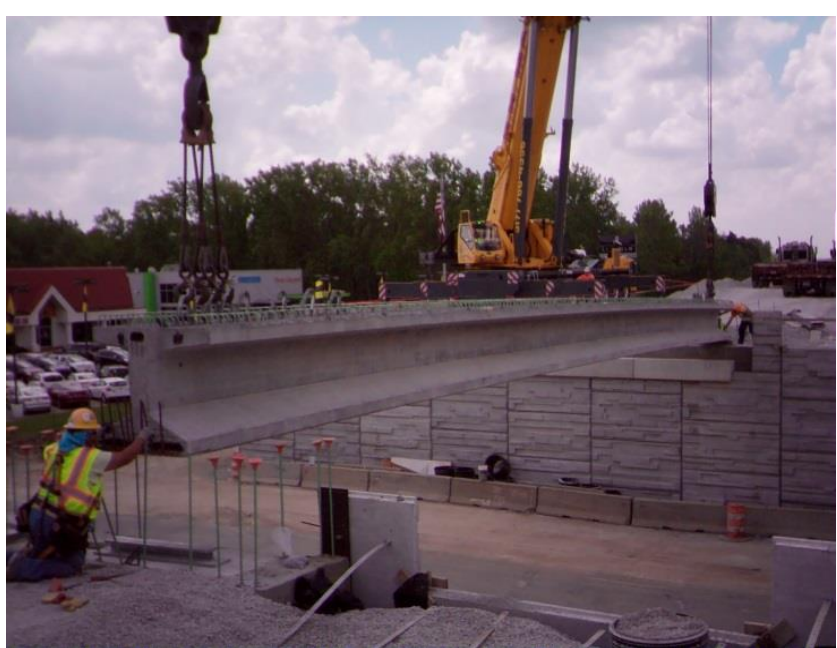

(b) View from time-lapse camera 1a on $6 / 5 / 2015$

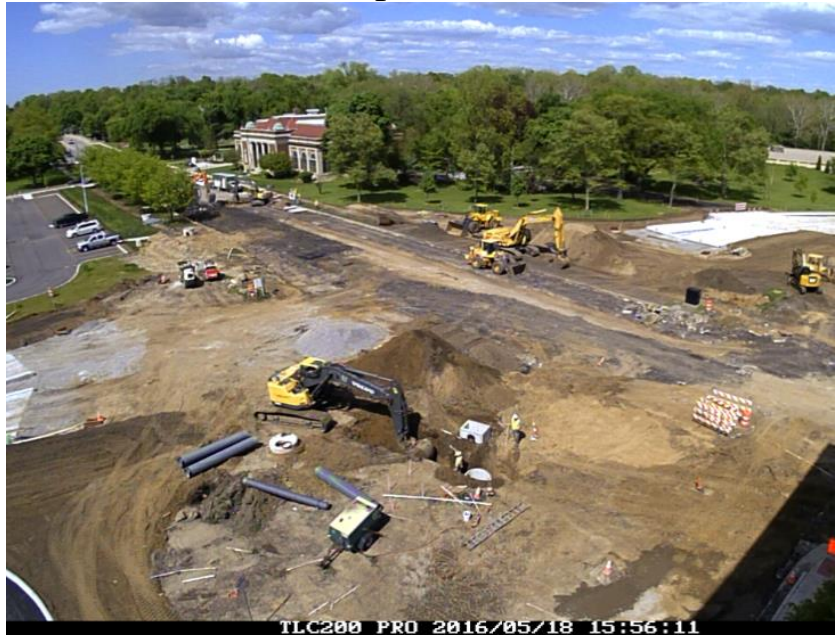

(d) View from time-lapse camera 1 b on 5/18/2016

Figure 1.4 Time-lapse cameras and views 
Depending on the size of the object to monitor, the availability and proximity of secure mounting locations to the object, and the space allotted for placement of a camera, there may be a significantly better choice. However, there are many instances that both cameras employed by the research team performed nearly identically.

Determining the proper location and mounting scheme is critical in obtaining a consistent video. The Wingscapes cameras have the ability to be mounted from the bottom (Figure 1.2a) or from the back (Figure 1.2d). The project team found that for consistency of video and for general ease of access, it is preferable to mount these cameras from the back. This prevents accidental positioning errors when changing the batteries, as bottom-mounting requires the user to remove the camera from the mount and therefore forfeit the current view in order to change the batteries (Figure 1.2e). In contrast, the Brinno time-lapse cameras have one single mounting scheme with the weather resistant cases, from the bottom (Figure 1.3c). Figure $1.3 d$ shows how the view is conserved although the camera is mounted from the bottom, and battery access is easily accomplished.

The project team found that in some situations, bottom-mounting is preferred to back mounting because of space restrictions at the mount location due to construction equipment or other physical barriers. Some mounting locations allow the photographer to be on either side of the camera. This is especially useful as it allows easier camera positioning and both cameras can be employed straightforwardly. However, many mounting locations can only be accessed from one side. For example, the mount itself may be a utility pole. The cameras can be mounted on the utility pole, but the back side 
of the camera is relatively difficult to access. This is a positioning issue for the Brinno camera as their positioning screen and controls are located on the back. In contrast, other mounting locations only allow safe and easy access from the rear, such as safety walkway railing overlooking a project. In this situation, the photographer would have to lean out over the railing and around the camera to see the LCD screen if he or she were to employ the Wingscapes time-lapse camera.

It was found that, in general, the Brinno cameras are more consistent and more reliable than the Wingscapes cameras. The Wingscapes cameras have been found to develop unexpected software glitches and experience random camera shut-off events. Aside from expected battery drain and memory limitations, the project team has experienced no such unpredictable issues with the Brinno cameras. In general, every site is different, and mounting availability is always a challenge. The photographer must be willing to adapt to his or her surroundings and a variety of camera types is recommended.

Overall, the project team has deployed more than 120 time-lapse cameras to capture and document various construction activities along the 13-mile US 31 corridor and other projects in 2015. To date, more than 160 time-lapse cameras have been deployed to document various projects throughout the state of Indiana. The project team has built a set of training modules for inspectors and engineers to help make the connection between construction plans, specifications, and the final construction product for mechanically stabilized earth retaining walls and for underdrain construction. These training modules are discussed in greater detail in Chapter 7. 


\subsection{Case Study Projects}

Since the project's inception in May of 2015, the project team has had the opportunity to monitor over 25 construction sites throughout the state of Indiana. Figure 1.5 shows four of the sites monitored by the project team that were selected as case studies in this document. Callout $i$. shows the main construction project on which time-lapse cameras have been implemented, the construction along US 31 in Hamilton County. Callout ii. shows the location of the concrete roundabout construction in South Bend. This was selected as a case study in Chapter 4. The demolition of the old Sagamore Parkway (US 52) bridge over the Wabash River in West Lafayette is shown in Callout iii. The demolition of the Old State Road 1 bridge over the Whitewater River in Cedar Grove is shown in Callout $i v$. Both Callouts iii and $i v$ show projects described in Chapter 6.

One project that will be utilized as a case study in this document takes place in Hamilton County, Indiana as an upgrade of US Route 31 from a signalized arterial to a grade-separated roadway. This project is discussed in detail in Chapter 2, which outlines the construction of the bridge over $169^{\text {th }}$ Street. Additionally, relevant passages from the INDOT Standard Specifications manual are extracted and highlighted in correspondence with the YouTube videos featured in the chapter. Figure 1.6 shows the sites from which other time-lapse sequences along the US 31 project were obtained. 


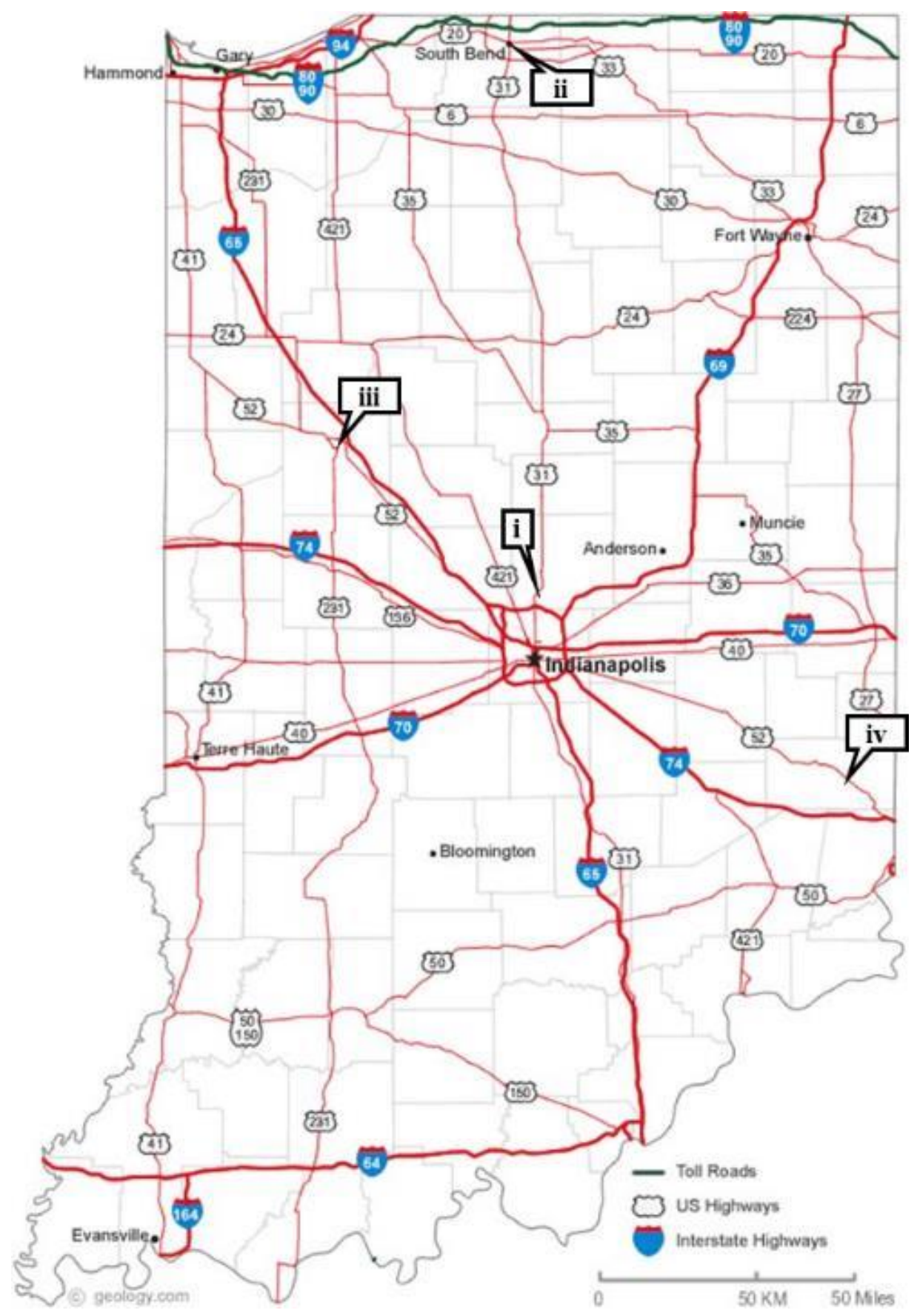

Figure 1.5 Project map of sites monitored

i. US 31 Corridor in Carmel and Westfield

ii. South Bend Roundabouts

iii. West Lafayette Sagamore Parkway Bridge

iv. Cedar Grove Old State Road 1 Bridge 


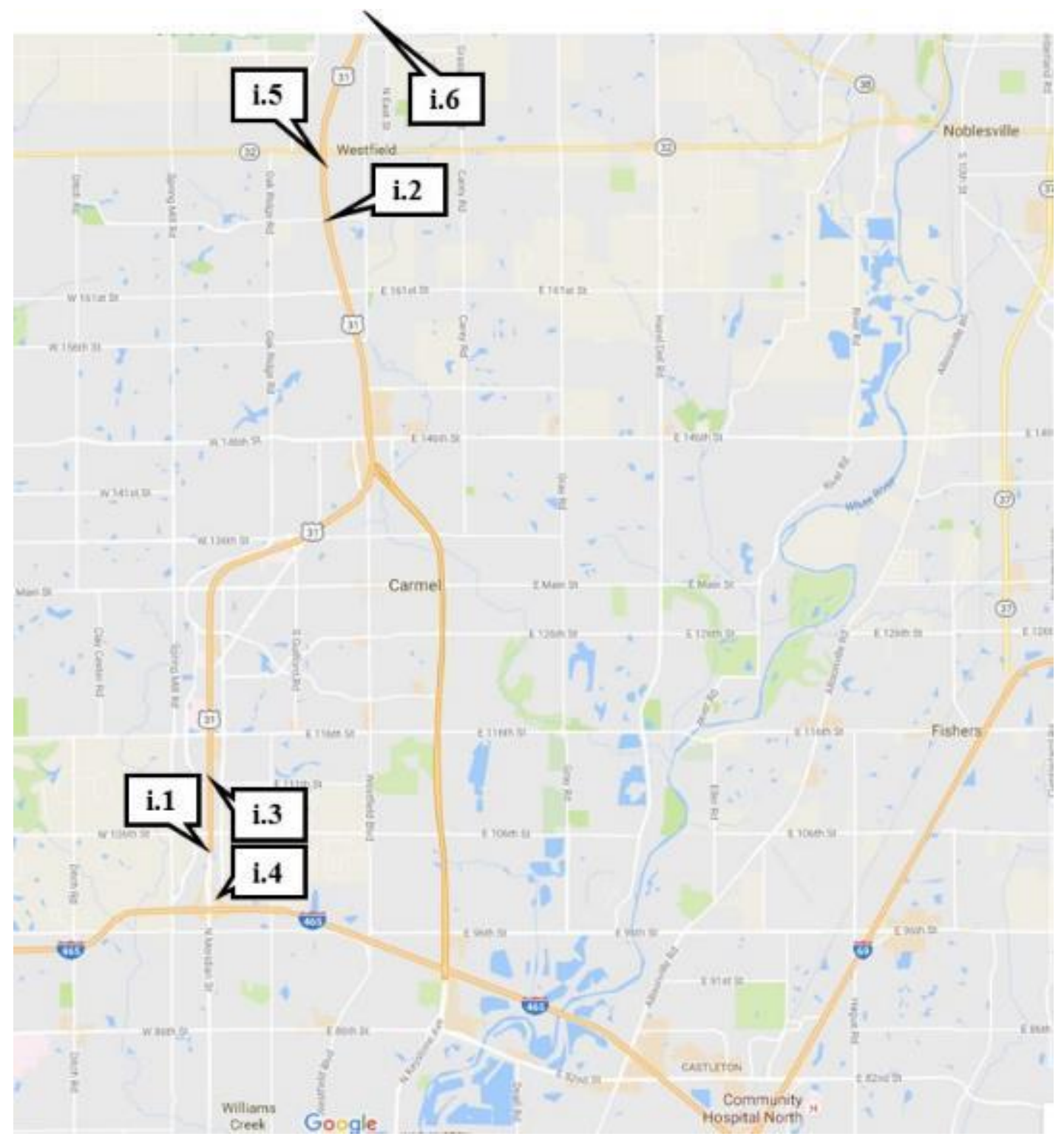

Figure 1.6 Detailed map for site i

1. US 31 and $106^{\text {th }}$ Street (Exit to 465)

2. US 31 and $169^{\text {th }}$ Street

3. US 31 and $111^{\text {th }}$ Street

4. US 31 and 465

5. US 31 and State Road 32

6. US 31 and $191^{\text {st }}$ Street 
Another construction topic featured in this document is roundabout construction. Callout $i i$ in Figure 1.5 shows the location of a concrete roundabout project that occurred at the intersection of Bartlett Street and Michigan Street at the Memorial Hospital in South Bend. This project is featured in greater detail in Chapter 4, which compares and contrasts the construction of concrete and asphalt roundabouts.

Callouts $i i i$ and $i v$ in Figure 1.5 show the locations of two separate bridge demolition events. The two events are the demolition of the eastbound bridge on Sagamore Parkway over the Wabash River in West Lafayette (Callout iii), and the Old State Road 1 bridge over the Whitewater River in Cedar Grove (Callout $i v$ ). These demolition events are described in detail in Chapter 6. 


\subsection{Potential Benefits}

The time-lapse and multimedia project will have many positive benefits to contribute to the construction and engineering industry. The project team sees the potential for benefits within the following areas: in the classroom, in the field, and in the media. The images and videos produced from this project can be utilized to help educate beginning engineers, contractors, inspectors, and the general public.

Many standard engineering classes focus on teaching the students how to perform the calculations, how to read and interpret the plan drawings, and how to report their findings. However, there exists a gap between formal education and on-site training. One of the aims of this project is to bridge that gap and to give the students a better sense of how their designs will look and be constructed in the field. One goal of this project for education in the classroom is to help the students make the connection between the plan drawings and the real-world products. Visualization is the first crucial step to understanding what construction plan drawings are really indicating. For example, a cross-section of the plan drawings at the end-bent of a steel bridge is seen in Figure $1.7 a$, while that same cross-section is seen in the field in Figure 1.7b. Figure $1.7 c$ and Figure $1.7 d$ show the bridge plans overlaid on images taken in the field. Once a student can visualize the product depicted in the plan drawings, he or she can then begin to understand the bigger picture for project development.

The next aim of this project is to assist in the education of contractors and inspectors that are actively working in the field. As previously discussed, beginning inspectors may be hired just weeks prior to the start of the construction work to be inspected. This is hardly enough time to formally educate them on all the intricacies 
that are involved with construction inspection. Additionally, a significant portion of the experience required of inspectors in on-site experience. This project aims to develop job-specific training modules that inspectors and contractors can view prior to starting a construction job. This will help provide the inspectors with visualizations of good and bad practices to be watching for in the field. The expectations of the agency will be made clear to the contractors if the contractors viewed these training modules as well. This is all done with the goal of assisting everyone to create the highest quality product possible.

Finally, a benefit that has resulted from this project is developing content that can be utilized by the media. As with any company or organization, our goal is to portray Purdue University, INDOT, and all other individuals involved in the best possible light. This involves developing content that can be shared with the media and distributed online that will help educate the public on the specifics of the project. One example of this is featured in Chapter 6. 


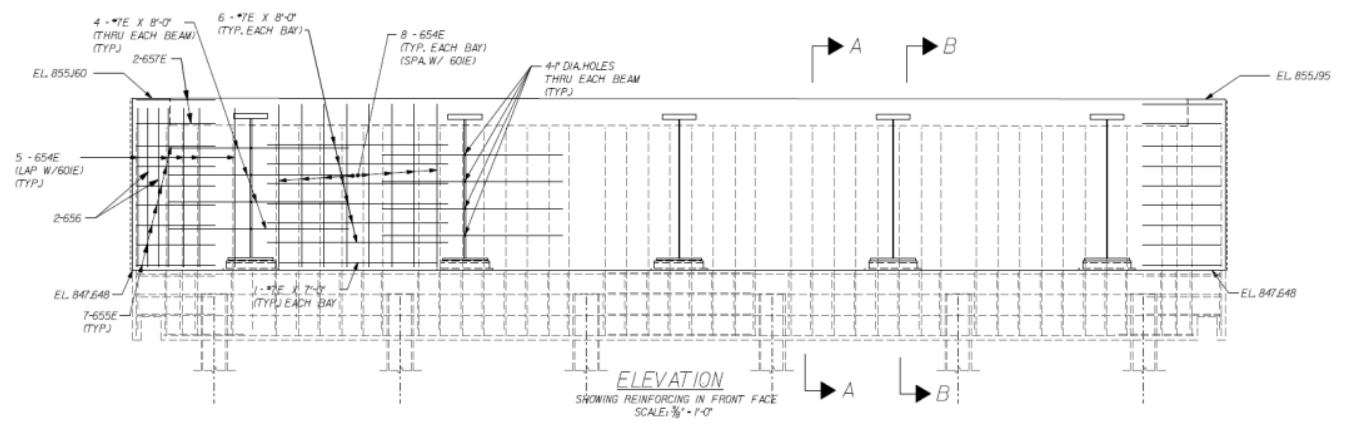

(a) Bridge plan drawings

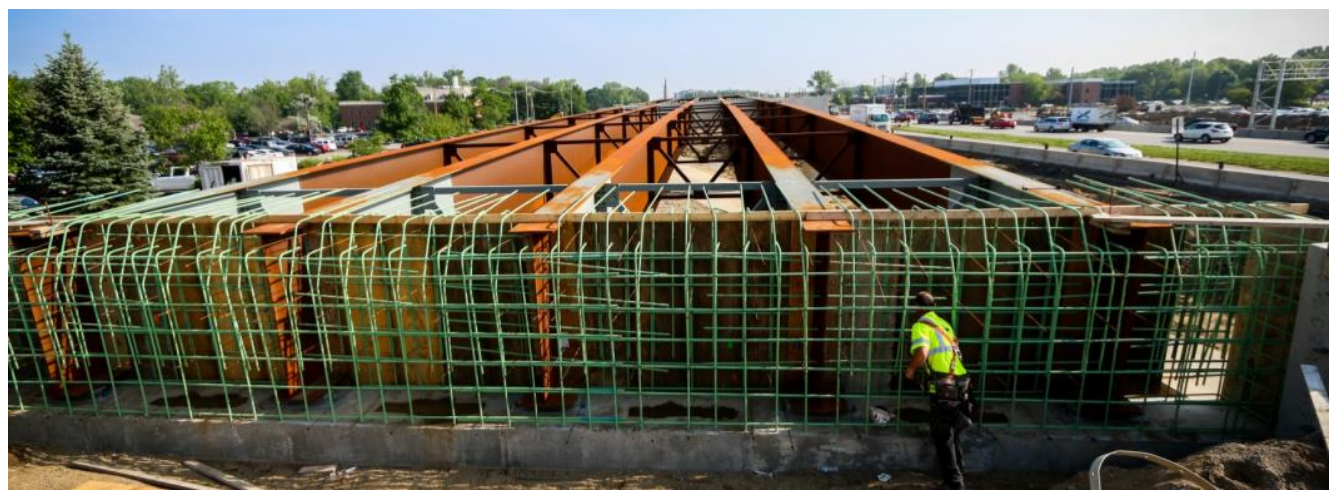

(b) Bridge under construction

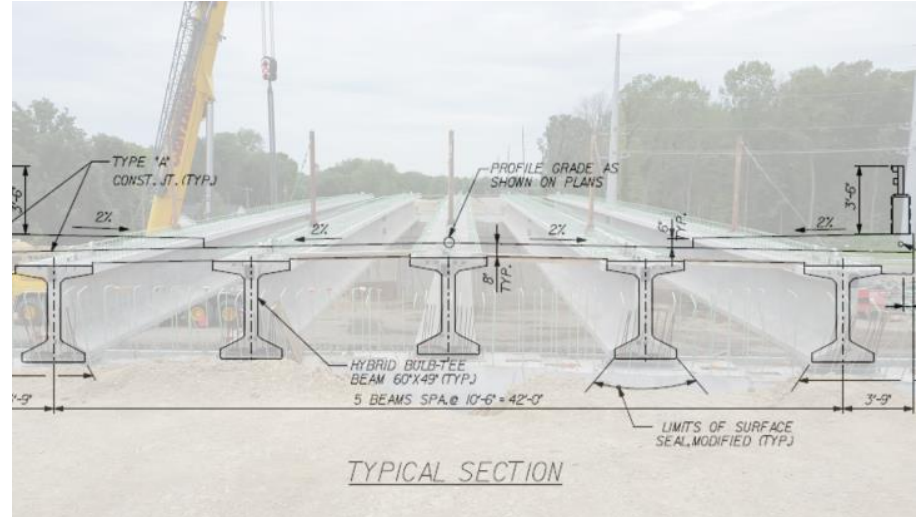

(c) Bridge construction plan overlay

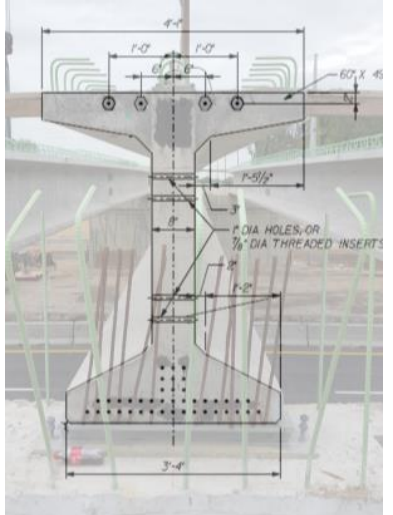

(d) Bridge beam detail overlay

Figure 1.7 Visualizing plan drawings 


\section{CHAPTER 2. BRIDGE CASE STUDY}

\subsection{Introduction}

The case study project featured in this chapter is the construction of the new US 31 in Hamilton County, Indiana. The end of the 2015 construction season substantially marked the end of a 4-year project upgrading the US route from a signalized arterial to a grade-separated roadway that conforms to the Federal freeway standards. Funded through part of Governor Mitch Daniels’ Major Moves initiative, the $\$ 350,000,000$ project upgrades and grade-separates 13 miles of US 31 between I-465 and State Road 38. The upgraded 13-mile stretch features 11 new interchanges and eliminates 32 traffic signals. Construction for the project began in 2011 and was 'substantially complete' by December of 2015 (7). The project team has selected the construction of the northbound section of the US 31 overpass across $169^{\text {th }}$ Street for this case study. Construction on the overpass, which can be seen in Figure 2.1 a began in May 2015, and was officially opened to traffic by December of that year. Part $b$ of Figure 2.1 shows the bridge overpass when time-lapse cameras were installed, and Figure $2.1 c$ shows the overpass after project completion. Figure 1.6 shows individual project sites within the 13-mile stretch on US 31.

The construction process on the bridge overpass, seen in Figure 2.1, has been separated into modules that correspond with the callouts in Figure 2.2. These callouts 
correspond to the major components: bridge support piles, mechanically stabilized earth retaining wall, bridge beams, concrete bridge deck, concrete approach slab, and hot-mix asphalt roadway. A time-lapse montage on the construction of the bridge overpass can be seen in Figure 2.3. The time-lapse cameras were placed in the beginning of May 2015 and construction was substantially complete on this bridge by September 2015, as seen in part $h$. Refer to the images in Figure 2.3 for temporal awareness throughout this case study. The following sections describe these components and reference relevant INDOT standards and specifications. Each of these case studies corresponds to a video link in Table 2.1 and Table 2.2.

\subsection{Bridge Support: Steel H-Piles}

Bridges often have driven or cast-in-place piles for support. Figure $2.2 a$ Callout ii shows the piles on the construction plans. The piles used for this bridge were $12 \times 74$ steel H-piles with pile shoes and pile sleeves driven to 667 kips nominal driving resistance. The H-piles driven for the bridge project are displayed in Figure 2.4. Figure $2.4 a$ shows the piles cut to the proper elevation in accordance with INDOT standards and specifications $701.13(1)$.

INDOT 701.13: "The tops of all steel piles shall be cut off at the elevation on the bridge plans." (1)

Figure $2.4 b$ shows the pile sleeves over the H-piles, as depicted on the construction plans. 


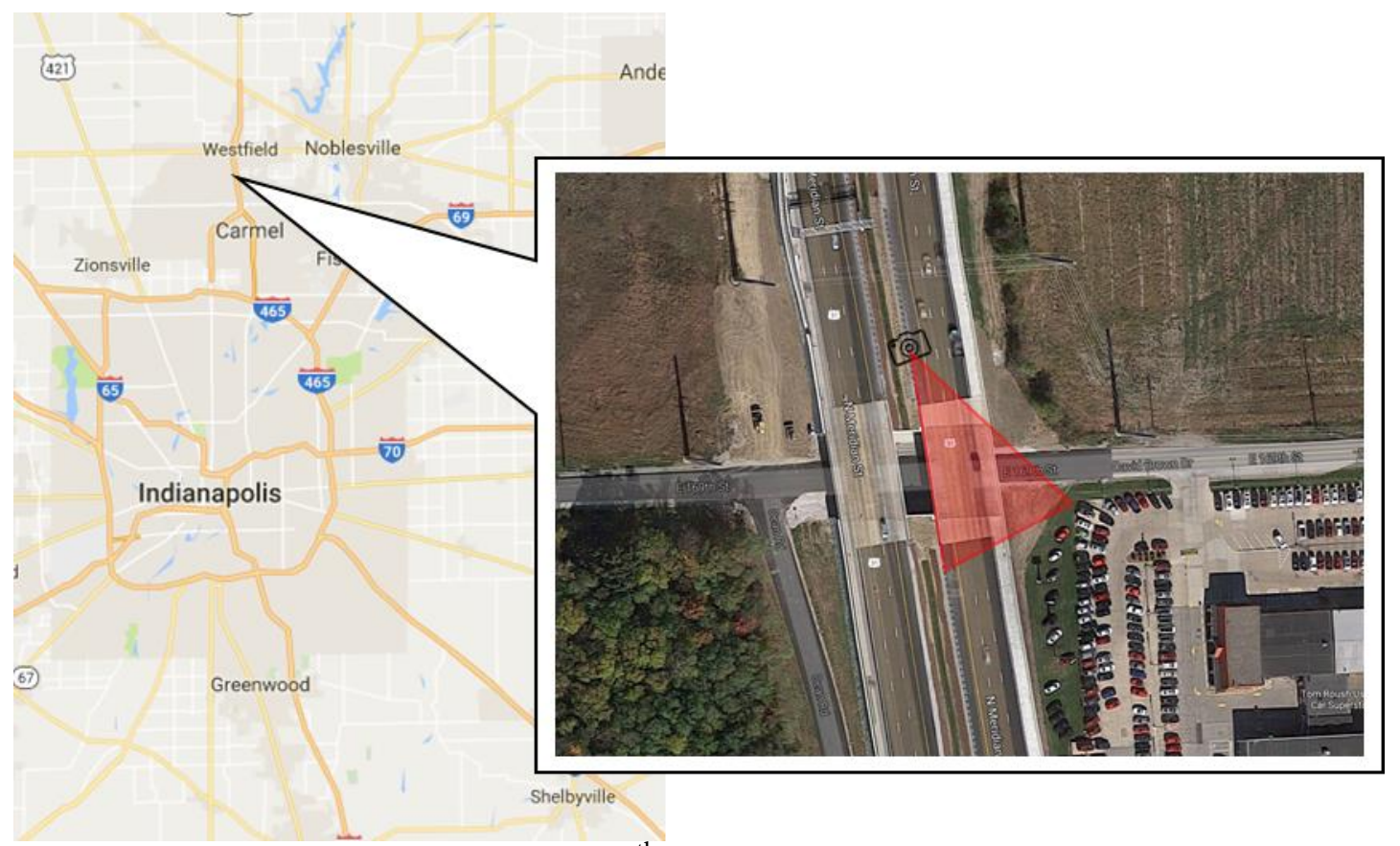

(a) US 31 Northbound bridge over $169^{\text {th }}$ Street in Westfield Indiana; camera location and view shown in red

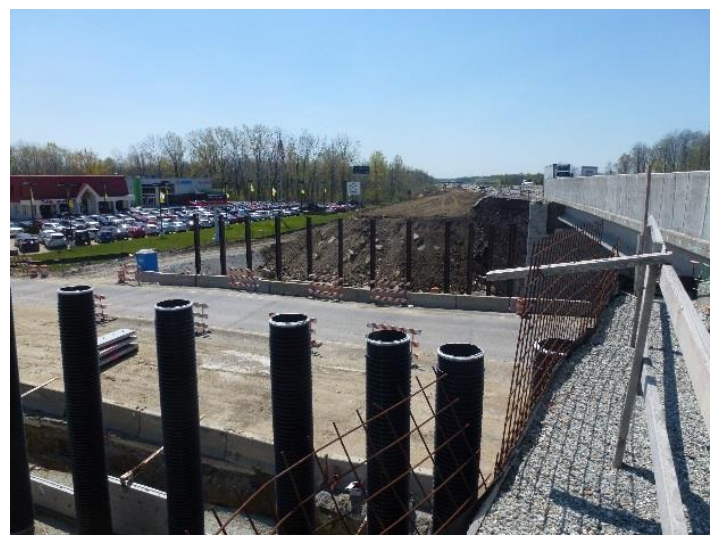

(b) Bridge during construction

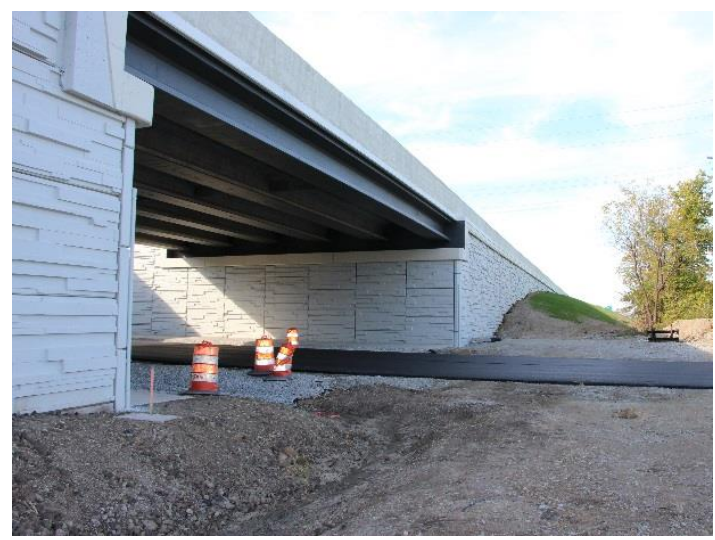

(c) Bridge construction complete

Figure 2.1 Bridge case study overview map 


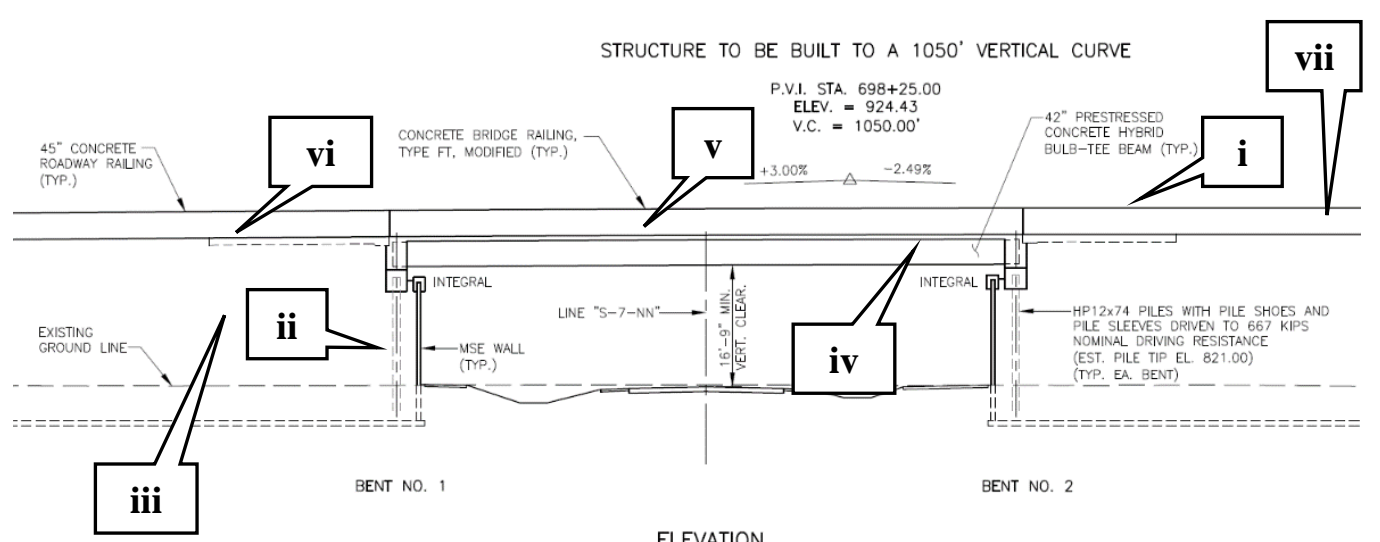

(a) Plan drawings of bridge structure for US 31 in Westfield, Indiana

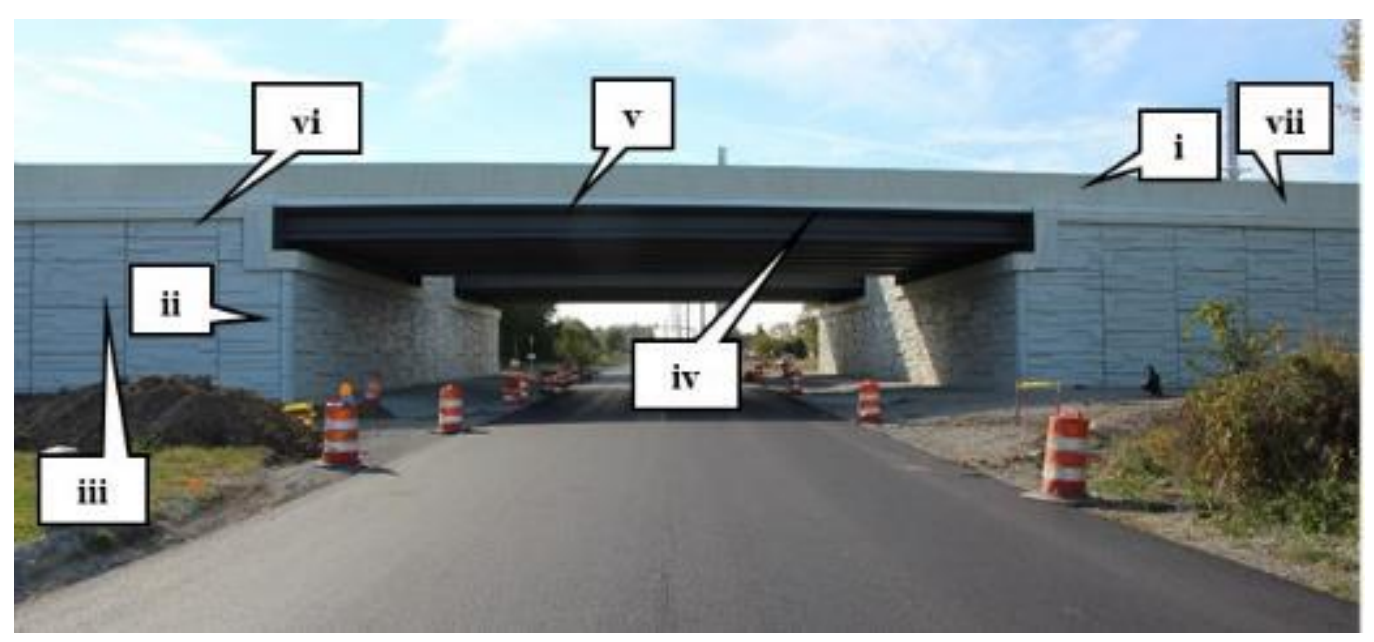

(b) Corresponding profile view of bridge

Figure 2.2 Plan view and site view for bridge structure

i. Camera location on mechanically stabilized earth wall, overlooking bridge

ii. Bridge support: HP $12 \times 74$ piles

iii. Mechanically stabilized earth wall

iv. Composite prestressed concrete hybrid bulb-tee beams

v. Concrete bridge deck

vi. Concrete bridge abutment

vii. Hot-mix asphalt roadway 


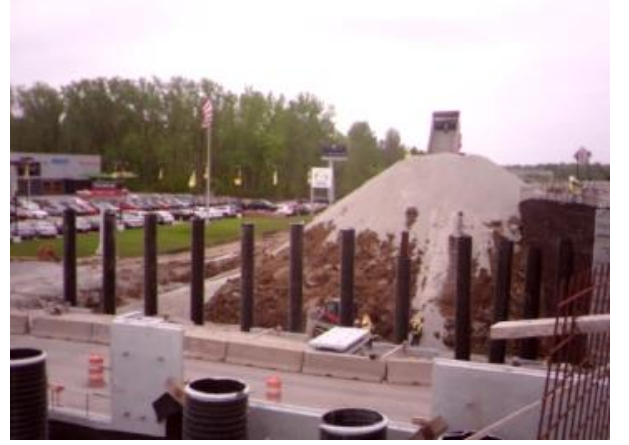

(a) Stockpiling structural backfill 5/14/15

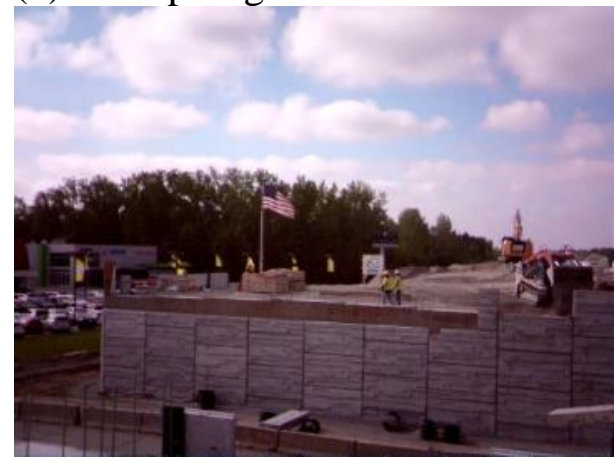

(c) Bridge beam support $6 / 2 / 15$

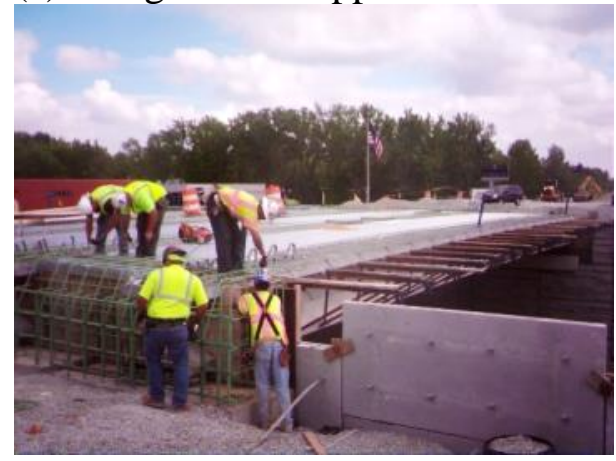

(e) Bridge decking operations $6 / 16 / 15$

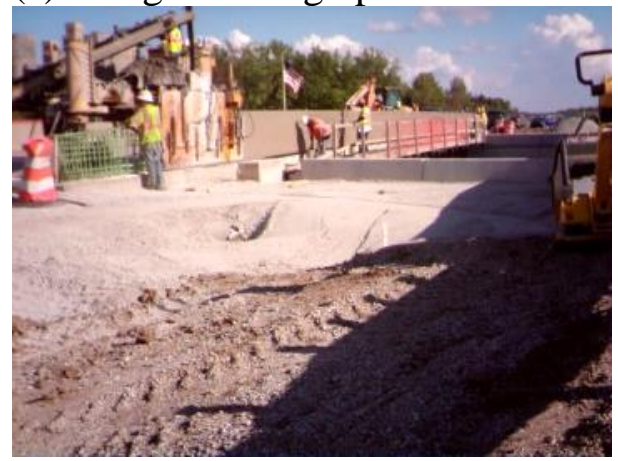

(g) Slip-form concrete guardrails 8/11/15

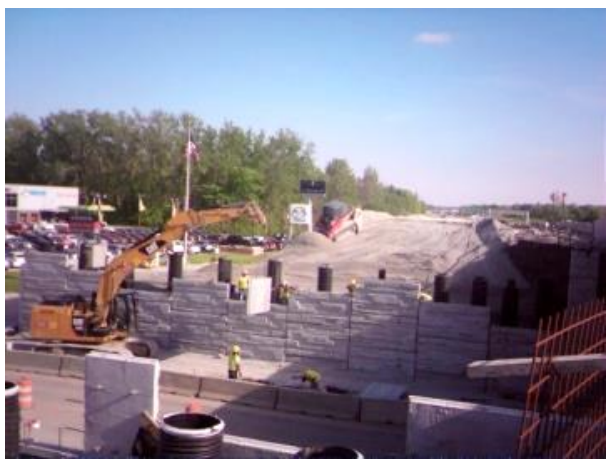

(b) Placing panels of MSE wall 5/19/15

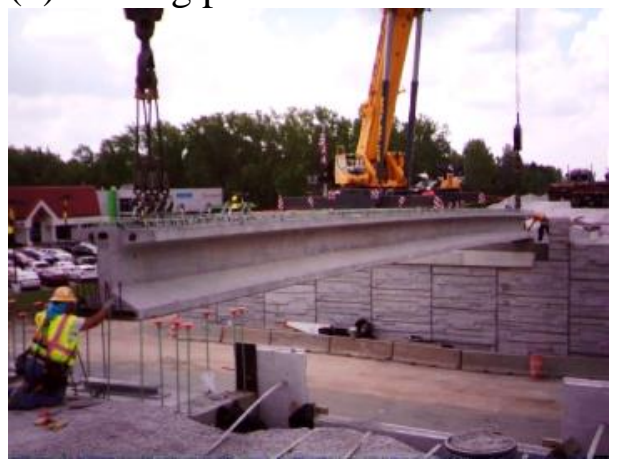

(d) Place concrete bridge beams 6/5/15

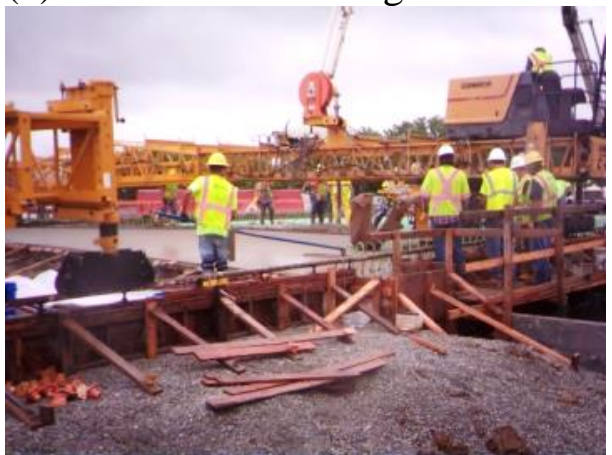

(f) Place concrete deck on bridge 7/9/15

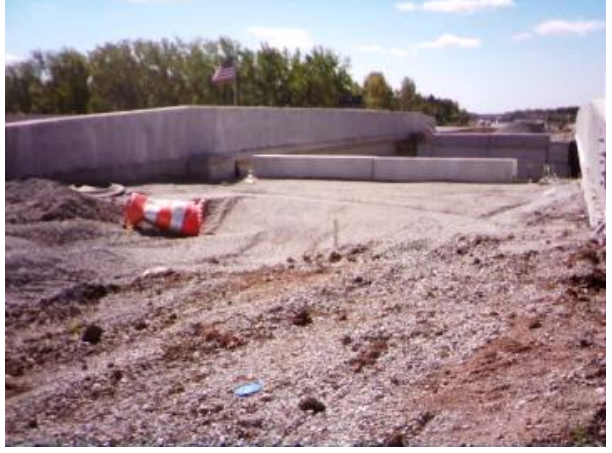

(h) Bridge is complete $8 / 31 / 15$

Figure 2.3 Construction of an overpass: Retaining wall and bridge construction 
Table 2.1 YouTube Video Demonstrating Time-Lapse Project Progress

\begin{tabular}{|c|c|c|c|}
\hline Activity & Date Range & $\begin{array}{l}\text { Completion Time } \\
\text { (Time in Video) }\end{array}$ & \multirow{7}{*}{ http://tiny.cc/BridgeMin } \\
\hline $\begin{array}{c}\text { Excavation/Earth } \\
\text { work }\end{array}$ & $\begin{array}{c}5 / 12 / 2015- \\
5 / 14 / 2015\end{array}$ & $\begin{array}{c}21 \text { hours } \\
(0: 00-0: 03)\end{array}$ & \\
\hline $\begin{array}{l}\text { MSE Panel } \\
\text { Installation }\end{array}$ & $\begin{array}{c}5 / 14 / 2015- \\
6 / 5 / 2015\end{array}$ & $\begin{array}{c}116 \text { hours } \\
(0: 03-0: 23)\end{array}$ & \\
\hline Beam Placement & $6 / 5 / 2015$ & $\begin{array}{c}4 \text { hours } \\
(0: 23-0: 25)\end{array}$ & \\
\hline $\begin{array}{l}\text { Bridge Decking } \\
\text { Procedures }\end{array}$ & $\begin{array}{c}6 / 9 / 2015- \\
7 / 8 / 2015\end{array}$ & $\begin{array}{c}75 \text { hours } \\
(0: 28-0: 48)\end{array}$ & \\
\hline $\begin{array}{c}\text { Deck Concrete } \\
\text { Placement }\end{array}$ & $7 / 9 / 2015$ & $\begin{array}{c}6 \text { hours } \\
(0: 48-0: 51)\end{array}$ & \\
\hline $\begin{array}{c}\text { Approach Slab } \\
\text { Placement }\end{array}$ & $7 / 20 / 2015$ & $\begin{array}{c}5 \text { hours } \\
(0: 51-0: 58)\end{array}$ & \\
\hline
\end{tabular}


Table 2.2 YouTube Time-Lapse Video Links For Case Study

\begin{tabular}{|c|c|c|c|}
\hline Video & Date Range & Description & Video Link \\
\hline$i i$ & $\begin{array}{l}5 / 5 / 2015- \\
5 / 6 / 2015\end{array}$ & $\begin{array}{c}\text { Pile Driving } \\
\text { http://tiny.cc/PileDrive }\end{array}$ & \\
\hline$i i i$ & $\begin{array}{l}5 / 6 / 2015- \\
5 / 11 / 2015\end{array}$ & $\begin{array}{l}\text { MSE Wall Construction } \\
\text { http://tiny.cc/MSEwall }\end{array}$ & \\
\hline$i v$ & $6 / 5 / 2015$ & $\begin{array}{c}\text { Beam Placements } \\
\text { http://tiny.cc/BridgeBeams } \\
\text { Bridge Placement with } \\
\text { Drawing Animations } \\
\text { http://tiny.cc/BridgeBeams3 }\end{array}$ & \\
\hline$v$ & $\begin{array}{l}6 / 4 / 2015- \\
7 / 14 / 2015\end{array}$ & $\begin{array}{l}\text { Bridge Deck Construction } \\
\text { http://tiny.cc/BridgeDeck }\end{array}$ & \\
\hline$v i$ & $\begin{array}{c}6 / 3 / 2015- \\
6 / 9 / 2015\end{array}$ & $\begin{array}{l}\text { Approach Slab Construction } \\
\text { http://tiny.cc/ApproachSlab }\end{array}$ & \\
\hline$v i i$ & $\begin{array}{l}5 / 6 / 2015- \\
5 / 15 / 2015\end{array}$ & $\begin{array}{l}\text { HMA Roadway Construction } \\
\text { http://tiny.cc/HMARoad }\end{array}$ & \\
\hline
\end{tabular}




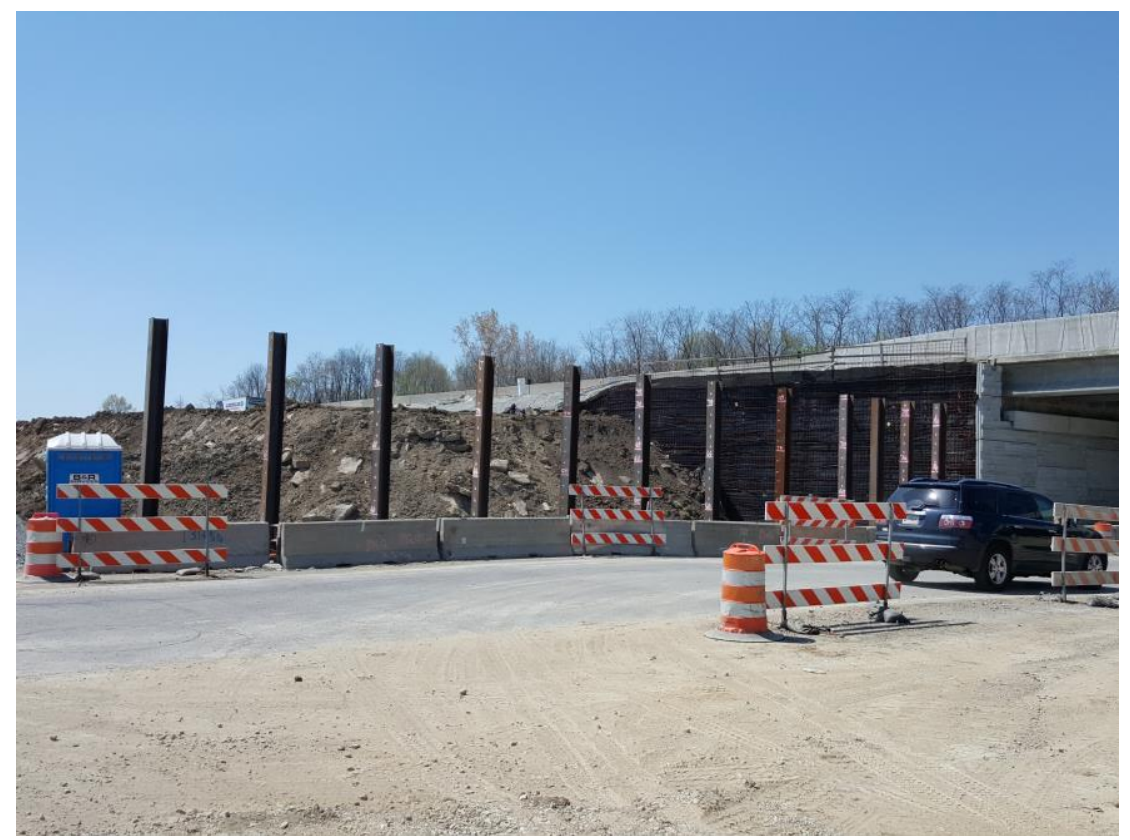

(a) HP 12x74 carbon steel H-piles ground view

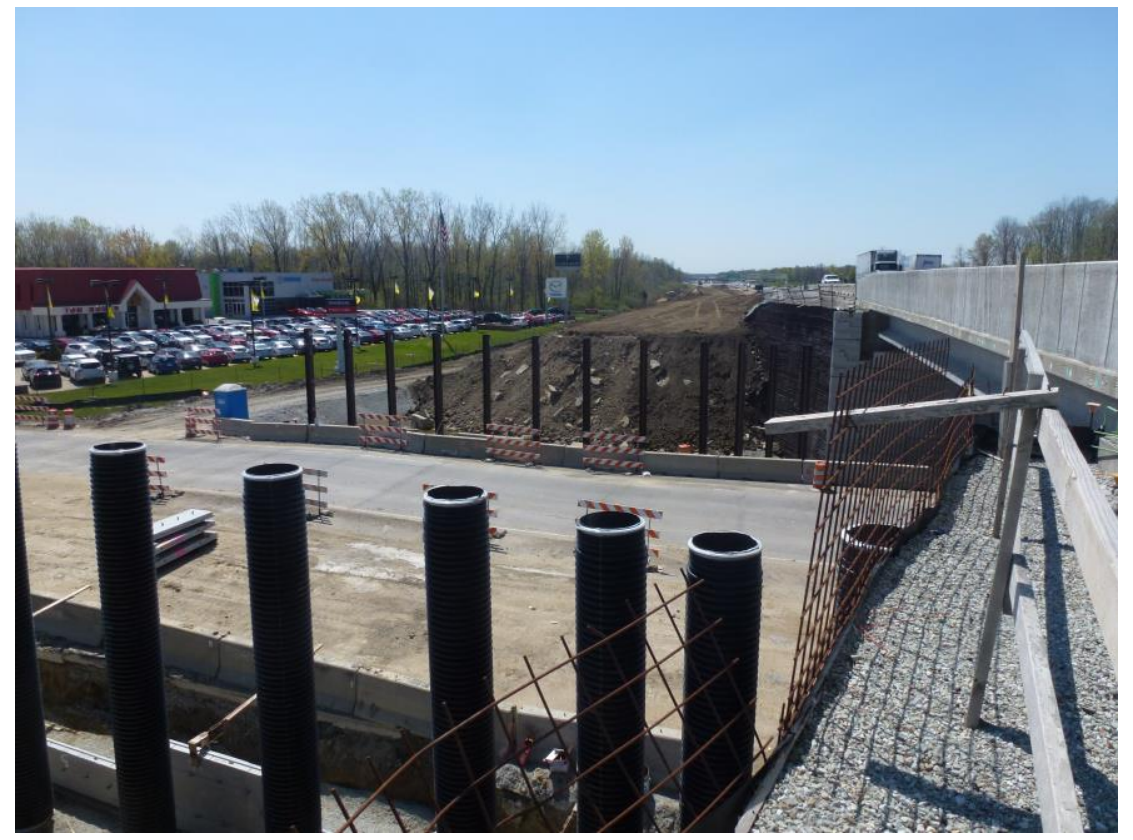

(b) View of uncovered H-piles and covered H-piles from time-lapse camera location

Figure 2.4 H-piles for mechanically stabilized earth wall and for bridge support 


\subsection{Mechanically Stabilized Earth Retaining Wall}

The mechanically stabilized earth (MSE) wall construction process is depicted in Figure 2.5. Figure $2.5 a$ shows an inspector conducting a compaction test on the structure backfill. According to the INDOT standards and specifications section 731.11, the AASHTO T99 compaction test must be conducted and reach $95 \%$ of the maximum dry density.

INDOT 731.11: "B borrow and No. 4 size structure backfill shall be compacted to 95\% of the maximum dry density in accordance with AASHTO T99."

Compaction is a critical element of MSE wall construction, as many MSE wall failures can be attributed to poor backfill placement or compaction. The image in Figure $2.5 b$ shows crews placing the straps and fixing them to the MSE wall panels. Figure $2.5 c$ illustrates the backfill placement, with the maximum loose lift thickness not to exceed 8 inches, per section 731.11 .

INDOT 731.11: "The maximum loose lift thickness shall not exceed 8 in. However, lifts within $3 \mathrm{ft}$ of the wall shall not exceed 5 in. in loose thickness."

Figure $2.5 d$ shows the compaction process with a vibratory plate compactor in order to satisfy INDOT specification 731.11. The image in Figure 2.5e shows the next layer of backfill being placed and compacted in Figure 2.5f. Figure $2.5 f$ also represents the completion of the lift, and new straps are ready to be placed to restart the process from Figure 2.5a. Figure 2.5g shows a detailed view of a panel at another MSE location where the inspector has placed markings corresponding to desired lift thickness to simplify the validation process with the time-lapse images. 


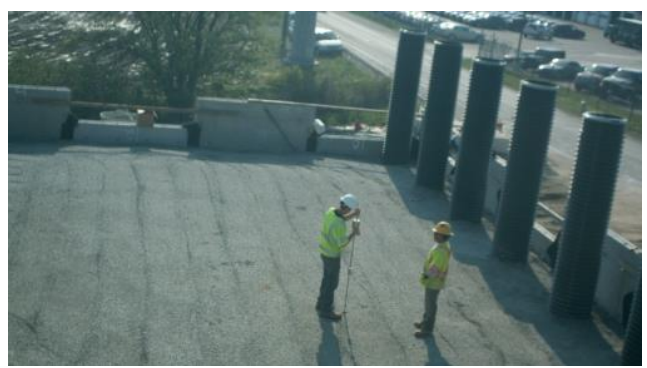

(a) 9:28 AM - Compaction test

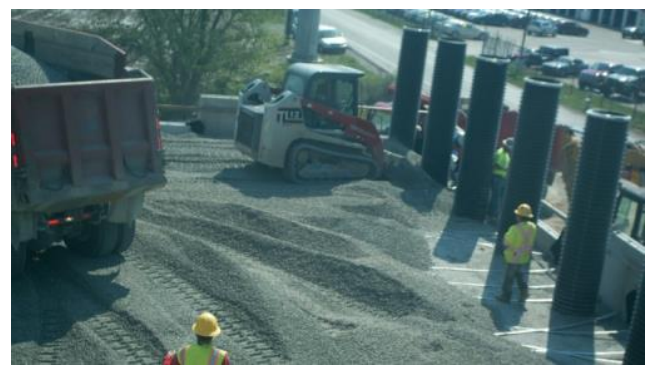

(c) 10:51 AM - Structural backfill placement

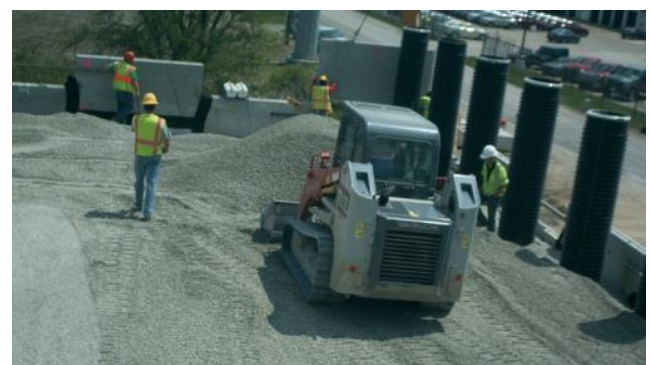

(e) 12:51 PM - Panel placement, soil placement

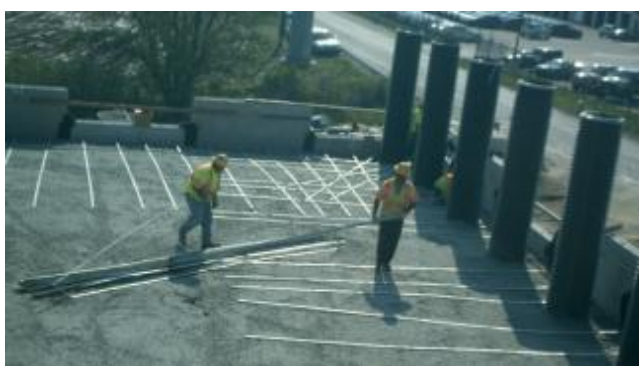

(b) 10:02 AM - Strap placement

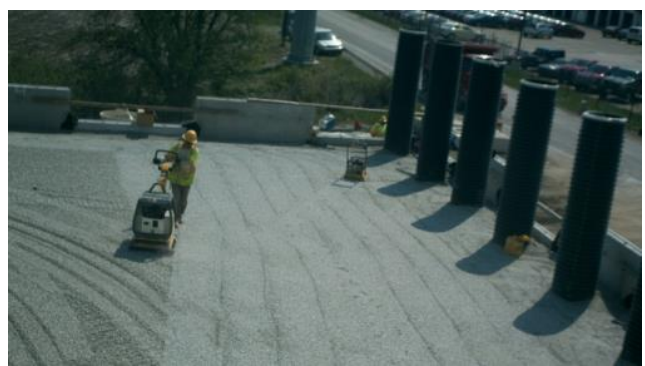

(d) 11:45 AM - Soil compaction

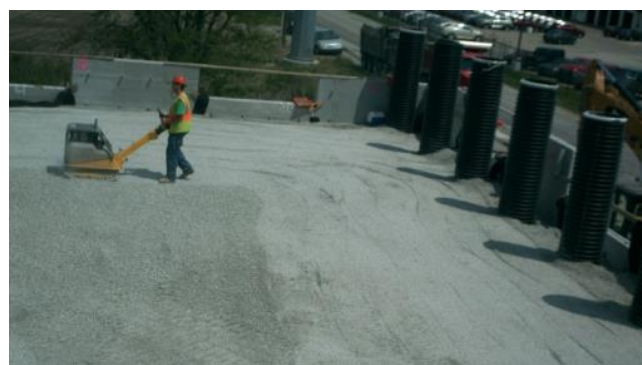

(f) 2:42 PM - Soil compaction

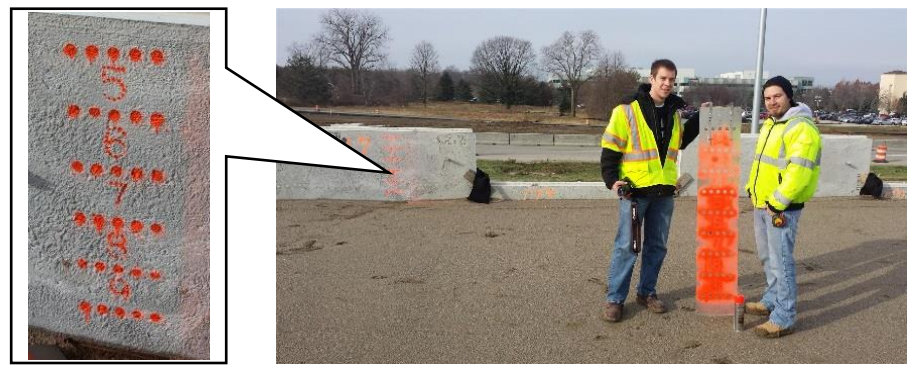

(g) MSE wall backfill lift thickness reference

Figure 2.5 Mechanically stabilized earth wall construction process on 5/7/2015 


\subsection{Concrete Bridge Beams}

The installation of concrete bridge beam number 8 is shown in Figure 2.6. The beams spanning this intersection are composite pre-stressed concrete hybrid bulb-tee beams, which are in accordance with INDOT specifications, section 707. Plan details of the beam placements on the bridge are shown in Figure $2.6 a$ and Figure 2.6b. Transportation and installation of the beam is depicted in Figure $2.6 c$ through Figure 2.6h. The images in Figure 2.6 supplement components of the INDOT specifications, including the handling and shipping of the beam to site, section 707.08 , and proper placement of the structural members, section 707.09.

INDOT 707.08: "Unless otherwise approved, precast and precast prestressed structural members shall be handled with a suitable hoisting device provided with a spreader sling. The spreader shall be of sufficient length to prevent horizontal forces being produced in the structural member due to lifting and shall be equipped with leads and hooks at each end. The structural members shall be lifted by the devices shown on the plans."

INDOT 707.09: "Structural members shall be set to proper line and grade with uniform bearing on bridge seats, mortar joints, or bearing pads as required on the plans."

The link to a video of the beam placement and coordinated animations of plan drawings can be found in Table 2.2, video $i v$. 


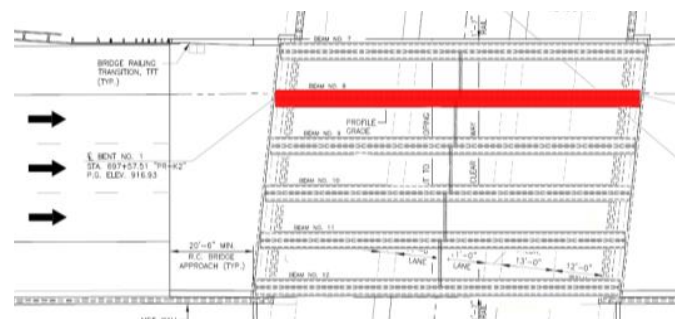

(a) Plan view on bridge plans for beam no. 8

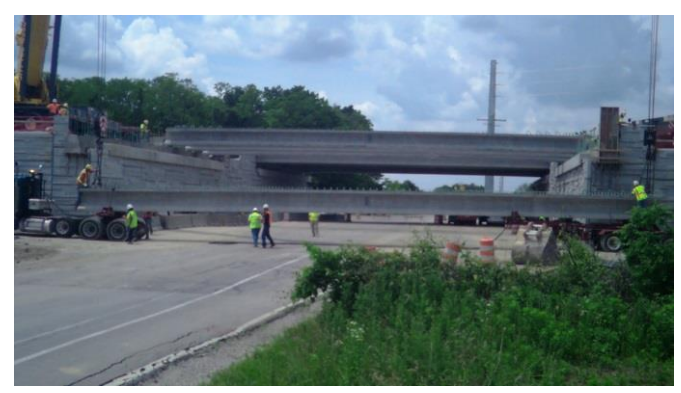

(c) 12:47 PM - Beam No. 8 is attached to cranes

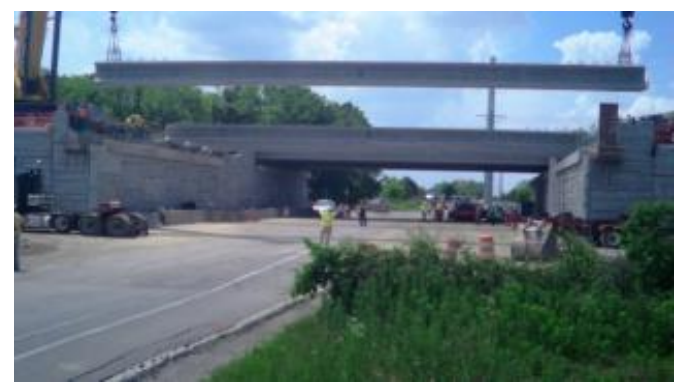

(e) 12:51 PM - Beam is lifted above bridge

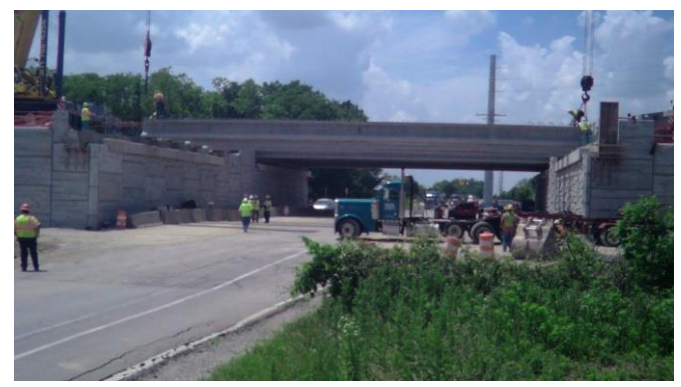

( $g$ ) 12:56 PM - Beam is detached from crane

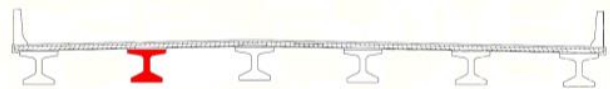

(b) Profile view of bridge plans for beam no. 8

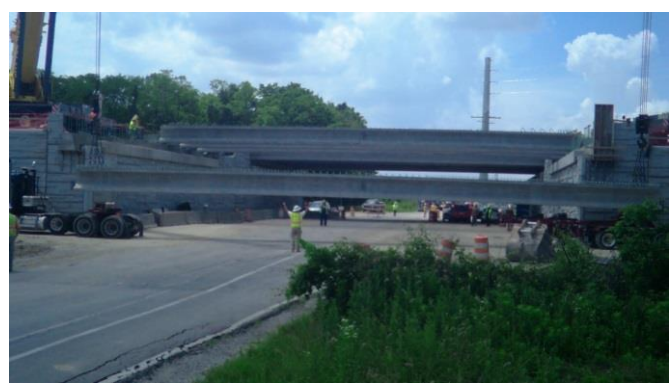

(d) 12:50 PM - Beam is lifted off truck

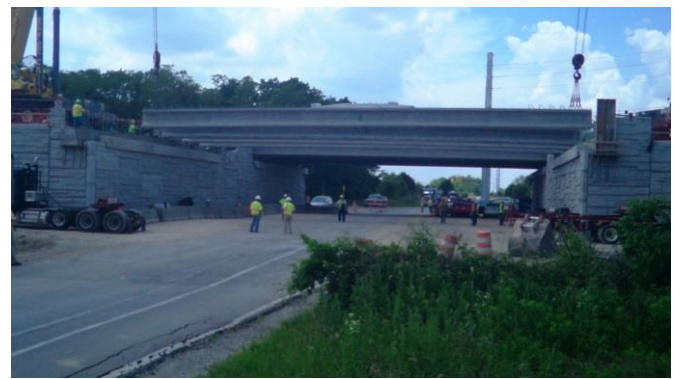

(f) 12:53 PM - Beam is lowered into place

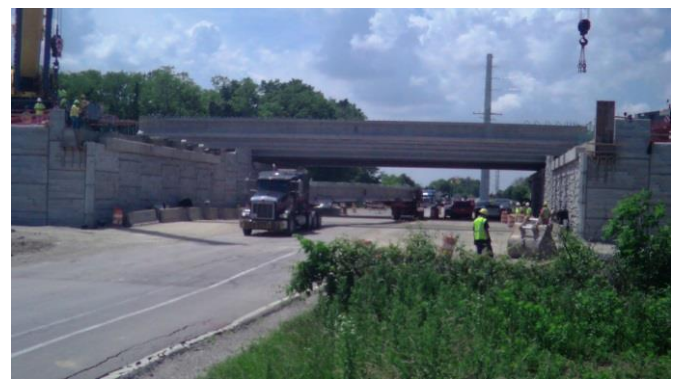

(h) 12:59 PM - Beam No. 9 arrives on site

Figure 2.6 Concrete bridge beam placement on 6/5/2015 


\subsection{Concrete Bridge Deck}

The general process of bridge deck preparation is depicted in Figure 2.7 from the installation of bridge deck pans in Figure $2.7 a$ to continuing bridge construction after the concrete cures in Figure 2.7h. Figure 2.7c and Figure 2.7d depict the process of the epoxy coated steel layout. Steel placement began on June 18, and concrete was placed on July 2, 2015. This is exactly two weeks prior to the start of steel work, which is in compliance with INDOT standards 703.04.

INDOT 703.04: "Once placed into the work, epoxy coated reinforcing bars shall not be exposed to ultraviolet light for a total of more than 21 days prior to the placement of concrete."

Figure $2.7 d$ shows workers tying the structural steel with steel wire in accordance with INDOT standards and specifications 703.06.

INDOT 703.06: "All reinforcing bars shall be wired rigidly or fastened securely at sufficient intervals to hold the bars in place."

Figure $2.7 e$ shows the concrete placement process. In the foreground, the steel rails to guide the paving machines can be seen, in accordance with INDOT standards and specifications 704.05 .

INDOT 704.05: "The [finishing] machine shall travel on steel rails, pipe, or other approved grade control, which shall be adequately supported by adjustable support securely fastened in place at spacing sufficiently close to prevent any appreciable deflection on the screed." 
Immediately after the concrete has been placed and finished, it should be cured in accordance with INDOT section 702.22. Figure $2.7 f$ and Figure $2.7 g$ depict the proper curing of the concrete according to 702.22.1.a.

INDOT 702.22.1.a: "Surfaces to be cured shall be protected by covering with cotton mats, burlap, or other satisfactory protective material and shall be kept continuously and thoroughly wet during the curing period." 


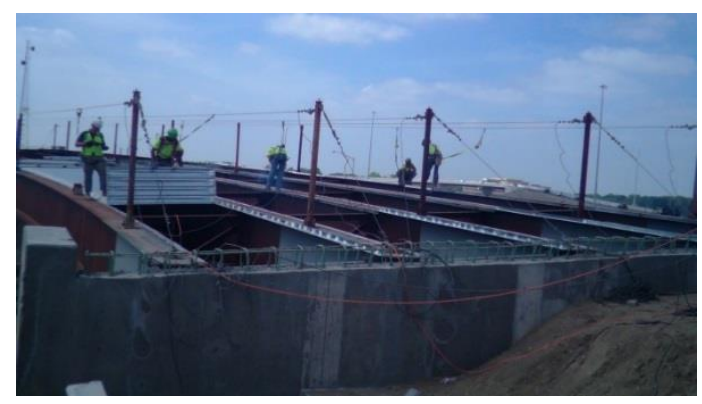

(a) $6 / 4 / 15$ - Bridge deck pan installation

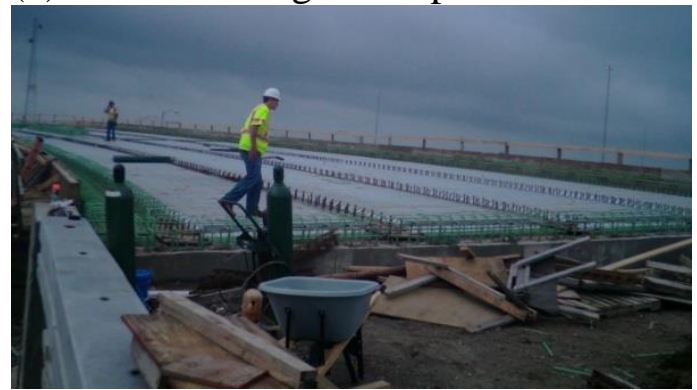

(c) 6/18/15 - Beginning of steel layout

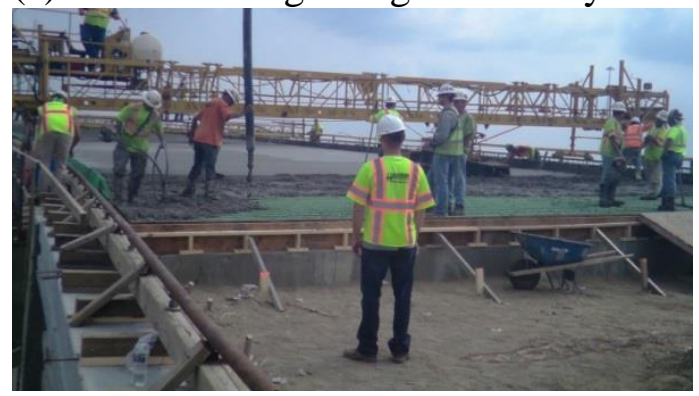

(e) $7 / 2 / 15$ - Concrete is placed on bridge deck

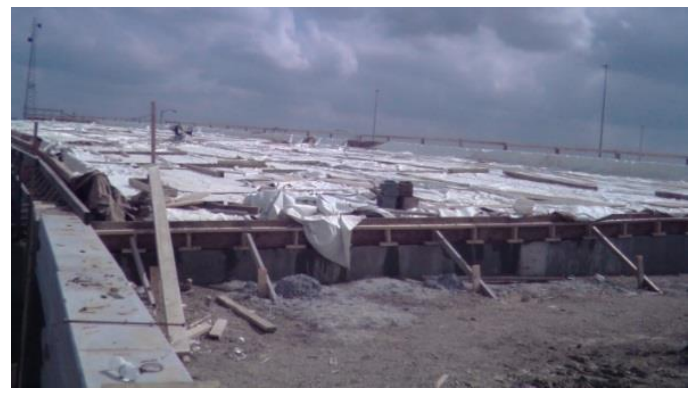

(g) 7/10/15 - Burlap and protective plastic

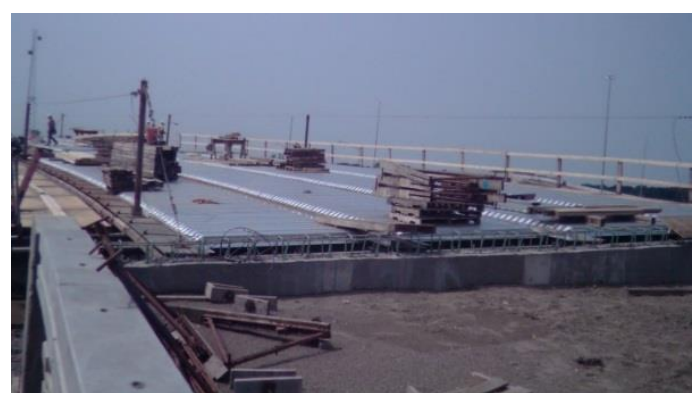

(b) 6/9/15 - Safety railing installed

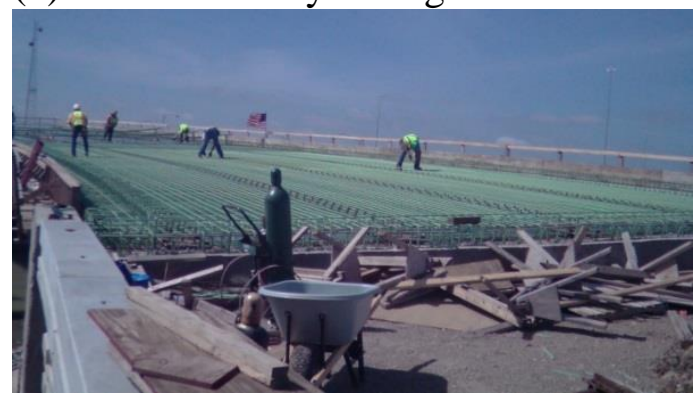

(d) 6/24/15 - Steel is placed on bridge

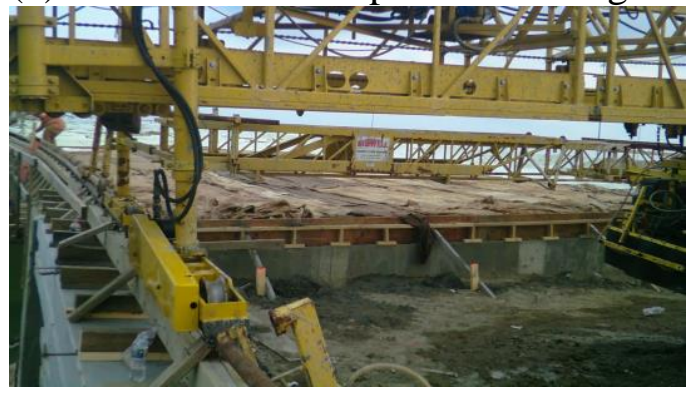

(f) 7/2/15 - Concrete curing under burlap

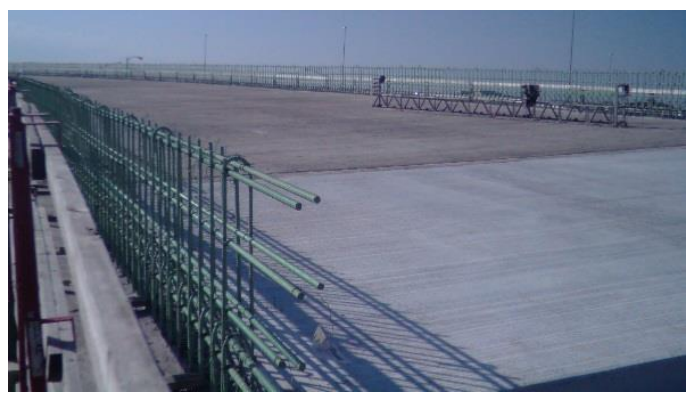

(h) 10/12/15 - Steel layout for concrete guardrail

Figure 2.7 Bridge deck construction process 


\subsection{Bridge Approach Slab}

INDOT specification section 609 details the requirements for the construction of a reinforced concrete bridge approach, as shown in Figure 2.8. Similar to many concrete paving processes, wooden formwork is placed in part $a$ and the subbase compacted in Figure $2.8 b$ in accordance with sections 609.04 and 302, respectively.

INDOT 609.04: "Forms shall be either steel or wood and shall be in accordance with 508.04 (c)1 or 508.04(c)2."

Specifications for the placement, spacing, and size of the steel reinforcement in Figure 2.8c and Figure 2.8d are emphasized in sections 609.06 and 609.07.

INDOT 609.07: "The depth of the reinforced concrete bridge approach will be checked by the Engineer prior to pouring, by making stringline measurements every 3 ft across the width of the approach. Any location deficient in depth by $1 / 2$ in. or more shall be corrected prior to placing the concrete."

Concrete placement and curing in Figure $2.8 e$ and Figure $2.8 f$ are outlined in sections 609.08 through 609.11 .

INDOT 609.10: "Reinforced concrete bridge approach shall be wet cured in accordance with 702 or shall have liquid membrane forming curing compound applied to exposed surfaces within 30 minutes after the finishing operations have been completed." 


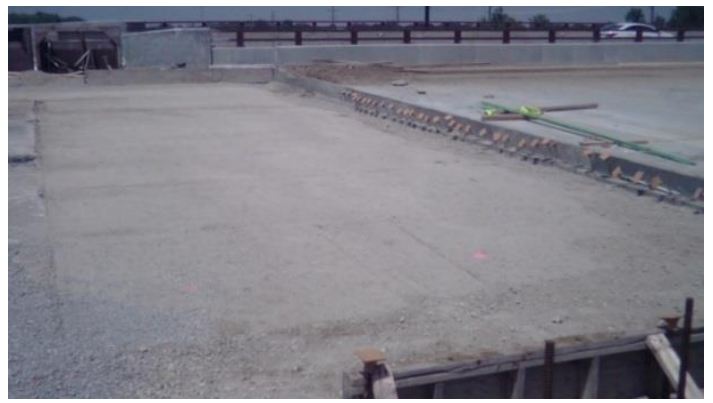

(a) $6 / 2 / 15$ - Bridge abutment formwork

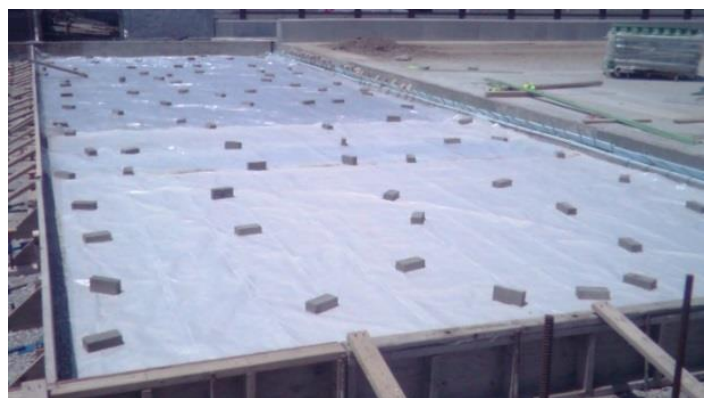

(c) 6/4/15 1:30 PM - Placement of steel spacers

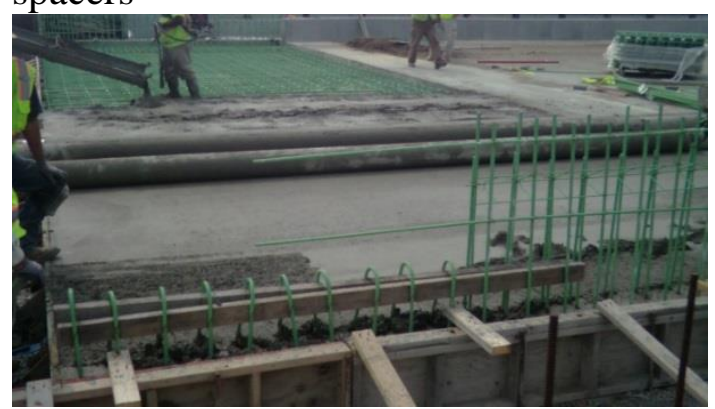

(e) 6/9/15 4:22 PM - Concrete is placed

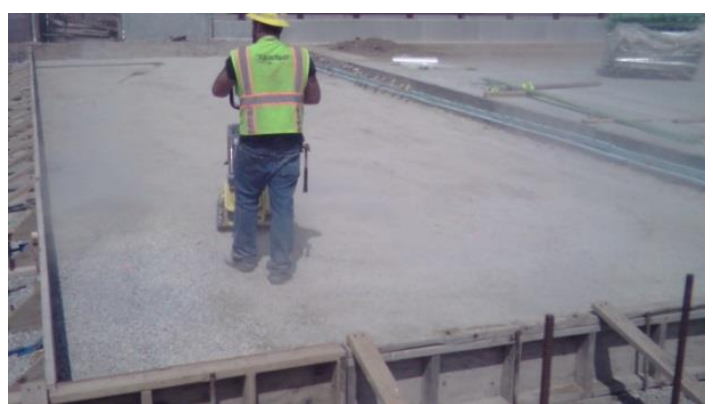

(b) 6/4/15 11:22 AM - Compaction of soil

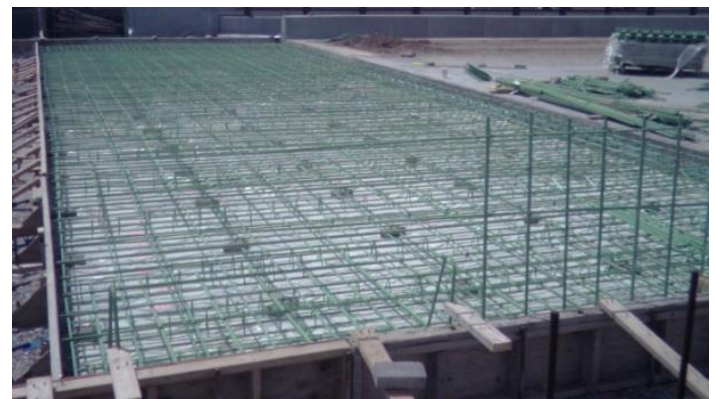

(d) $6 / 5 / 15$ - Steel is placed for abutment

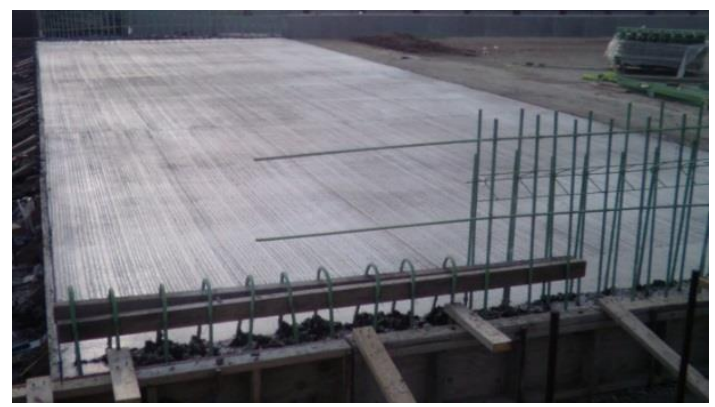

(f) 6/9/15 6:06 PM - Concrete begins to cure

Figure 2.8 Bridge abutment construction process 


\subsection{Hot-Mix Asphalt Roadway}

The final component of this case study is the preparation and construction of the asphalt roadway. Figure 2.9 shows the complete preparation of an asphalt roadway from the initial earthwork in Figure $2.9 a$ to the asphalt compaction in Figure 2.9h. Figure $2.9 a$ through Figure $2.9 e$ show the subbase preparation and construction. Figure $2.9 f$ demonstrates the underdrain installation, which can be seen in further detail in Figure 2.10, which gives an overview of underdrain installation. See Figure $2.10 a$ to observe the trenching machine and Figure $2.10 b$ shows the placement of geotextile fabric. The underdrains are then placed in the trench (Figure 2.10c), and aggregate is placed in the trench around the pipe to facilitate drainage (Figure 2.10d). Figure $2.9 \mathrm{~g}$ and Figure $2.9 \mathrm{~h}$ depict the asphalt paving process. The subgrade and subbase were constructed in accordance with INDOT standards and specifications 207.03 general requirements. A video of the construction of the roadway can be seen in Table 2.2, video vii.

INDOT 207.03: "The subgrade shall be constructed uniformly transversely across the width of the pavement including the shoulders or curbs unless shown otherwise on the plans, by one of the following methods: a) chemical modification in accordance with $215 \ldots . . "$

INDOT 215.01: "This work shall consist of the modification of soils by uniformly mixing portland cement, fly ash, lime, or a combination of the materials with soil to aid in strength gain and achieving the workability of soils having excessive moisture content." 
Figure $2.9 c$ shows the chemical modifiers being mixed into the soil in accordance with INDOT specifications section 215.08 .

INDOT 215.08: "The chemical modifier, soil, and water when necessary, shall be thoroughly mixed by rotary speed mixers or a disc harrow."

Figure $2.9 b$ shows the beginning of chemical soil stabilization occurring on May 8. Figure $2.9 e$ shows soil compaction completion at the end of that same day, in compliance with INDOT 215.09.

INDOT 215.09: "Lime modified soils shall be compacted within 24 hours."

Figure $2.9 g$ shows the asphalt being placed by equipment in accordance with 409. Figure $2.9 h$ shows vibratory rollers compacting the asphalt in accordance with the compaction requirements in INDOT 402.15. 


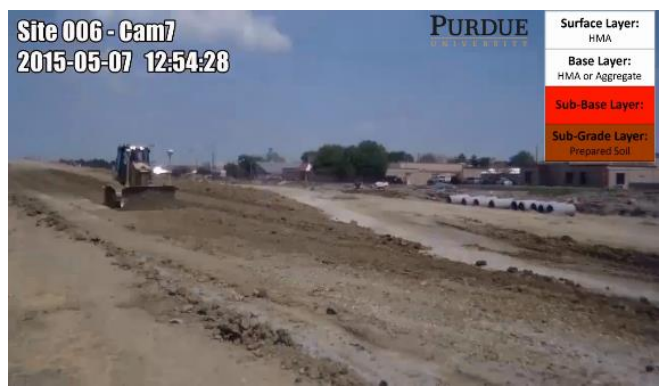

(a) 5/7/15 - Roadway Earthwork

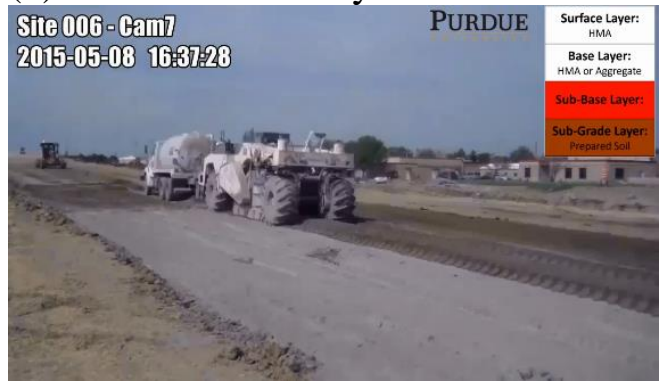

(c) 5/8/15 - Lime mixed into soil

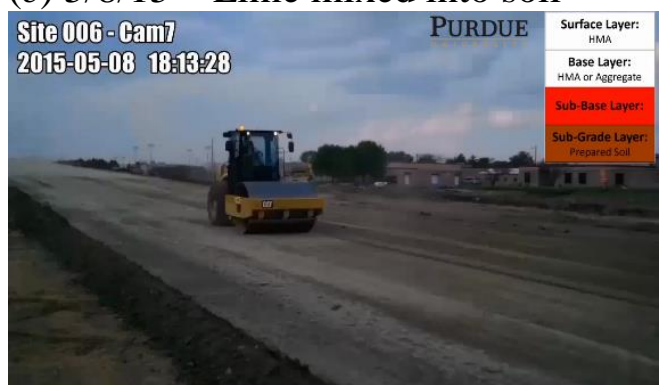

(e) 5/8/15 6:13 PM - Soil is compacted

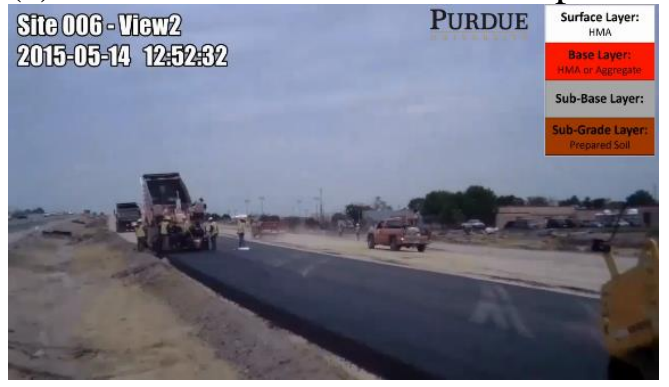

(g) 5/14/15 1:28 PM - Hot mix asphalt is placed as a base layer

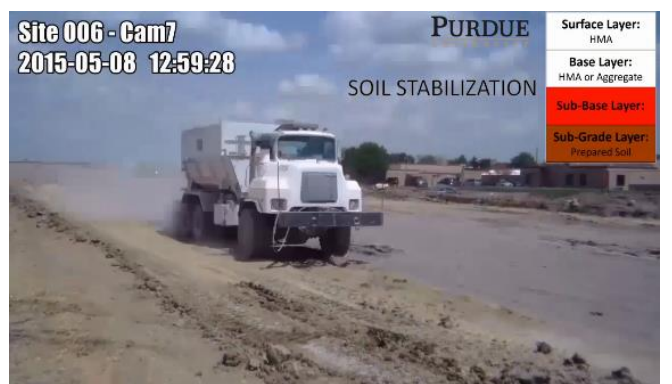

(b) 5/8/15 - Lime soil stabilization

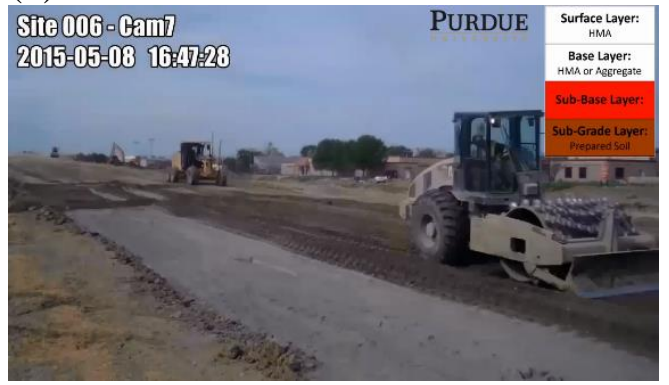

(d) 5/8/15 4:28 PM - Compaction begins

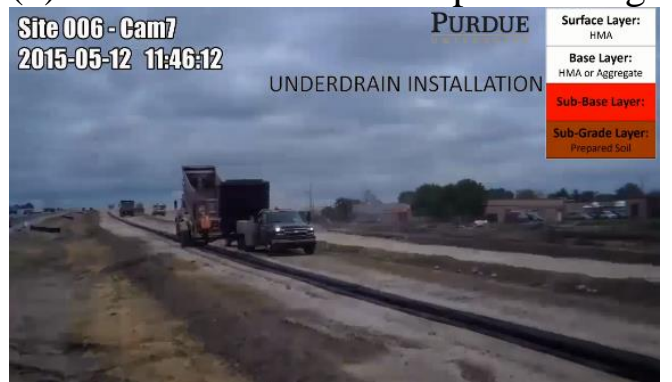

(f) 5/12/15 - Underdrain installation

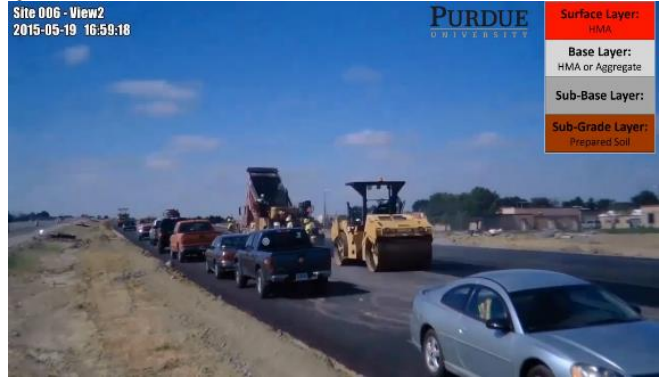

(h) 5/19/15 1:56 PM - Asphalt surface layer is applied

Figure 2.9 Asphalt roadway construction process 


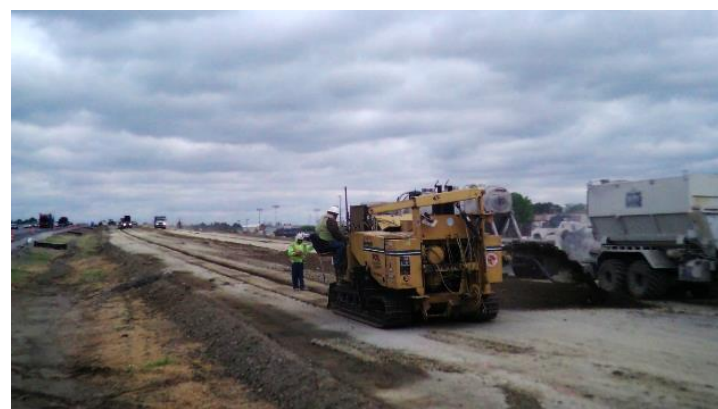

(a) Trench cut for underdrains

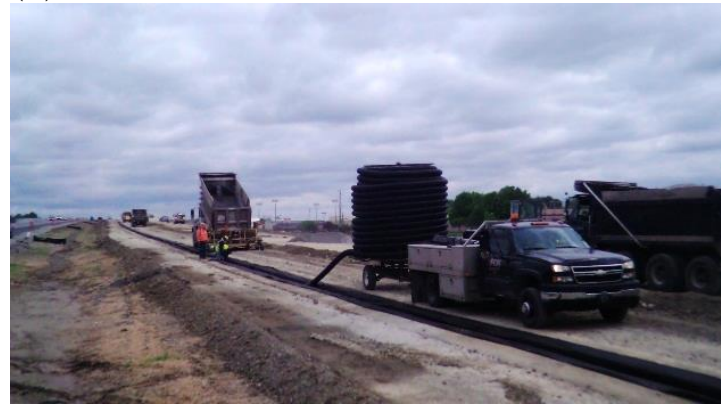

(c) Underdrain pipe placement

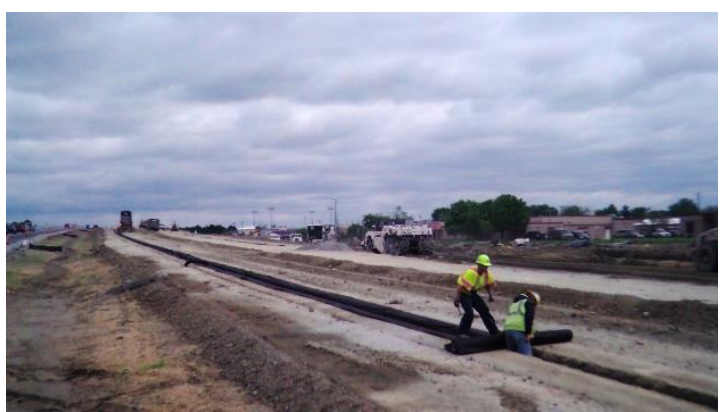

(b) Placing geotextile fabric

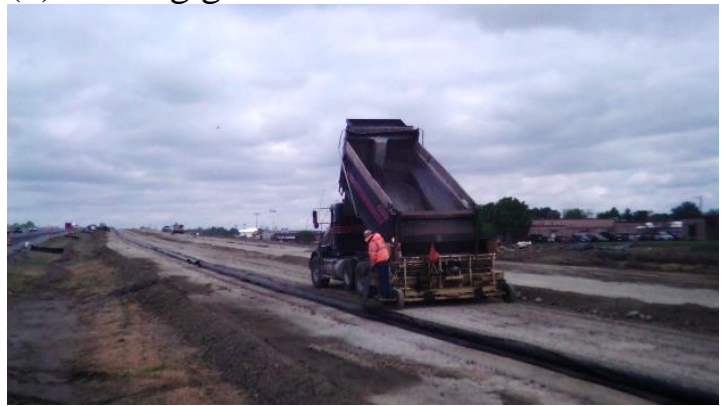

(d) Aggregate placed to facilitate drainage

Figure 2.10 Underdrain installation process 


\subsection{Discussion}

The above case study illustrates how digital documentation from the time-lapse cameras can serve as a demonstration tool for future and newly-hired inspectors, contractors, and engineers. These video modules could be used as an off-site orientation to construction practices or supplement lectures and presentations in classroom settings such as Highway Technician School. The advantage of observing construction processes before entering the field is invaluable for newly-hired construction workers and engineers.

From a continuing-education perspective, there is also tremendous opportunity for applying these concepts. Continuously observing a construction activity from start to finish is an opportunity that many senior-level design engineers may have never experienced. This is especially true as construction technology continues to mature after senior-level engineers have advanced within the organization. In this way, documenting an entire project with time-lapse photography can become an invaluable reference for senior staff as well. 


\section{CHAPTER 3. MSE WALL CONSTRUCTION}

\subsection{Introduction to Mechanically Stabilized Earth Walls}

Mechanically stabilized earth retaining walls (MSE walls) have become quite popular over the past few decades and are quickly becoming the most common retaining wall utilized on highway construction projects. MSE walls have many advantages to traditional concrete retaining walls. They leave a small footprint and can reach heights of over 50 feet tall with relatively minimal surface preparation. MSE walls take up less space than sloped embankments, especially when reaching heights greater than 10 feet. In addition, MSE walls do not require a crew of specially skilled workers to erect, and they require minimal heavy equipment. Finally, MSE retaining walls take less time to construct and can easily be used in custom designs.

Mechanically stabilized earth walls are created by stacking precast concrete panels and connecting them to the earth embankment with reinforcement straps behind the panels. The reinforcement straps connect to the backs of the panels and extend into the embankment that is being constructed. Panels are placed, reinforcement straps are connected, and soil is compacted on top of the straps to hold the panels in place. The panels are not connected to any adjacent panels. In fact, the reinforcement straps are responsible for holding the panels in place. This design makes the MSE wall highly effective in seismic events, as its design allows individual panels of the wall to settle 
without directly affecting the other members of the wall. Therefore, proper care must be taken when constructing these relatively simple retaining walls.

This chapter will highlight the general construction process of mechanically stabilized earth retaining walls, while also indicating relevant INDOT standards and specifications. The case study project for this chapter is seen in Figure 3.1, and is part of the US 31 renovation project, as seen in part $a$. This chapter will give a step-by-step analysis on the proper construction techniques set forth by INDOT for erecting an MSE wall from start to finish (Figure $3.1 b$ and Figure 3.1c). The overall construction process is shown in Figure 3.2. This figure shows the complete construction of an MSE wall from placing the concrete leveling pad (part $a$ ) to placing the finishing coping (part f). 


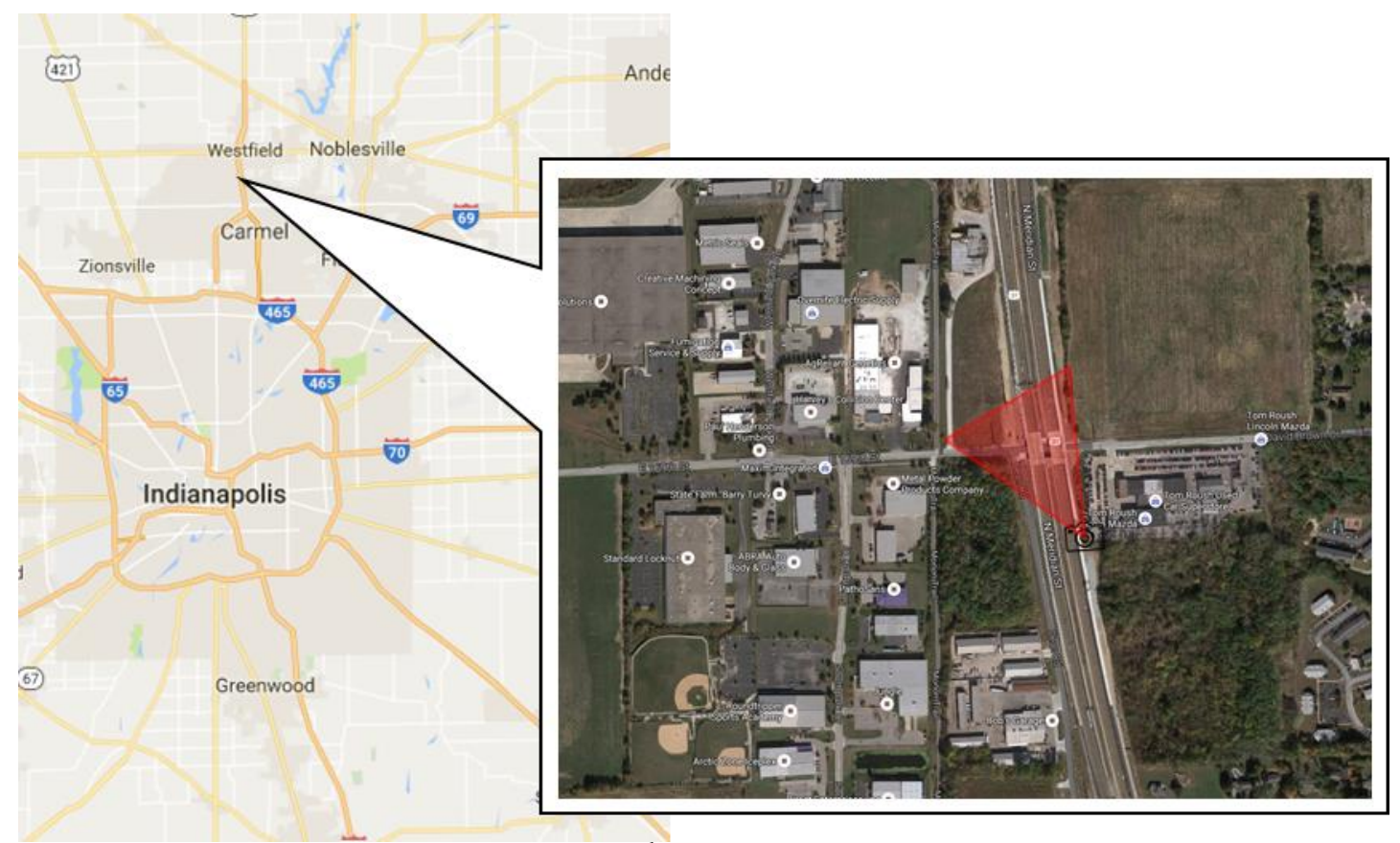

(a) US 31 Northbound bridge over $169^{\text {th }}$ Street in Westfield Indiana; camera location and view shown in red

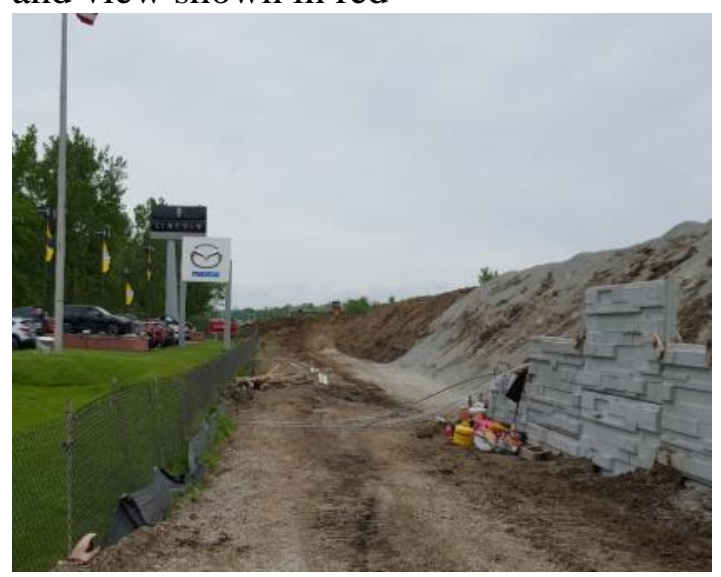

(b) Bridge during construction

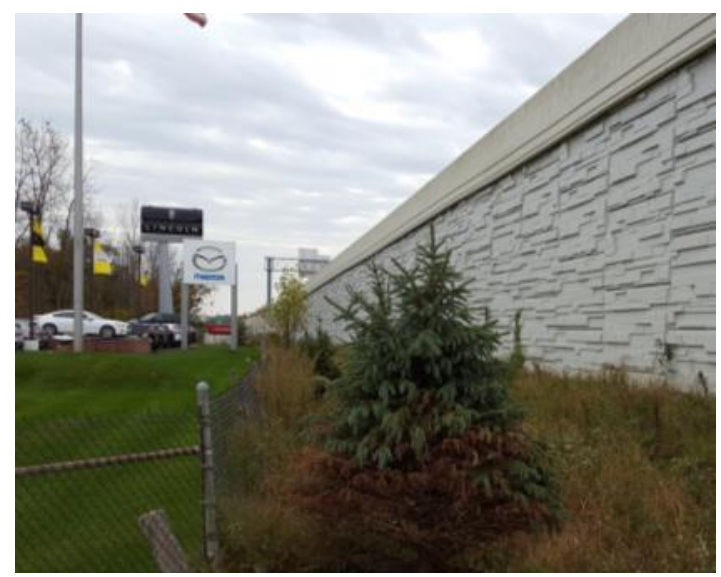

(c) Bridge construction complete

Figure 3.1 MSE wall construction overview map 


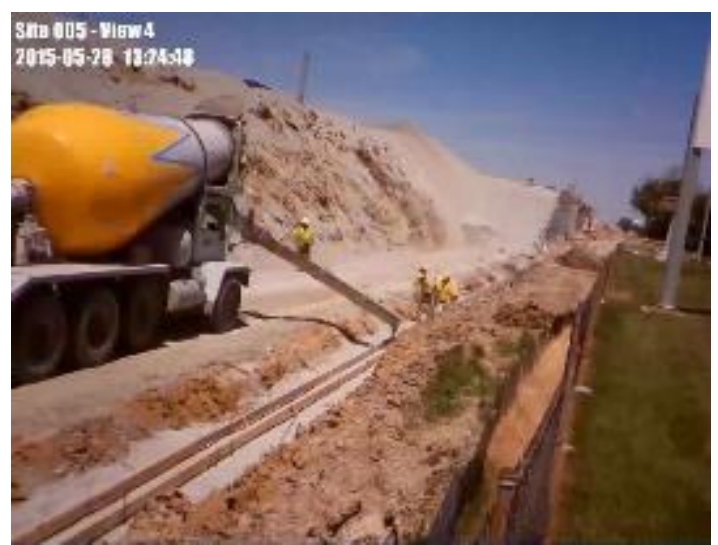

(a) Placing concrete for leveling pad

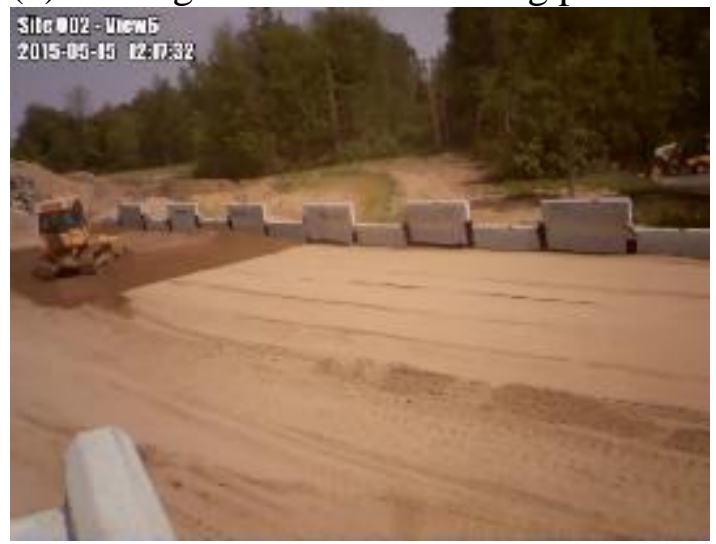

(c) Soil placement - beginning of a lift sile 002 - पICW15

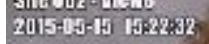

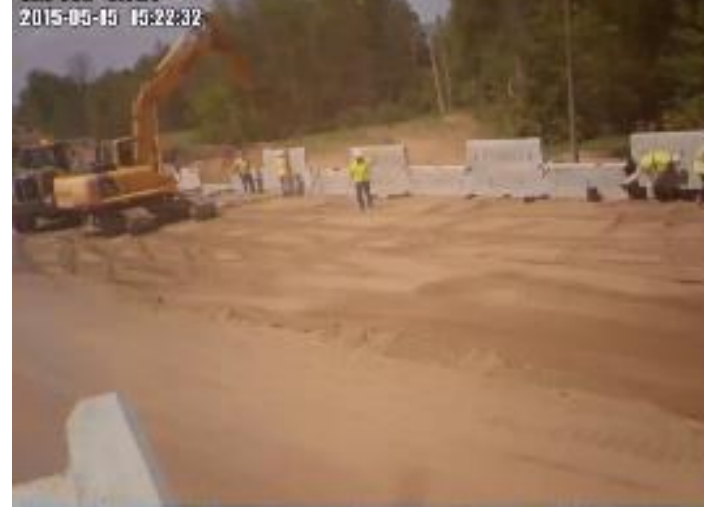

(e) Placing next row of panels

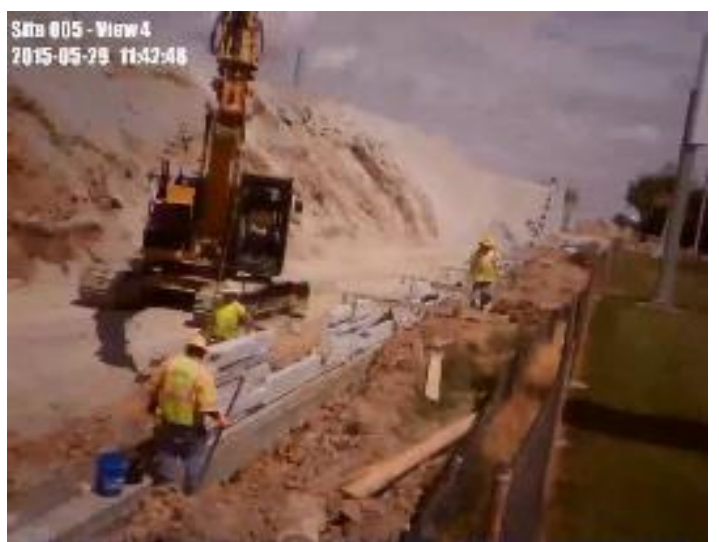

(b) Placing first row of panels

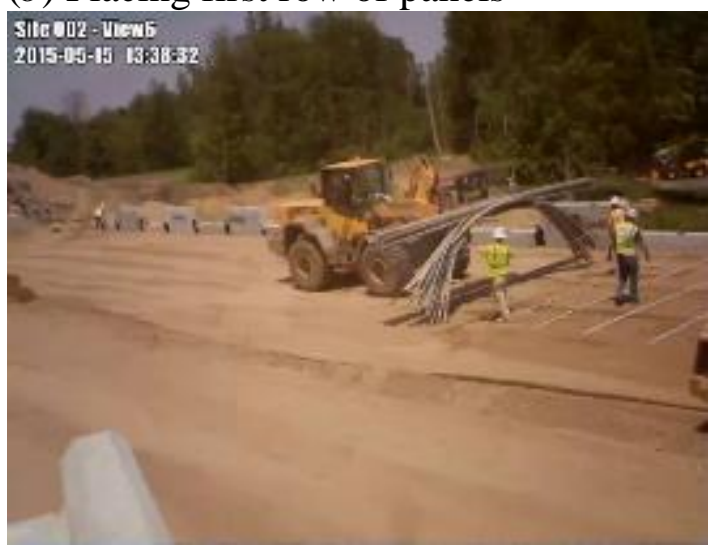

(d) Placing reinforcement straps

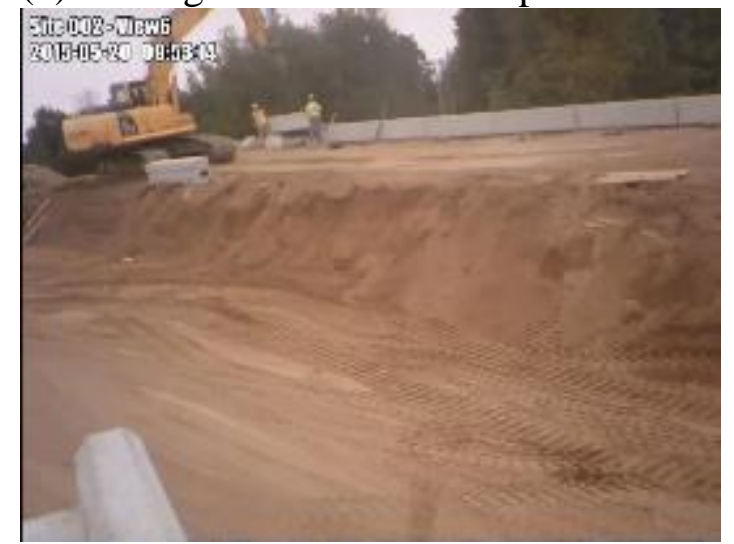

(f) Placing finishing coping

Figure 3.2 Construction process of a mechanically stabilized earth wall 


\subsection{Leveling Pad Preparation and Construction}

Before the construction of any structure can begin, the proper foundations must be prepared. For the construction of an MSE wall, maintaining the proper elevation and level throughout the entire construction process is crucial. INDOT standard specifications indicates this clearly, and this is shown in Figure 3.3a.

INDOT 731.07: "Prior to wall construction, the foundation for the structure shall be graded for a width equal to or exceeding the length of the ground reinforcement or as shown on the plans. The foundation, if not in rock, shall be compacted in accordance with 203."

Figure $3.3 b$ and Figure $3.3 c$ show the iterative process of reaching the proper elevation for the wall foundation. After the proper elevation is reached, the soil is to be proofrolled with a fully-loaded tandem-axle truck. If it is determined that unsuitable soil exists at the wall foundation, it must be removed and replaced with B borrow and compacted in accordance with INDOT standards.

INDOT 731.07: "The foundation shall be proofrolled in accordance with 203.26. If unsuitable foundation material is encountered, it shall be removed and replaced with B borrow in accordance with 211.02 and compacted in accordance with 211.04."

Figure $3.3 d$ shows the foundation after proper compaction and replacement of unsuitable soil. It can be seen in the image which shows the wood forms for the leveling pad being placed. The leveling pad is to be constructed of Class A concrete, and the leveling pad is to have no reinforcement as its purpose is not structural, but rather practical. As the name suggests, it is constructed to maintain the wall level throughout the construction process. 
INDOT 731.07: "An unreinforced concrete leveling pad shall be provided at each foundation level as shown on the plans. The leveling pad shall be cured in accordance with 702.22 for a minimum of 12 hours before placement of concrete panels."

Figure $3.3 e$ shows the placement of leveling pad concrete on 7/24/15 at 16:40 and Figure $3.3 f$ shows the removal of the forms in preparation for placement of the concrete face panels on 7/25/15 at 7:10, which is in accordance with INDOT 731.07 as it exceeds the 12-hour minimum cure time. 


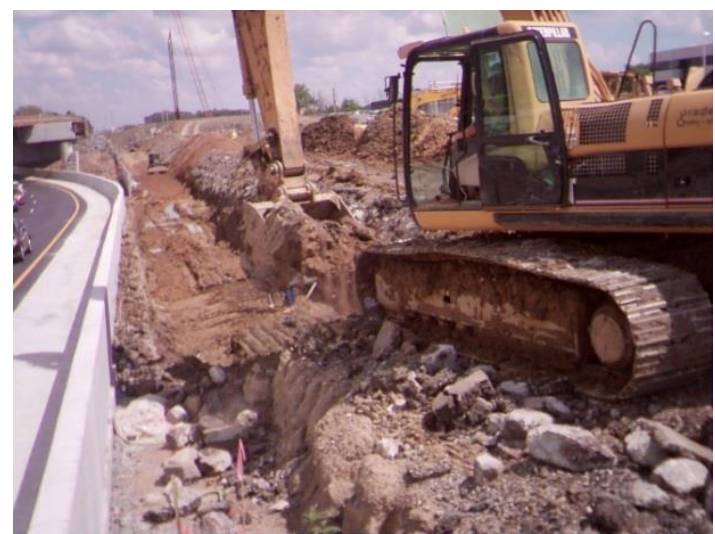

(a) Earthwork for placement of pad

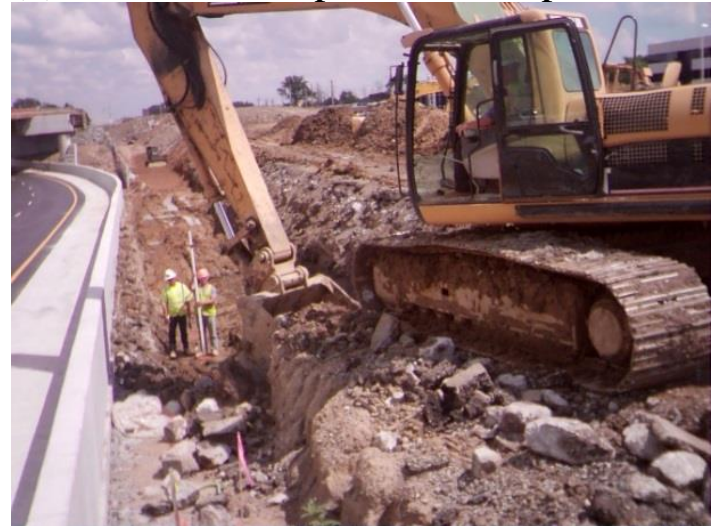

(c) Iterate until proper level is reached

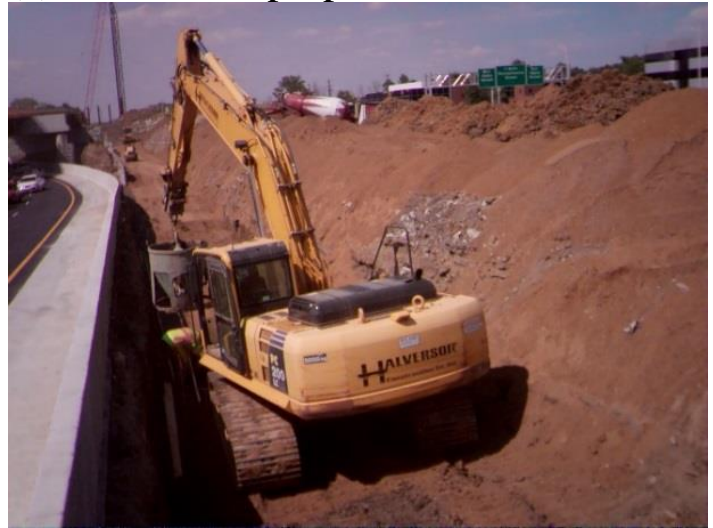

(e) Place leveling pad concrete

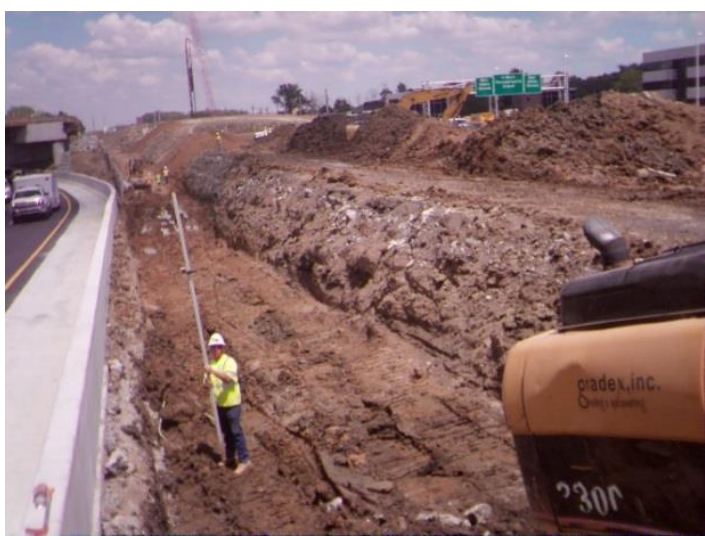

(b) Check level for pad

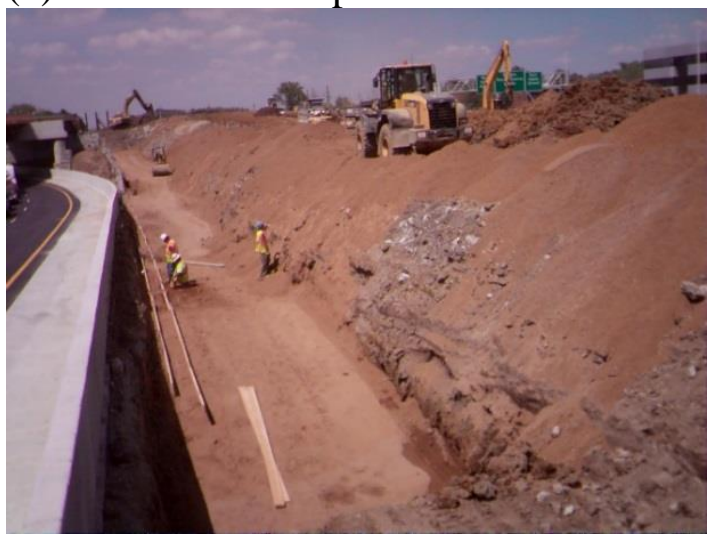

(d) Place pad wood forms

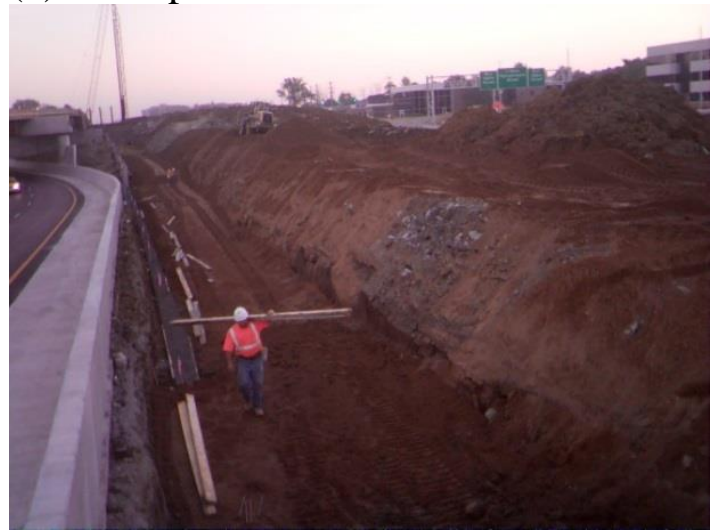

(f) Remove forms and place panels

Figure 3.3 Leveling pad construction process 


\subsection{Panel Placement}

Immediately following the construction of the leveling pad (Figure 3.4a), the first row of precast concrete panels can be placed. Figure $3.4 b$ shows how panels are transported, as depicted in INDOT 731.09.

INDOT 731.09: "Concrete face panels shall be handled by means of a lifting device set into the upper edge of each panel."

Once concrete pads are ready to be placed on the leveling pad, care must be taken to verify that they are properly leveled both vertically and horizontally, as seen in Figure $3.4 c$ in accordance with INDOT 731.09.

INDOT 731.09: "Plumb, vertical tolerances, and horizontal alignment tolerances shall not exceed $3 / 4 \mathrm{in}$. as measured with a $10 \mathrm{ft}$ straightedge. The maximum allowable offset in panel joints shall be $3 / 4$ in. For a wall over $10 \mathrm{ft}$ height, the overall plumb from top to bottom of the wall shall not exceed 0.05 in./ft of wall height."

Figure $3.4 d$ shows the temporary wooden supports used to level the first row of concrete panels as they initially have no support.

INDOT 731.09: "External bracing will be required for the initial lift."

The first and last row of panels are the only rows that contain panels of different sizes. All other rows of panels are uniform size. Figure $3.4 e$ shows the panels as they are placed on the leveling pad, making the first row staggered. This pattern allows for settlement to occur in successive rows without showing. 


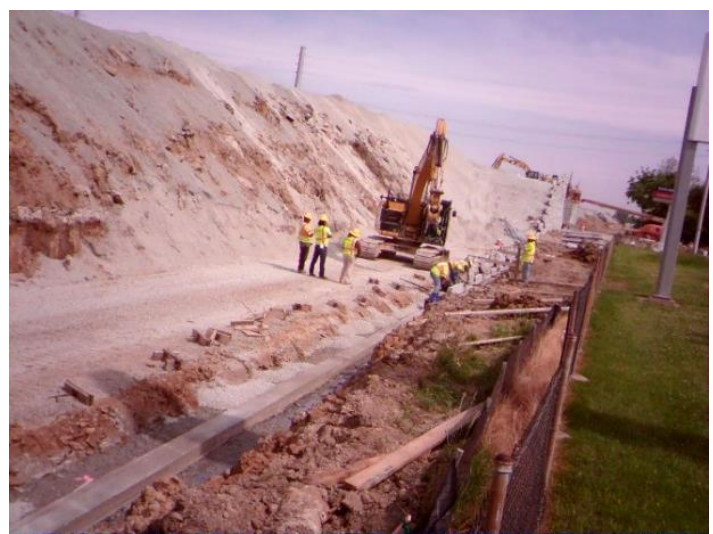

(a) Bare leveling pad - start panel placing

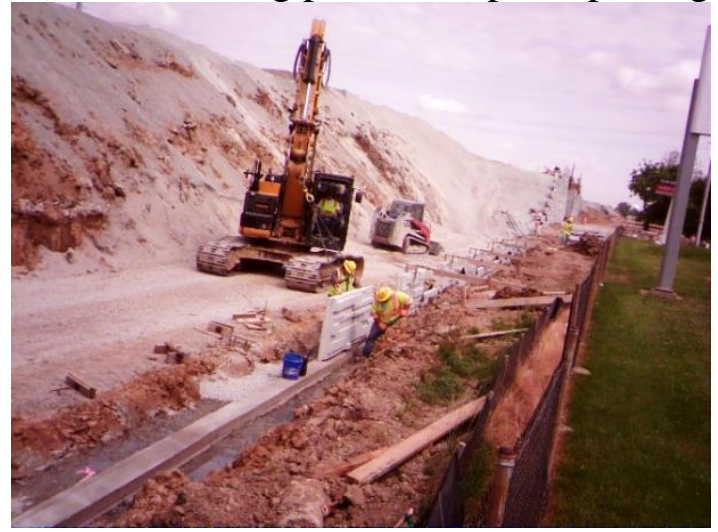

(c) Place on leveling pad and level vertically and horizontally

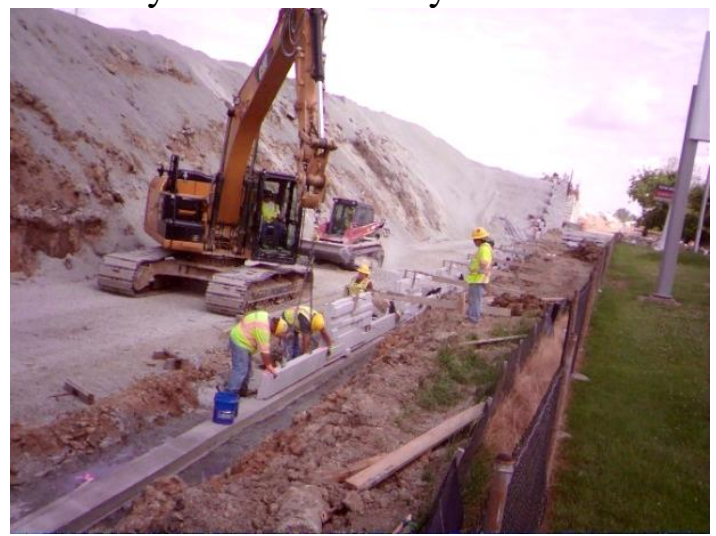

(e) First row of panels contains two distinct panel types

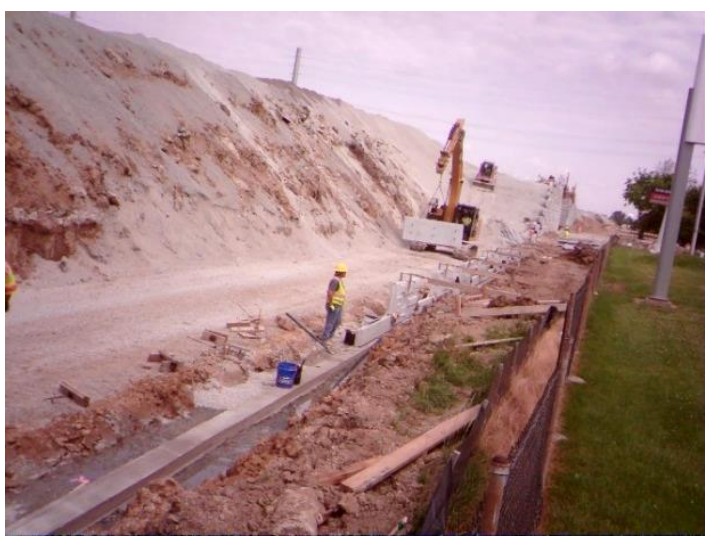

(b) Panels are not connected to each other

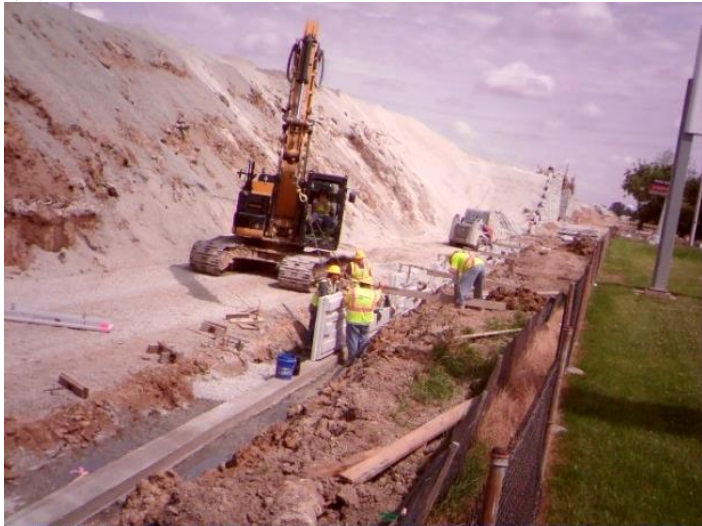

(d) Place temporary wood panel supports

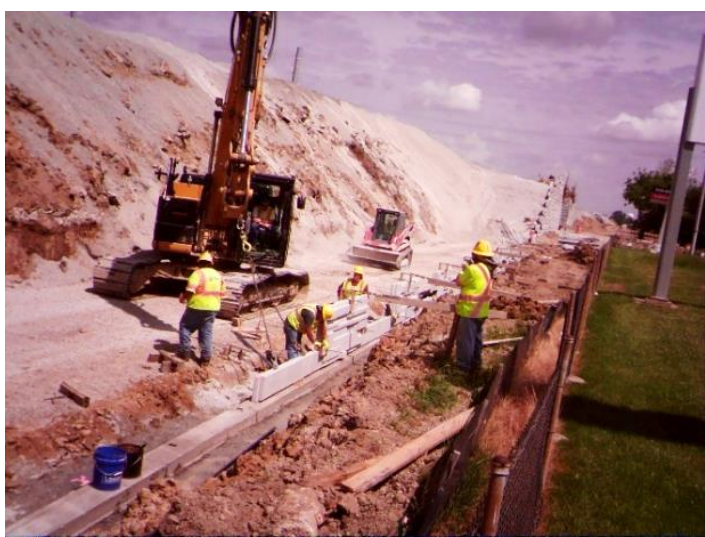

(f) Level half-size panels with wooden shims

Figure 3.4 Erecting the first row of MSE wall panels 
INDOT 731.09: "For aesthetic considerations and to make differential settlement unnoticeable, the panels shall be erected such that the horizontal site line is discontinuous at every other panel. This shall be accomplished by starting erection with the lower panel level of each wall by alternating full-height and half-height panels. Panels above the lowest level shall be of a uniform size, except as required to top out the wall, to be in accordance with the plan elevations.

Figure $3.4 f$ shows how the contractor must level the half-size panels on the first row. These panels are leveled with wooden shims. However, also in the figure are the neoprene pads set out to support the adjacent panel to be placed at the wall. 


\subsection{Soil Placement and Compaction}

After panels are placed, leveled, and temporarily secured, Figure 3.5 shows the general process for placing a lift of backfill soil. INDOT standard specifications indicate the proper and improper fill materials that are acceptable for use in constructing an MSE wall. Great care must be taken when performing lifts of soil placement. Strict adherence to the standard specifications must occur in order to maximize the life of the retaining wall as the mechanism for holding up the panels lies in proper placement and compaction of the structure backfill.

Figure $3.5 a$ shows a view of the MSE wall from the back where the wall is ready for the next lift of soil placement. As seen in Figure 3.5b, the soil is being pushed in the direction of, but not directly to the panels. In order to avoid panel displacement, the soil must be pushed toward the wall, but heavy equipment shall keep a distance of no less than 3 feet from the wall. Soil placement close to the wall shall be accomplished by hand. Appropriate structure backfill for placement within the wall is Type 3 structure backfill and shall be placed in accordance with INDOT 731.05 and INDOT 731.11 respectively.

INDOT 731.05: "MSE wall backfill shall consist of structure backfill type 3 in the reinforced backfill zone in accordance with 211, except that nominal size aggregate No. 30 shall not be used. Structure backfill in the retained backfill zone shall be type 3 or B borrow as shown on the plans."

INDOT 731.11: "Backfill shall be placed so as to avoid damage or disturbance to the wall materials or misalignment of the concrete face panels. All material for backfill shall be subject to approval and shall be free from lumps, wood, or other undesirable material." 


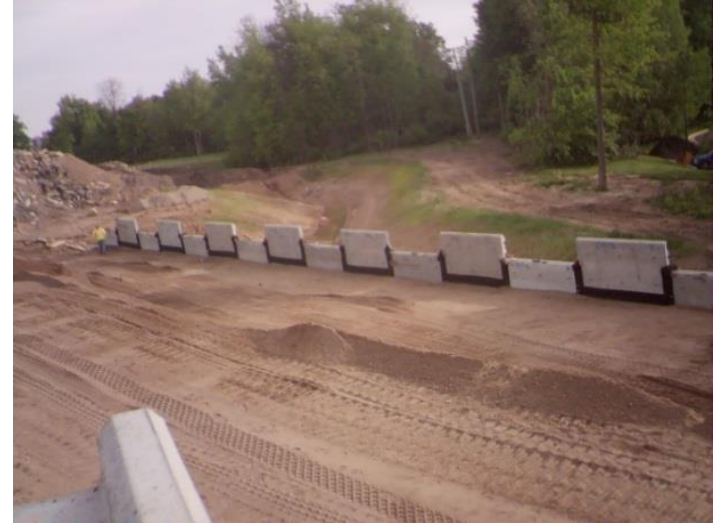

(a) MSE wall ready for next lift of soil

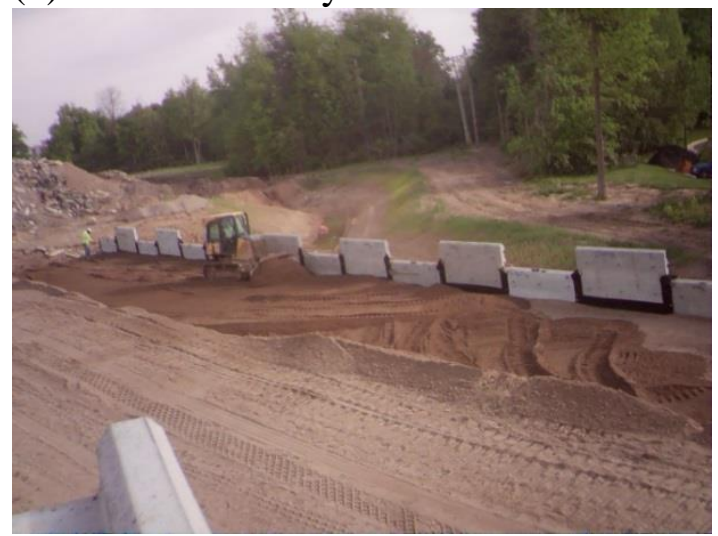

(c) Soil near panels is pushed along the length of the panels

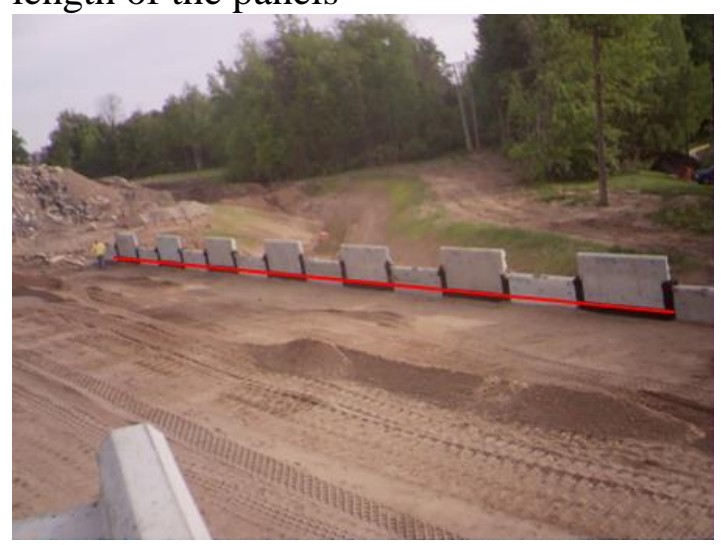

(e) Soil level before lift

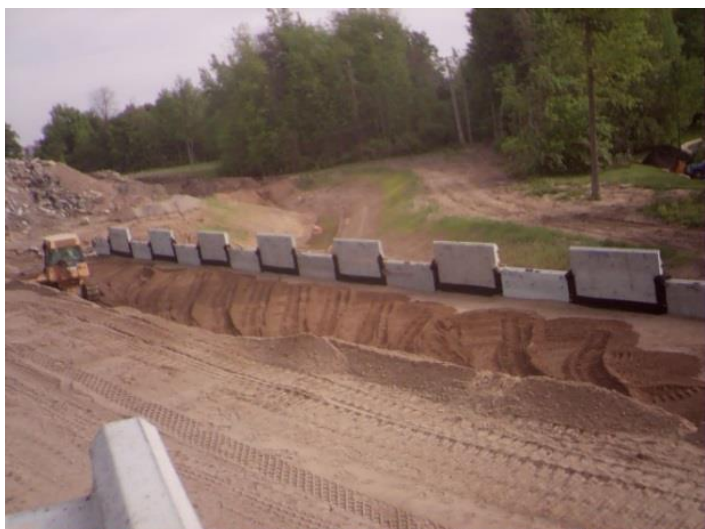

(b) Soil is pushed toward the panels

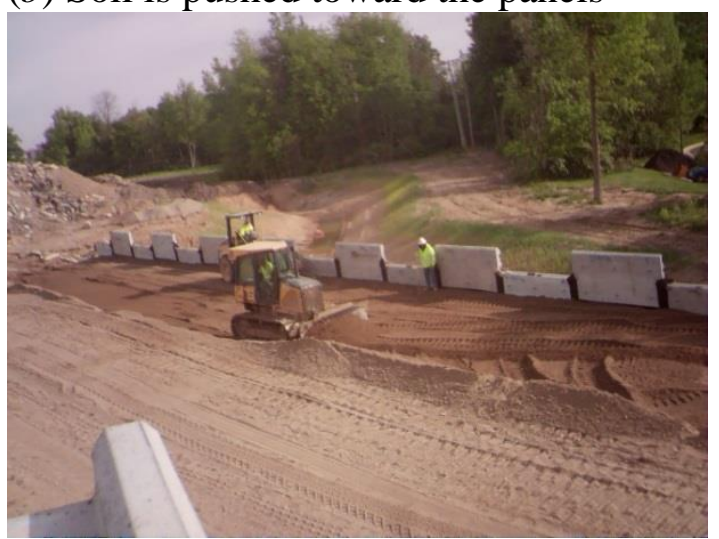

(d) Compaction begins, lift is complete

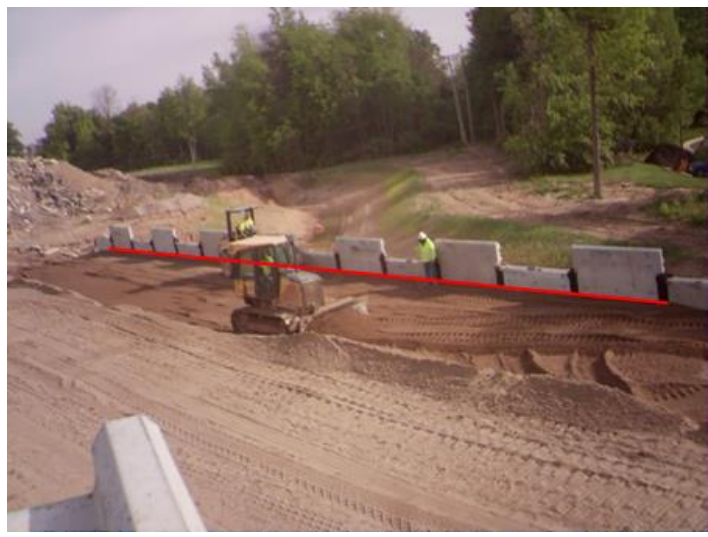

(f) Soil level after lift

Figure 3.5 Loose lift soil placement 
Care must be taken so that the proper amount of soil is placed with each successive lift. Prior to compaction, the maximum allowable loose-lift soil thickness is not to exceed 8 inches. However, this requirement becomes stricter within 3 feet of the wall. Maximum loose-lift thickness shall not exceed 5 inches within 3 feet of the wall. Figure $3.5 d$ shows the end of loose-lift soil placement and the beginning of soil compaction. Figure 3.5 e shows the soil level before the next lift occurs and puts a line along the panel backing material, which is nominally 12 inches wide. Figure $3.5 f$ shows the soil level after compaction with the line shown indicating that the loose lift may have been slightly thicker than 8 inches.

INDOT 731.11: "The maximum loose lift thickness shall not exceed 8 in. However, lifts within $3 \mathrm{ft}$. of the wall shall not exceed 5 in. in loose thickness. This lift thickness shall be decreased if necessary, to obtain the specified density."

Compaction of the soil can occur a few different ways, but the soil must reach the specified density requirements at the end of the soil placement and compaction. However, compaction within 3 feet of the wall shall only occur with a vibratory plate compaction unit, as seen in Figure 3.6a. Figure 3.6c shows the vibratory roller compactor compacting the soil too close to the wall, in violation of INDOT 731.11. 
INDOT 731.11: "B borrow and No. 4 size structure backfill shall be compacted to 95\% of the maximum dry density in accordance with AASHTO T 99. Density of the B borrow and No. 4 size structure backfill will be determined in accordance with 203.24(b). Compaction equipment shall be in accordance with 409.03(d). For all other structure backfill material used, compaction shall consist of four passes with a vibratory roller and one pass with the same roller in static mode..."

INDOT 731.11: "Compaction within $3 \mathrm{ft}$. of the back face of the concrete face panels shall be achieved by means of a minimum of five passes with a lightweight mechanical tamper, roller, or an alternative vibratory system." 


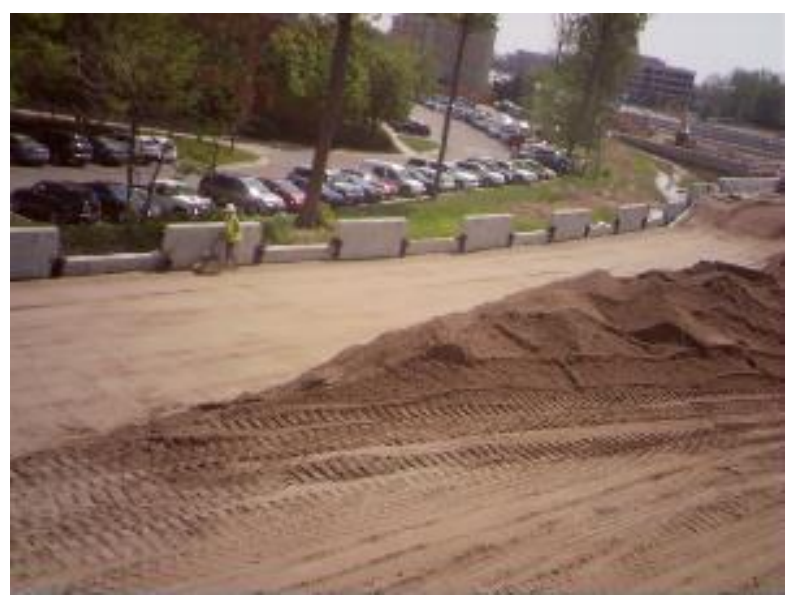

(a) Vibratory plate compactor within 3 feet of wall

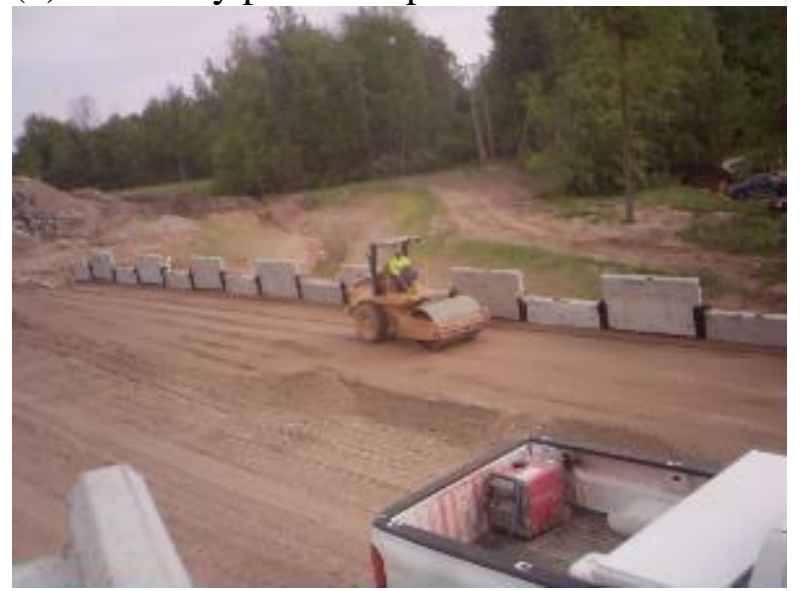

(b) Vibratory roller must make 5 passes over soil

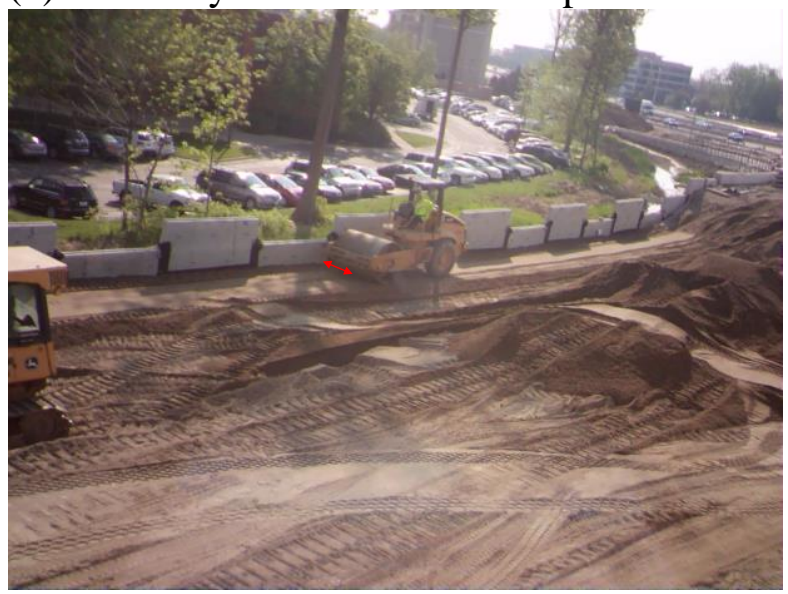

(c) Vibratory roller is too close to the wall

Figure 3.6 Proper/improper compaction methods 


\subsection{Reinforcement Straps}

A crucial, yet rarely seen component of the MSE wall is its reinforcement straps, seen in Figure 3.7a. Consistency is key for proper storage and installation of the ground reinforcement of the MSE wall.

INDOT 731.03: "The ground reinforcement shall be the same length from the bottom to the top of each wall section regardless of the type of ground reinforcement used."

The reinforcement strap connections are often designed by the fabricators of the MSE wall panels and must adhere to strict requirements set forth by INDOT. The panel strap connectors can be seen up close in Figure 3.7c and from a distance in part $a$.

INDOT 731.09: "The connections of the ground reinforcement to the panels shall be in two elevations for full height panels. The connections shall not be more than $30 \mathrm{in}$. vertically apart. To prevent out-of-plane rotation, full height face panels shall be connected to the ground reinforcement on at least three different points in two different planes..." 


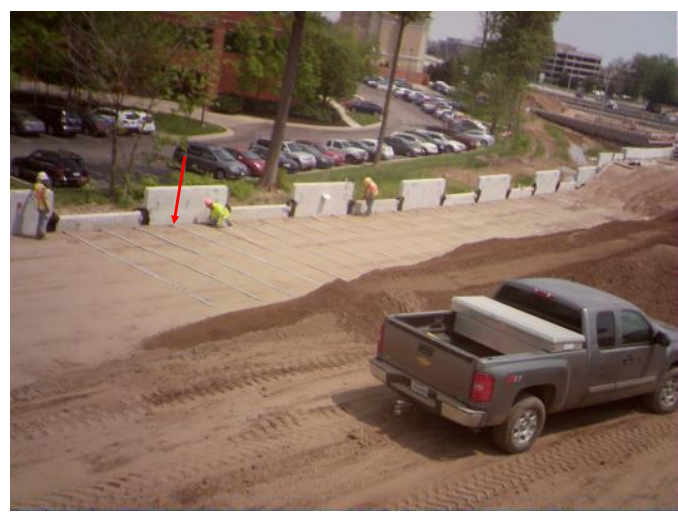

(a) Connecting straps to panels

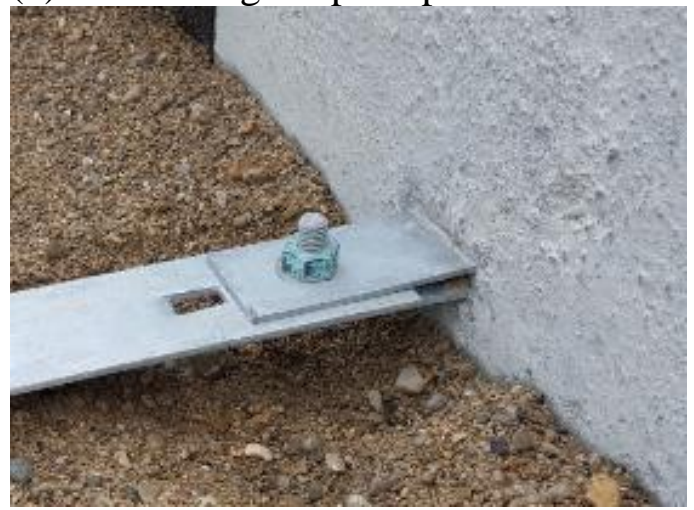

(c) Panel strap connectors

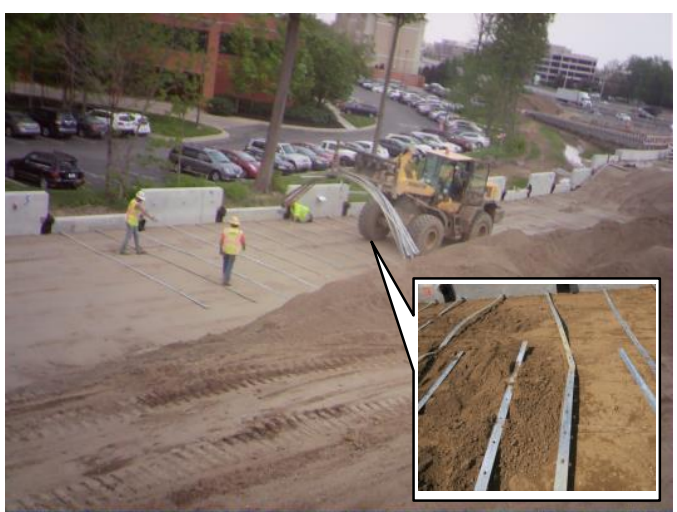

(b) Driving over straps causes damage

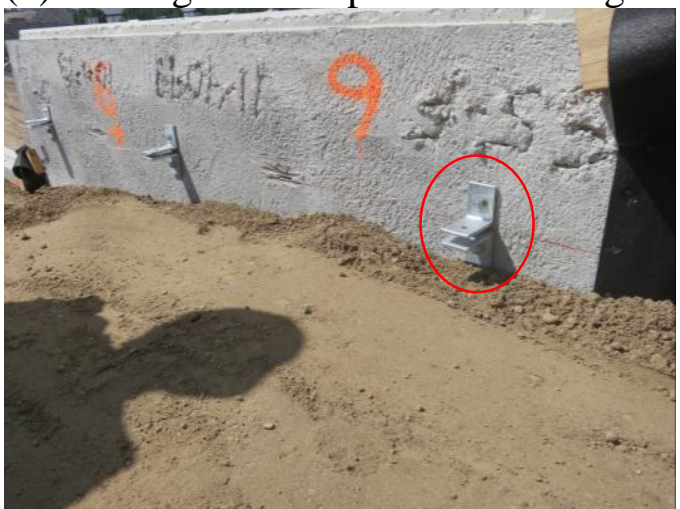

(d) Improper fix of broken connectors

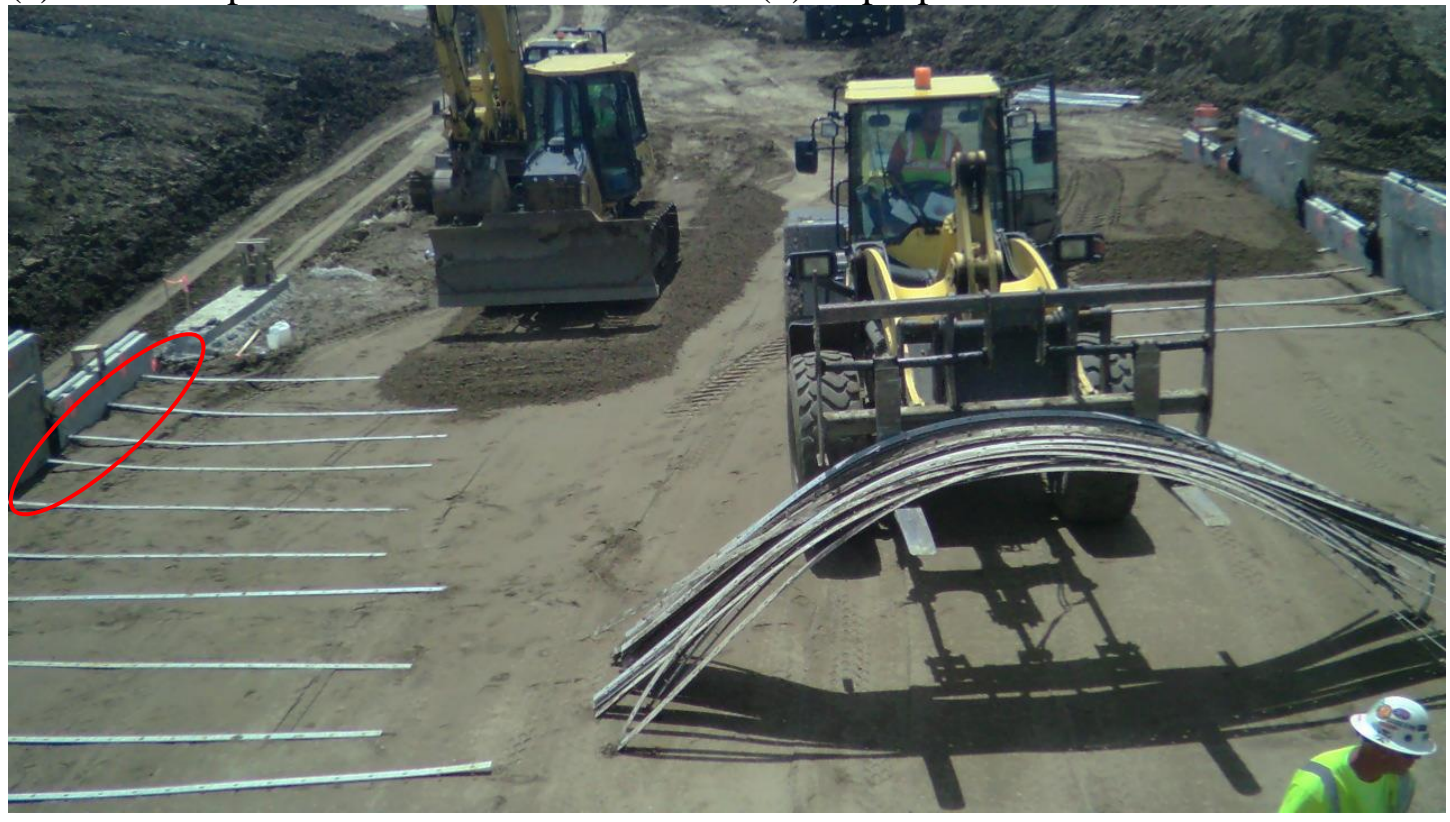

(e) MSE wall ready for next lift of soil

Figure 3.7 Reinforcement strap placement and considerations 
Figure $3.7 d$ shows an improper fix of the broken connectors for the reinforcement straps. Such a fix is not approved by the agency and will not be acceptable in the field. In the event that connectors for MSE wall reinforcement straps break in the field, it is recommended that such panels be treated as broken and not usable, and replacement panels be ordered. Once proper reinforcement strap connections are verified, the straps are ready to be connected to the MSE wall if and only if the soil is compacted directly below and supporting the reinforcement straps. Reinforcement straps should be placed perpendicular to the wall, unless obstructions prevent this. Inspectors should consult the plan drawings to verify all straps that are not perpendicular to the wall.

INDOT 731.09: "Ground reinforcement shall be placed normal to the face of the wall, unless otherwise shown on the plans or as directed. Prior to placement of the ground reinforcement, backfill shall be compacted in accordance with 731.11."

An example where contractors are in violation of INDOT 731.09, stated above, is circled in Figure 3.7e. Here, there is a considerable gap between the compacted soil and the reinforcement straps. Further levels of compacted soil will cause stress on the interface between the panel and the strap connector, which will compromise the integrity of the wall. Note the different lengths of reinforcement straps in part $e$. An inspector should consult the plans to verify that each strap is the length specified. Cutting soil reinforcement in the field is strictly prohibited unless specifically called out and pre-approved in the plans. Finally, after placement of the ground reinforcement, contractors should be careful not to drive over the reinforcement for fear of bending, breaking, or otherwise damaging the galvanized coating on the reinforcement straps. See Figure $3.7 b$ for such an example. 
INDOT 731.11: "Cutting or altering of the basic structural section of ground reinforcement at the site will be prohibited, unless the cutting is preplanned and detailed on the approved working drawings. Cutting shall be considered only if adequate additional ground reinforcement is provided to produce the required strength shown in the approved calculations. If the ground reinforcement is shortened in the field, the cut ends shall be covered with a galvanized paint or coal tar to prevent corrosion of the metal." 


\subsection{Other MSE Wall Considerations}

One final consideration for the proper construction of mechanically stabilized earth walls is the panel joint covering fabric, which can be seen in Figure 3.8. The third full panel from the right has no panel joint covering fabric in Figure 3.8a. Figure 3.8b shows the contractor beginning to place the panel joint covering fabric onto the panel, and part $c$ shows the panel after installation. The panel joint covering fabric serves as the only barrier preventing fine soils from passing through the wall, as panels are to maintain consistent spacing to prevent concrete-concrete rubbing. Further, the joint covering fabric is designed to allow water to pass through it while retaining the fine soil particles. It is therefore imperative for the joint covering fabric to be applied to the wall in the correct manner. Fabric should be applied to the wall with adhesive. The adhesive should be applied to the wall, not to the fabric, so as not to cover the pores in the fabric, which would prevent proper drainage through the wall.

\section{INDOT 731.10: "Horizontal and vertical joint spacers shall be provided between adjacent face panels to prevent concrete-to-concrete contact and chipping if differential settlement occurs. Panels without an uninterrupted vertical joint shall have a minimum joint thickness of $3 / 4 \mathrm{in}$. Joint covering shall be provided and attached to the rear face of the panels."}




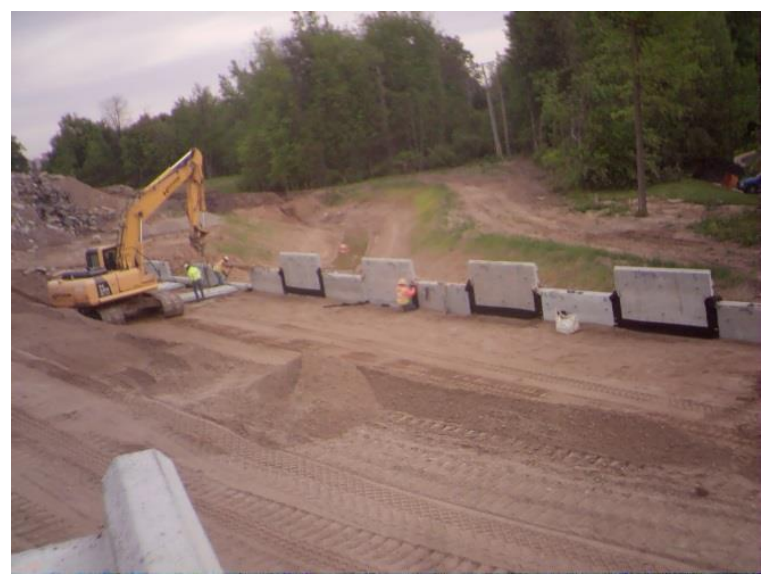

(a) Panel before joint covering fabric is placed

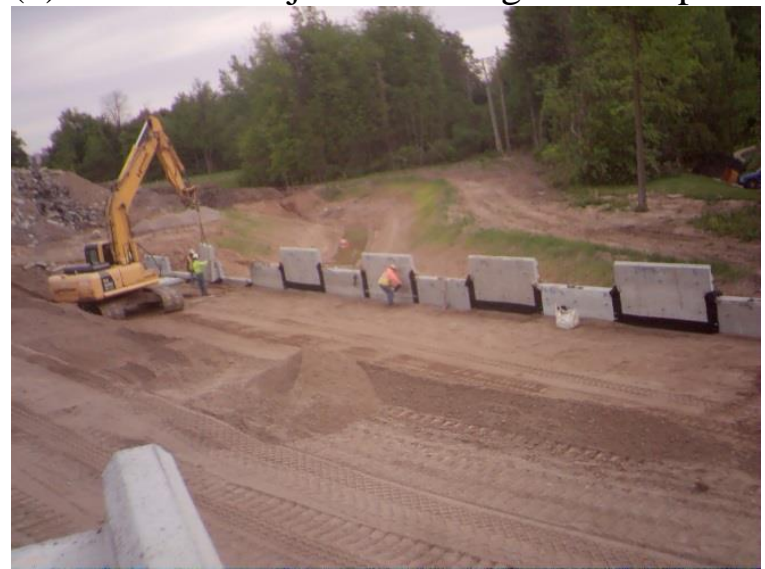

(b) Fabric is placed vertically along the seams

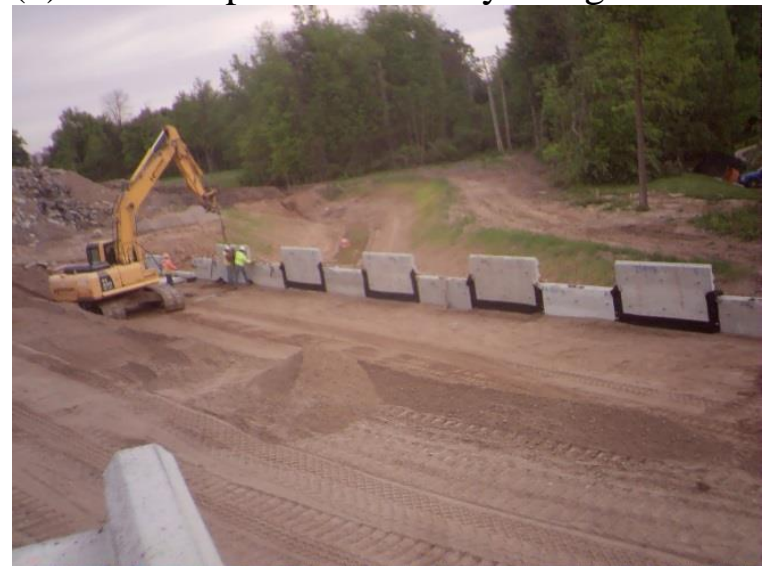

(c) Fabric is then placed horizontally along the seam

Figure 3.8 Panel joint covering fabric 


\section{CHAPTER 4. CONSTRUCTION OF ROUNDABOUTS}

\subsection{Introduction to Roundabout Construction}

The project team investigated the construction of two separate roundabouts since May of 2015. The primary difference between the two roundabouts featured in this chapter is the paving material utilized to create the driving layer. One roundabout is located at $191^{\text {st }}$ Street at US 31 in Westfield as part of the project to upgrade and gradeseparate a 13-mile stretch of US 31 to freeway standards. This roundabout uses flexible pavement and is constructed as a service interchange below the newly upgraded and elevated US 31. Therefore, the roundabout is not a standard roundabout, but a dog bone roundabout to service all travel directions from both sides of US 31 in one roundabout. The other roundabout featured in this chapter is at the intersection of Bartlett Street and Michigan Street in South Bend. This roundabout utilizes rigid pavement and is constructed in place of an existing intersection. Traffic was removed from both streets for the entire duration of construction.

An overview map of the roundabout at $191^{\text {st }}$ Street and US 31 can be seen in Figure 4.1a. This chapter will highlight the construction process of this roundabout from the beginning of construction (Figure 4.1b) to its reopening (Figure 4.1c). Similarly, an overview map of the roundabout at Bartlett Street and Michigan Street in 
South Bend can be seen in Figure 4.2a. The project team used time-lapse cameras to record the 4-month

construction process from beginning of construction when road closure began, seen in Figure $4.2 b$ to official opening for traffic after construction completion, seen in Figure $4.2 c$.

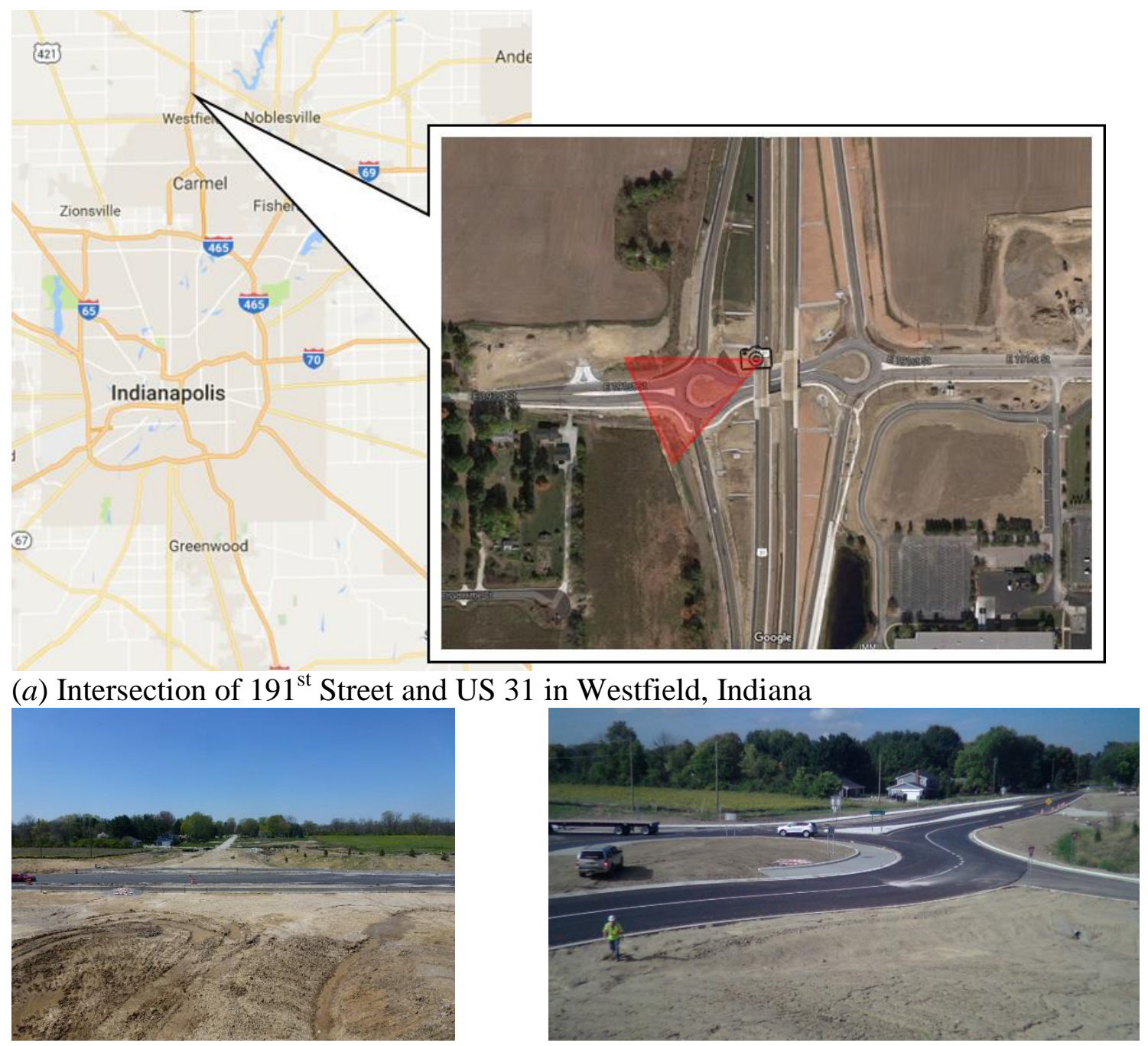



(b) Intersection during construction
(c) Roundabout construction complete

Figure 4.1 Flexible pavement roundabout overview and map

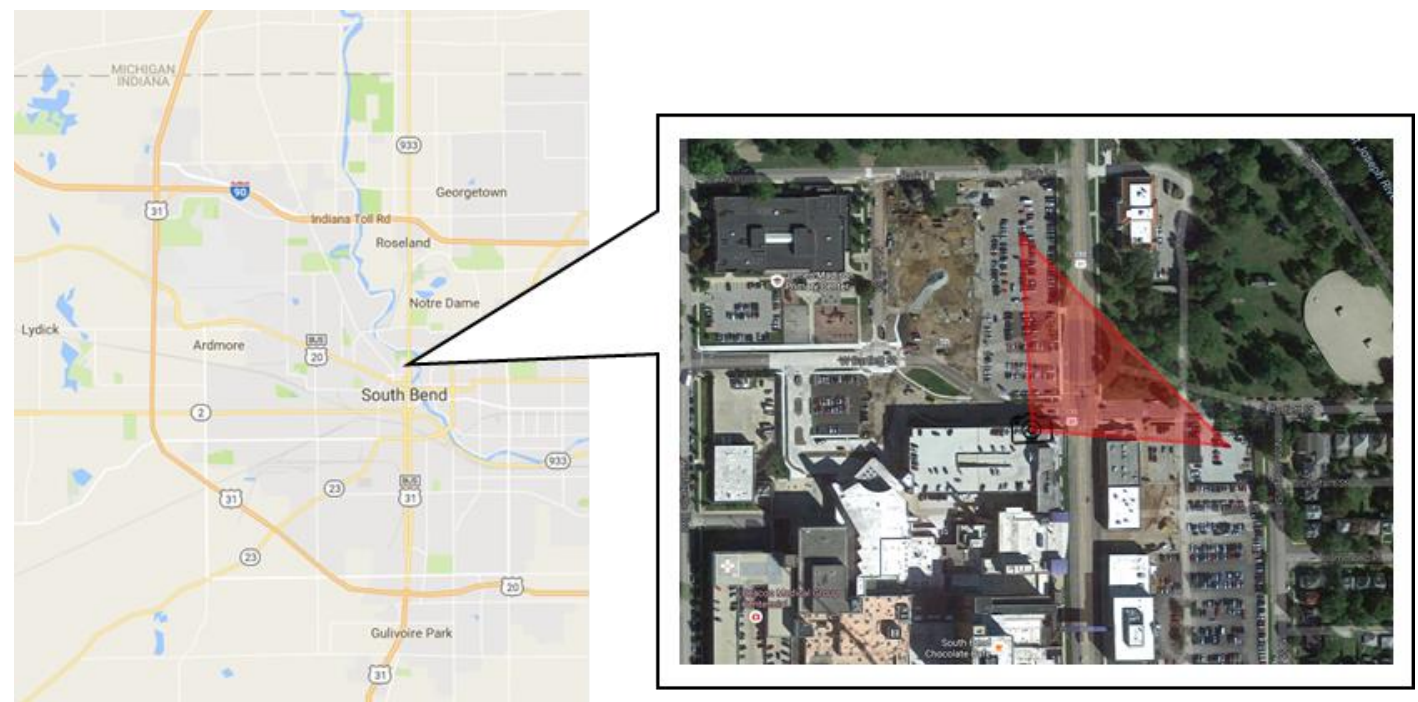

(a) Intersection of Bartlett and Michigan Street in South Bend, Indiana

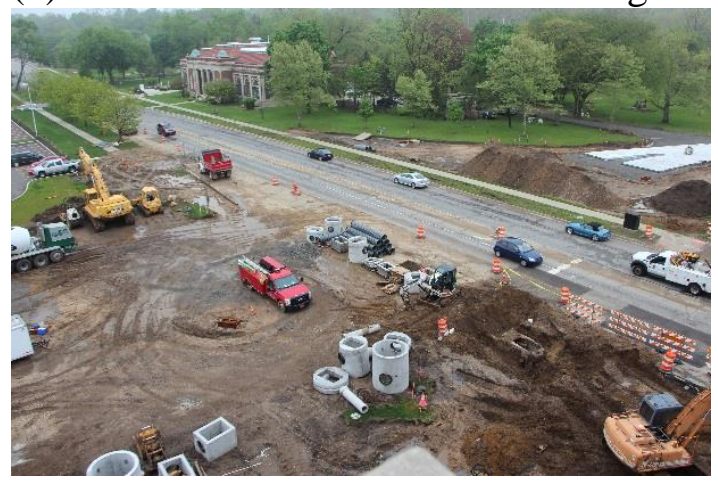

(b) Roundabout during construction

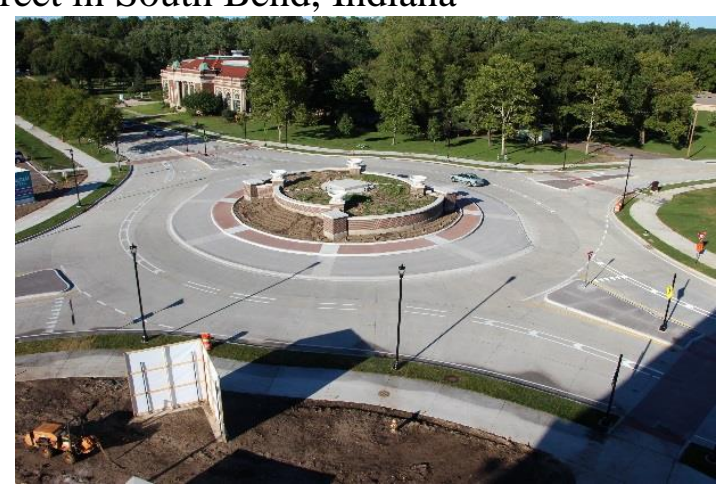

(c) Roundabout construction complete

Figure 4.2 Rigid pavement roundabout overview and map 


\subsection{Asphalt Roundabout Construction}

Construction of the asphalt roundabout in Westfield at $191^{\text {st }}$ Street and US 31 started in the spring of 2015 after the road was closed to traffic. The roundabout interchange was officially opened to traffic at the end of September, 2016. The US 31 and $191^{\text {st }}$ Street interchange was closed for approximately 3 months. Demolition of the old roadway was initiated on June 23, 2015, as shown in Figure 4.3a. The process of demolishing the old road included the use of an asphalt milling machine and many triaxle dump trucks to remove the asphalt millings. Once the old roadway was fully removed, the site was graded on June 30, 2015 and prepared for the earthwork required by the geometry of the roundabout and for pavement support. Grading can be seen in Figure $4.3 b$.

Earthwork for the roundabout began in the beginning of July, 2015. Drainage pipes were installed July 10 and July 11. Figure $4.3 c$ shows earthwork occurring on the roundabout just before soil stabilization occurred. Chemical soil stabilization took place on July 15, 2015. After the chemical stabilizer was mixed with the subbase, the soil was compacted and let to rest without introducing loads of heavy machinery for a period of time. Compare the consistency of the soil subbase layer in Figure $4.3 c$ to the subbase layer after soil stabilization and compaction in Figure 4.3d. After the subbase reached the appropriate strength level, heavy machinery was once again permitted onto the subbase and drainage structures were installed. The concrete box structure for a curb drainage structure can be seen in Figure 4.3d. Drainage operations were performed for nearly two weeks, until the site was ready to accept the first asphalt base layer. 


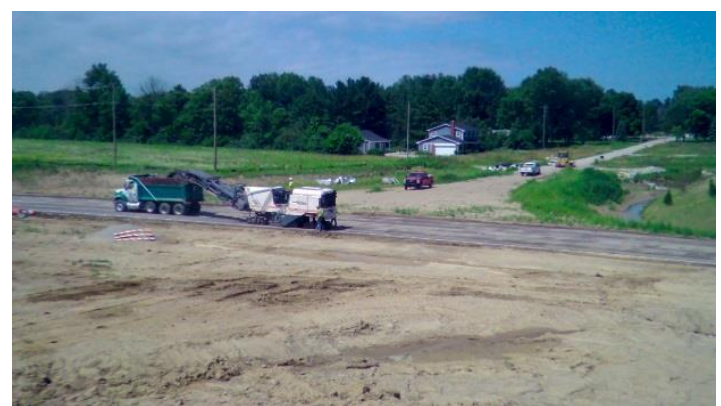

(a) 6/23/15 - Demolition of old roadway

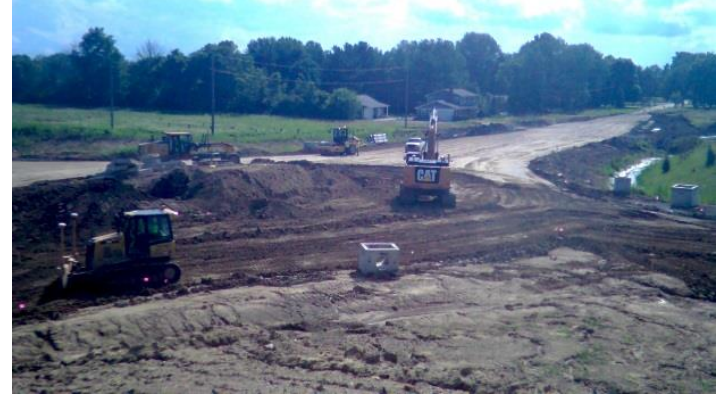

(c) $7 / 14 / 15$ - Roundabout earthwork

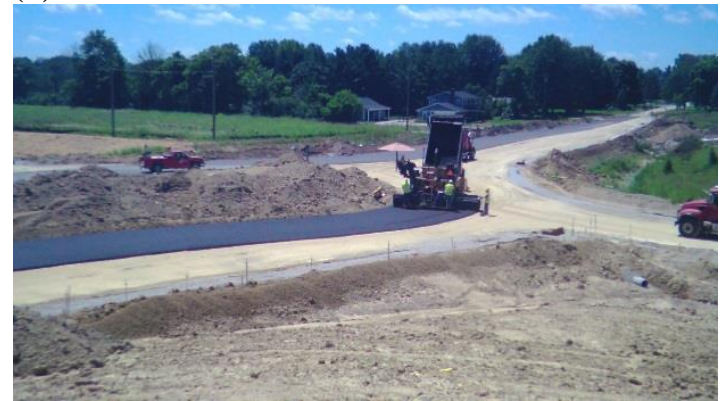

(e) $7 / 30 / 15$ - Place asphalt base layer

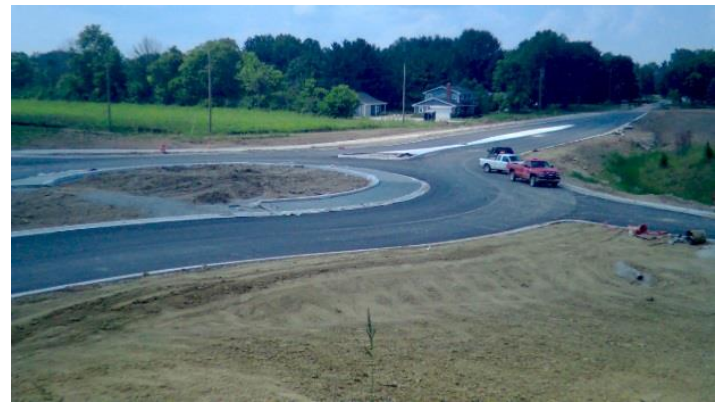

(g) 8/31/15 - Allow concrete to cure

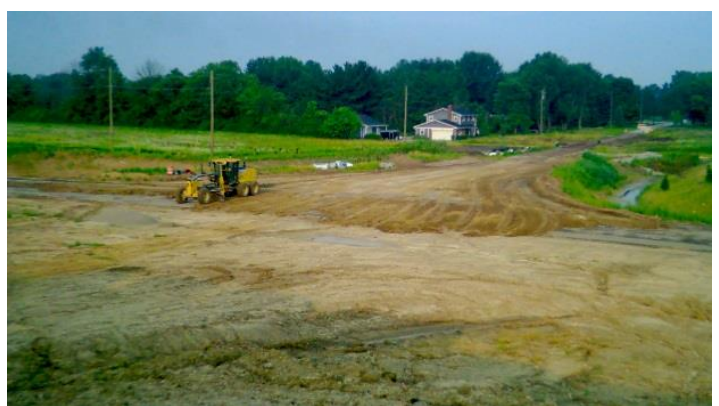

(b) $6 / 30 / 15$ - Grading

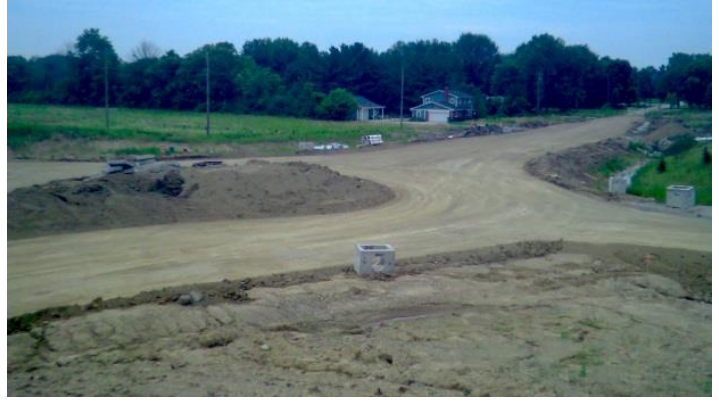

(d) $7 / 16 / 15$ - Drainage structures

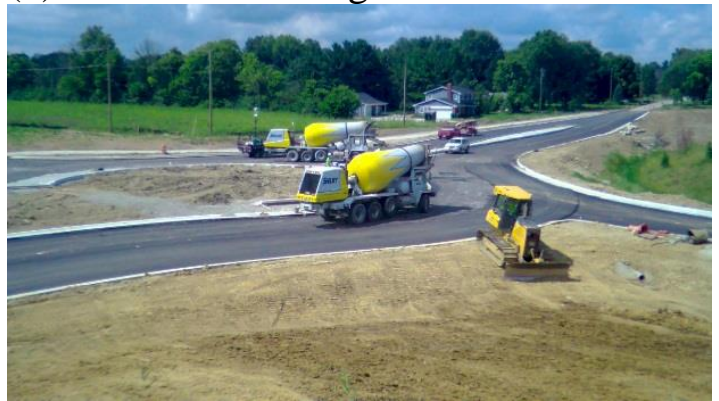

(f) 8/26/15 - Place concrete curbs and truck apron

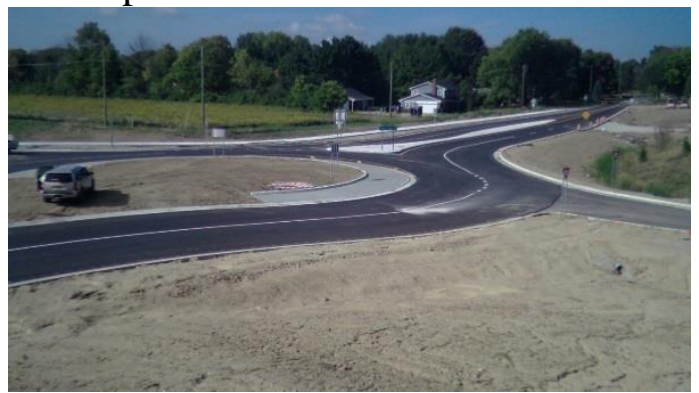

(h) 9/28/15 - Striping, signage, and open to public

Figure 4.3 Asphalt roundabout construction process 
Figure $4.3 e$ shows the first hot-mix asphalt base layer being installed. The process of placing hot-mix asphalt is very time-sensitive. As the name suggests, in order to properly place the material, the asphalt must be hot. The work done during placement of asphalt is highly dependent upon the availability of trucks hauling asphalt. It is preferable to have a steady and reliable flow of asphalt hauling trucks with at least one truck waiting in the queue at all times so the paving machine is never stopped waiting on the next load of material. An inspector will follow the paving machine and perform tests on the uncompacted asphalt. The inspector will take asphalt samples and will also perform tests on the compacted asphalt.

Figure $4.3 f$ shows the completion of construction of the truck apron and concrete curbing. Within the 26 days prior to the image shown in Figure $4.3 f$, drainage pipes were laid, ditch earthwork was performed, storm drain inlets were installed, and many concrete curbs were installed. Unlike concrete curbing, the concrete truck apron, shown in the center of the roundabout in Figure $4.3 \mathrm{~g}$, has some steel reinforcement within the concrete. Also, the concrete curbs are slip-formed whereas the concrete truck apron is placed, formed, and finished by hand.

After the concrete curbing and the truck apron were placed, additional layers of asphalt were placed to supplement the base layer of asphalt. Eventually, the wearing layer was installed on September 16. Additional site preparation and cleanup occurred between September 16 and September 28. Signs were installed around the roundabout on September 21. Some finishing earthwork was conducted on September 23 and initial striping was placed on the roadway. The intersection was officially opened to traffic on September 26, 2015, as shown in Figure 4.3h. 


\subsection{Concrete Roundabout Construction}

Construction on the concrete roundabout at Bartlett Street and Michigan Street in South Bend took place after closure of the intersection in May 2016. The $\$ 20,000,000$ project started in April and is expected to conclude December 2016 (8). The upgraded intersection was part of a much larger initiative to convert the previously one-way Michigan and Main Streets to allow for two-way traffic. Other intersections that received upgrades included Michigan and Marion Streets and Michigan and Chippewa Streets. The project includes upgraded interchanges, conversion of one-way streets to two-way streets, new curbs, dedicated bike lanes, and streetscaping. Contractors working on the intersection at Bartlett and Michigan Streets had until September 10, the date of the first Notre Dame home football game, to upgrade the existing signalcontrolled intersection to a two-lane roundabout. From the construction schedule to the football game, the project can be viewed as a success. The roundabout was officially opened to traffic on September 8, and two days later the Fighting Irish football team defeated Nevada 31-10. Complete time-lapse of roundabout construction can be seen at the following link: http://dx.doi.org/10.4231/R7S46PXT

Demolition of the old intersection began in early May 2016. While Bartlett Street was closed at Michigan Street, the major through street, Michigan Street, was kept open to traffic until May 18, as seen in Figure 4.4a. After the demolition of the old roadway, construction crews began installing new drainage structures. New pipes were run to new drainage basins. On May 23, earthwork for the base layer was initiated. The base layer was compacted and installation of drainage structures continued. Table 4.1 shows 
a brief overview of some of the major construction activities through the entire duration of the project. The table was created by reviewing the time-lapse footage captured by the camera seen in Figure $1.4 c$.

The installation of drainage structures took nearly three weeks to complete, and Figure $4.4 b$ shows the construction crew halfway through drainage installation. Also seen in part $b$ is the earthwork and compaction of the subgrade soil for the roundabout. Referring to Table 4.1, the subgrade earthwork and compaction occurred within a period of two weeks, weeks 2 and 3. Other activities that occurred within that time period are earthwork and compaction of the crushed aggregate base layer, which is shown in Figure $4.4 c$.

Formwork, preparation for, and placement of the concrete surface layer occurred between weeks 3,4 , and 5 . Figure $4.4 d$ shows the formwork and the placement of the concrete surface layer. After the concrete surface layer was worked smooth, the curing compound was applied to the surface of the pavement, changing its color from a dark grey to a white color. Once the concrete had set, crews marked and saw-cut the pavement joints. After the construction crews completed placing the concrete pavement, they began to construct the roundabout centerpiece structure. 


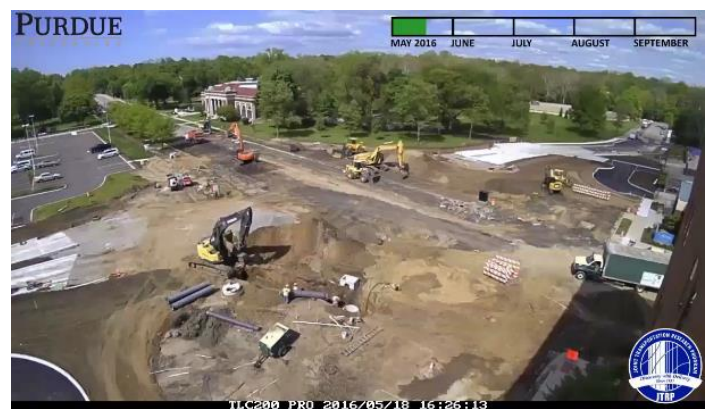

(a) Demolish original intersection

$5 / 18 / 16$

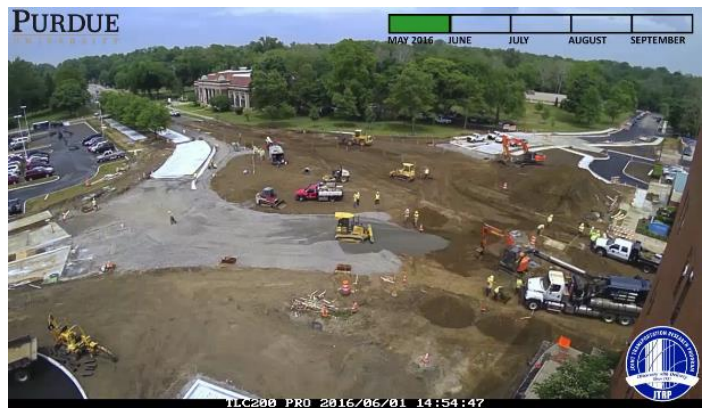

(c) Place aggregate base for concrete pavement $6 / 1 / 16$

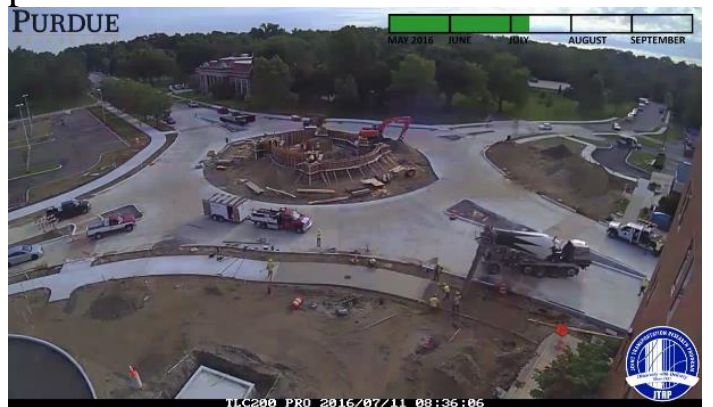

(e) Place concrete sidewalk and construct center piece $7 / 11 / 16$

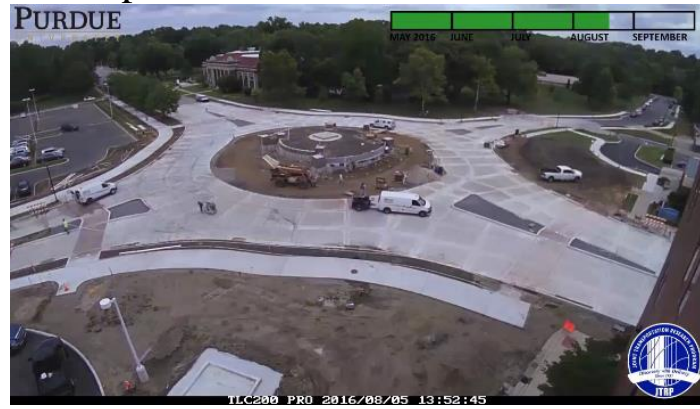

(g) Saw-cut pavement panel joints 8/5/16

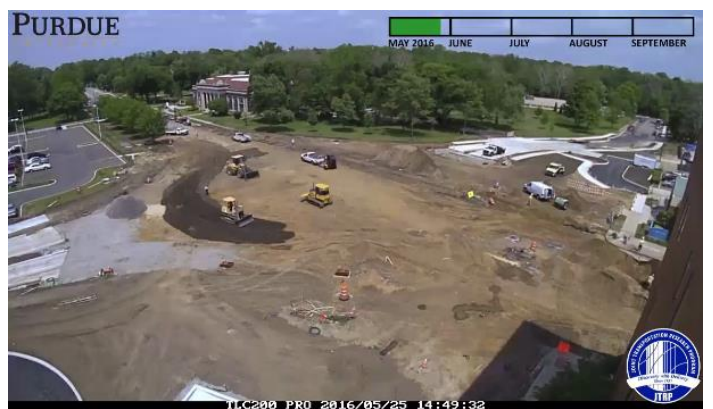

(b) Place subgrade soil for concrete pavement 5/25/16

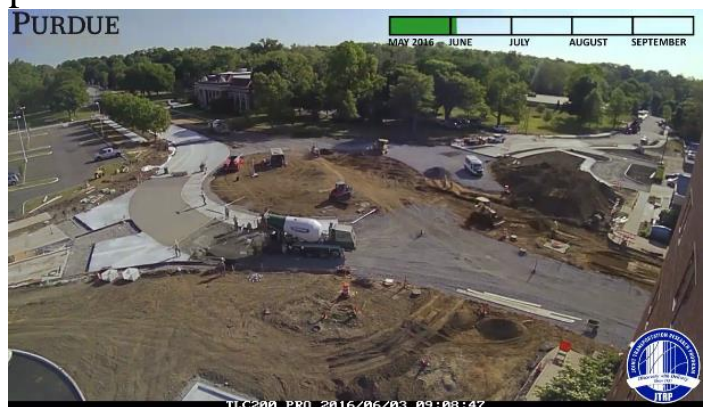

(d) Form up and place concrete pavement 6/7/16

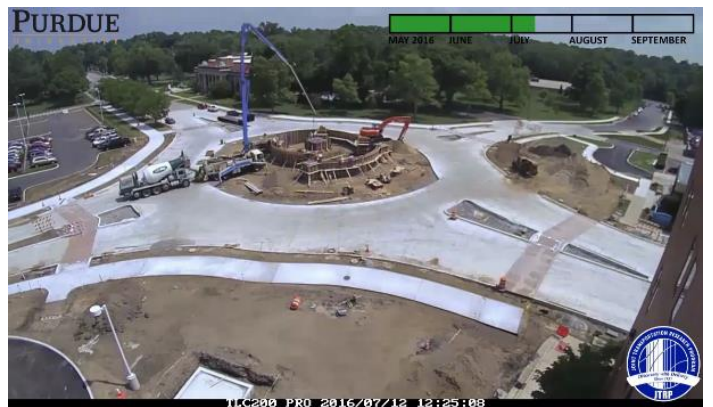

(f) Place concrete at roundabout center $7 / 12 / 16$

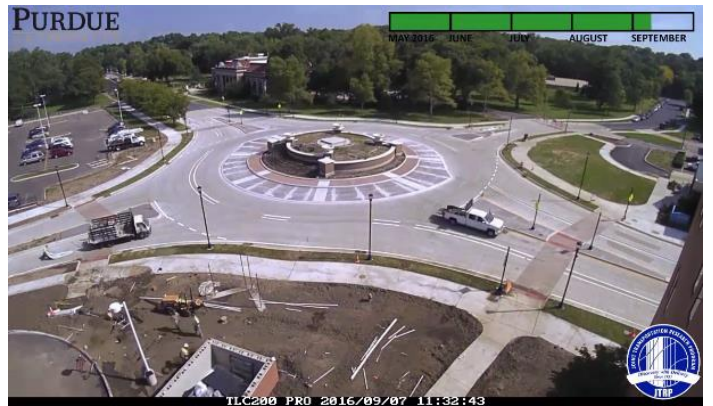

(h) Construct truck apron, lighting, striping, and signage 9/7/16

Figure 4.4 Concrete roundabout construction 
Table 4.1 South Bend Roundabout Construction Schedule

\begin{tabular}{|c|c|c|c|c|c|c|c|c|c|c|c|c|c|c|c|c|c|}
\hline Week & 1 & 2 & 3 & 4 & 5 & 6 & 7 & 8 & 9 & 10 & \begin{tabular}{l|l}
11 & \\
\end{tabular} & 12 & 13 & 14 & 15 & 16 & 17 \\
\hline Activity & 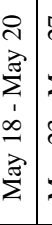 & 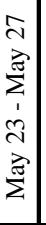 & 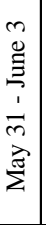 & 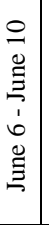 & $\begin{array}{l}\Xi \\
0 \\
\Xi \\
\dot{\Xi} \\
\dot{m} \\
0 \\
\Xi \\
\Xi\end{array}$ & 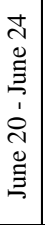 & 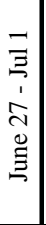 & $\begin{array}{l}\frac{a}{\Xi} \\
i \\
\Xi\end{array}$ & $\begin{array}{l}\cong \\
\Xi \\
\Xi \\
1 \\
\Xi \\
\Xi\end{array}$ & $\begin{array}{l}\mathcal{J} \\
\Xi \\
\vdots \\
\infty \\
\Xi \\
\Xi\end{array}$ & $\begin{array}{c}\vec{a} \\
\vdots \\
\Xi \\
1 \\
\check{a} \\
\Xi \\
\Xi\end{array}$ & 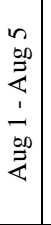 & 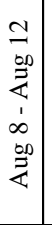 & 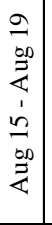 & 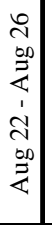 & $\begin{array}{l}2 \\
\tilde{\nu} \\
\tilde{n} \\
1 \\
\grave{2} \\
\text { on } \\
\vec{z}\end{array}$ & $\begin{array}{l}\infty \\
0 \\
2 \\
\sim \\
1 \\
1 \\
0 \\
0 \\
2\end{array}$ \\
\hline Road Demolition & $\mathbf{x}$ & & & & & & & & & & & & & & & & \\
\hline Drainage Structure Install & $\mathbf{x}$ & $\mathbf{x}$ & $\mathbf{x}$ & & & & & & & & & & & & & & \\
\hline Earthwork - Subgrade & & $\mathbf{x}$ & $\mathbf{x}$ & & & & & & & & & & & & & & \\
\hline Compaction - Subgrade & & $\mathbf{x}$ & $\mathbf{x}$ & & & & & & & & & & & & & & \\
\hline Earthwork - Base Layer & & $\mathbf{x}$ & $\mathbf{x}$ & & & & & & & & & & & & & & \\
\hline Compaction - Base Layer & & $\mathbf{x}$ & $\mathbf{x}$ & & & & & & & & & & & & & & \\
\hline Formwork for Concrete Surface Layer & & & $\mathbf{x}$ & $\mathbf{x}$ & & & & & & & & & & & & & \\
\hline Place Concrete Surface Layer & & & $\mathbf{x}$ & $\mathbf{x}$ & $\mathbf{x}$ & & & & & & & & & & & & \\
\hline Sawcut Concrete Joints & & & $\mathbf{x}$ & $\mathbf{x}$ & $\mathbf{x}$ & & & & & & & & & & & & \\
\hline Earthwork for Center Structure & & & & $\mathbf{x}$ & $\mathbf{x}$ & & & & & & & & & & & & \\
\hline Place Concrete - Crosswalk Install & & & & $\mathbf{x}$ & $\mathbf{x}$ & & & & & & & & & & & & \\
\hline Place Concrete - Curb Install & & & & $\mathbf{x}$ & $\mathbf{x}$ & & & & & & & & & & & & \\
\hline Place Steel - Center Foundation & & & & & $\mathbf{x}$ & $\mathbf{x}$ & & $\mathbf{x}$ & & & & & & & & & \\
\hline Place Concrete - Center Foundation & & & & & $\mathbf{x}$ & & & & $\mathbf{x}$ & & & & & & & & \\
\hline Formwork for Roundabout Center Structure & & & & & $\mathbf{x}$ & $\mathbf{x}$ & $\mathbf{x}$ & $\mathbf{x}$ & $\mathbf{x}$ & & & & & & & & \\
\hline Install Sidewalk & & & & & & & & $\mathbf{x}$ & $\mathbf{x}$ & & $\mathbf{x}$ & & & & & & $\mathbf{x}$ \\
\hline Remove Formwork on Center Structure & & & & & & & & & $\mathbf{x}$ & $\mathbf{x}$ & & & & & & & \\
\hline Sawcut Concrete Joints Roundabout Center & & & & & & & & & & $\mathbf{x}$ & & & & & & & \\
\hline Waterproof Center Structure & & & & & & & & & & $\mathbf{x}$ & & & & & & & \\
\hline Earthwork - Median and Outside Roundabout & & & & & & & & & & $\mathbf{x}$ & & $\mathbf{x}$ & & & & & \\
\hline Fill \& Compact Roundabout Center Structure with Soil & & & & & & & & & & & $\mathbf{x}$ & & & & & & \\
\hline Earthwork for Truck Apron & & & & & & & & & & & $\mathbf{x}$ & & & $\mathbf{x}$ & & & \\
\hline Center Structure Brick Install & & & & & & & & & & & & $\mathbf{x}$ & $\mathbf{x}$ & $\mathbf{x}$ & $\mathbf{x}$ & $\mathbf{x}$ & \\
\hline Sawcut Concrete Pavement & & & & & & & & & & & & $\mathbf{x}$ & & & & & \\
\hline Place Concrete - Median Install & & & & & & & & & & & & & $\mathbf{x}$ & & & & \\
\hline Place Concrete - Truck Apron Install & & & & & & & & & & & & & & & $\mathbf{x}$ & $\mathbf{x}$ & \\
\hline Light Pole Install & & & & & & & & & & & & & & & & $\mathbf{x}$ & \\
\hline Signage Install & & & & & & & & & & & & & & & & $\mathbf{x}$ & \\
\hline Landscaping & & & & & & & & & & & & & & & & $\mathbf{x}$ & $\mathbf{x}$ \\
\hline Install Lane Striping & & & & & & & & & & & & & & & & & $\mathbf{x}$ \\
\hline Site Cleanup & & & & & & & & & & & & & & & & & $\mathbf{x}$ \\
\hline Grand Opening & & & & & & & & & & & & & & & & & $\mathbf{x}$ \\
\hline
\end{tabular}


Week 4 and 5 marked the beginning and completion of earthwork for the center structure and the installation of secondary concrete infrastructure such as curbs and crosswalks. The foundation for the centerpiece was constructed in week 5 , and once the concrete was placed for the foundation, formwork began for the construction of the centerpiece structure. Formwork and steel placement for the roundabout centerpiece spanned the duration of nearly 5 weeks, Weeks $5-9$. Figure $4.4 e$ shows the construction of concrete sidewalks in Week 8, while Figure $4.4 f$ shows the construction crews placing concrete for the roundabout centerpiece.

After the centerpiece concrete set, forms were removed in Weeks 9 and 10. Once the forms were removed, the concrete centerpiece was saw-cut and prepared for brick installation. The concrete centerpiece was also lined with a waterproof lining in preparation for the centerpiece being filled with soil in Week 11. Lifts of soil were made and compacted within the center structure. The earthwork for the truck apron around the centerpiece was also performed in Week 11. The brick installation for the outside of the roundabout centerpiece was initiated in Week 12. Figure $4.4 g$ shows the final saw-cutting that was made to the concrete pavement in Week 12. The brick-laying and additional work on the roundabout centerpiece took a period of nearly 5 weeks, spanning from Week 12 to Week 16. 
The concrete truck apron was installed in Week 15. Week 16 saw the installation of utility-related infrastructure such as light poles, lights on the roundabout centerpiece, signs, and pedestrian cross buttons. Landscaping and signage were also installed the same week. September 6 marks the beginning of Week 17, and the completion of this roundabout project, as seen in Figure 4.4h. Final tasks accomplished by the construction crew included landscaping, lane striping and signage, site cleanup, and finally the grand opening on September 8, 2016. 


\subsection{Discussion}

The highlighted cells in Table 4.1 correspond to work completed only for the roundabout centerpiece. As seen in Figure 4.4h, the roundabout centerpiece looks very aesthetically appealing and overall enhances the look of the roundabout and surrounding area. However, the highlighted cells in the table show that there was a significant amount of time and effort spent on the construction of the roundabout centerpiece. Specifically, the tasks of steel layout, formwork, and brick and auxiliary installation took many weeks to complete. When designing any entity, it is the responsibility of the design engineer to consider factors such as aesthetics, cost, size, safety, and time. There may have been a centerpiece design that would have reduced the time the roundabout was closed to traffic, and therefore would have reduced cost. However, the decision is ultimately up to the project owner, which in this case is the City of South Bend.

A comparison of the construction of the asphalt roundabout and the concrete roundabout reveal a few striking differences. The most significant difference between the two projects is the presence of a centerpiece, which adds to the construction time and cost. While the asphalt roundabout took a month less to construct than the concrete roundabout, it is possible that an alternative centerpiece design would have made these two pavement type designs virtually interchangeable. The next difference between designs stems from standard pavement layering techniques. Flexible pavement requires very stable soil, whereas rigid pavement designs have much less stringent requirements. Chemical soil stabilization was performed under the contract on $191^{\text {st }}$ Street and US 31, but this process was not observed on the roundabout at Bartlett Street and Michigan 
Street. Flexible pavements require subgrade, subbase, base, and surface layers, whereas rigid pavement designs require subbase, base, and surface layers and features a thinner cross section overall. Although there were differences between the two designs, there were many similarities between the two designs. Both designs required demolition of the old intersection, installation of new drainage structures and pipes, significant earthwork for the pavement and roundabout center, curbing, crosswalk, and sidewalk installation, truck aprons, lighting, signs, lane striping, and landscaping. 


\section{CHAPTER 5. CLASSROOM ASSESSMENT}

\subsection{Introduction}

On April 11, 2016 time-lapse images from the US 31 roadway project in Carmel were used to teach a class of CE 361, Introduction to Transportation Engineering. The subject introduced in the class was pavement design, and featured sections on flexible pavement, rigid pavement, and truck weights. The PowerPoint presentation contained time-lapse videos of flexible and rigid pavement construction. Typical pavement crosssections were shown in the video and highlighted as each section was being constructed.

The 28 students who participated in this study were given two identical quizzes, one before the lecture, and one after the lecture. The questions in the quizzes were from material that was covered in the required reading for that day. The goal of this research is to identify the impacts of including time-lapse photography into curriculum. This is accomplished through administering a quiz before lecture, administering an identical quiz after lecture, and offering a short follow-up survey.

In order for the aims of this study to be accomplished, it is necessary to first attempt to impart the knowledge to the students in a conventional manner. This was accomplished by assigning required reading of specific sections in the book. Upon completion of the required reading, students should reasonably be able to answer the 
questions on the quiz, which were formulated from the required reading. In order to meet the requirements set forth by Purdue's Human Research Protection Program, IRB protocol was used. Anonymity was retained throughout the entirety of the research process. Each set of quizzes, had a unique pre-assigned number identifier. No names were signed, thus no quiz could be traced back to any particular individual.

At the beginning of the class period, students were given an overview of the research. The quiz was administered to them directly after the introduction, and were given sufficient time to complete the quiz. Figure 5.1 shows samples taken from the quiz given to the students. There are two distinct portions to the quiz, matching and open-ended.

The matching section, shown in Figure 5.1a, contains images of various stages of flexible and rigid pavement construction. Students were asked to identify the type of pavement being constructed, rigid or flexible. Although the researchers were specifically looking for the proper terms 'rigid' or 'flexible,' the terms 'asphalt' and 'concrete' were also accepted. A true/false question was asked after the matching section and can be seen in Figure 5.1b. The text for this question can be found nearly word-for-word in the required reading material.

The open-ended section, shown in Figure 5.1b, although not directly stated in the required reading, can be reasoned through based on the knowledge they should have obtained from the readings. Question \#3 asks what options are available to a designer if it is determined that a subgrade is too weak. One option available to the designer is to remove the unsuitable soil and replace the soil with structure backfill that meets the subgrade strength requirements. 


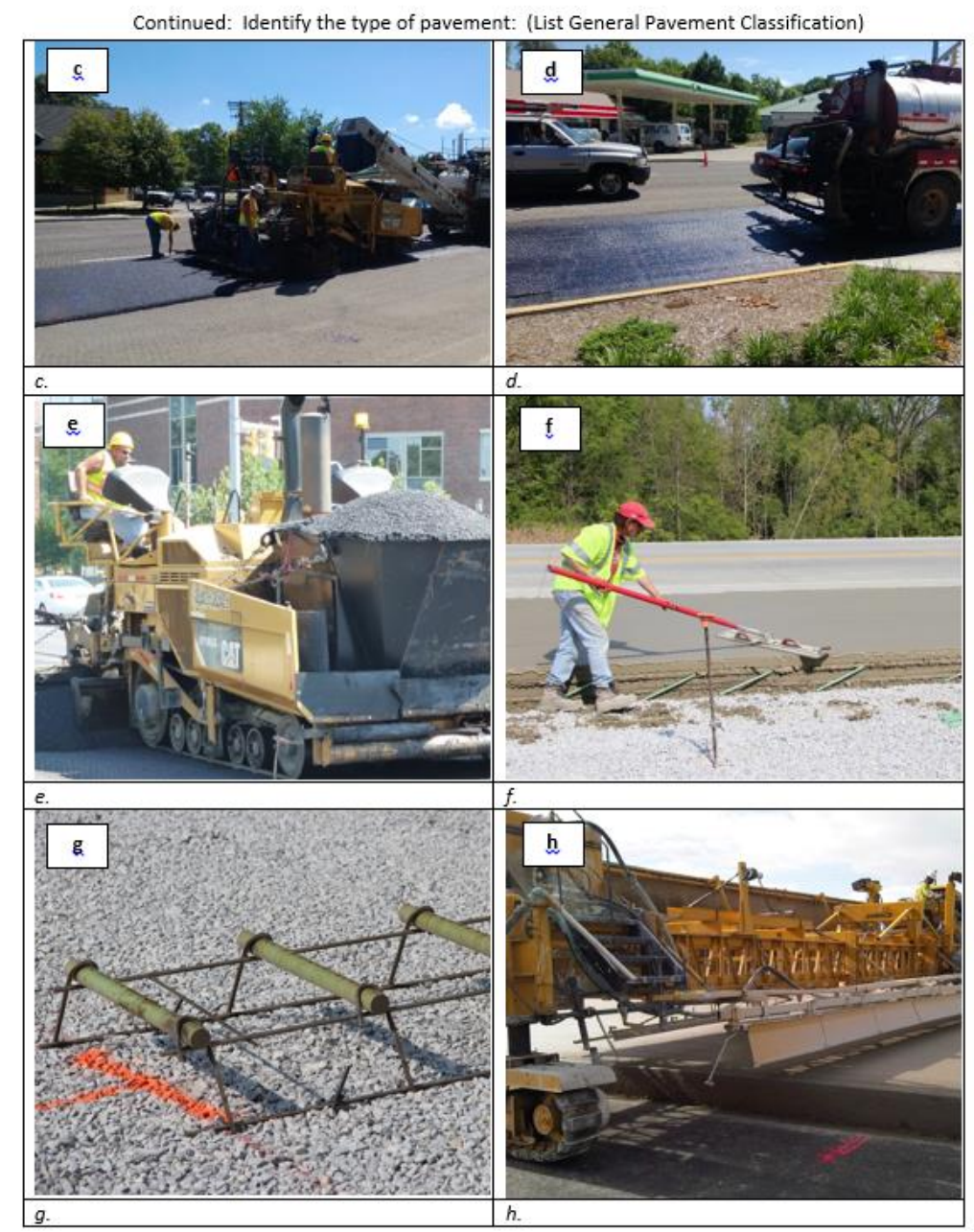

(a) Question $1 \mathrm{c}-\mathrm{h}$

\section{Question \#2: Circle True or False}

True/False: In roadway pavement design, passenger car (automobile) loads can be ignored when determining the total vehicle load on the highway pavement. (NO JUSTIFICATION NEEDED)

\section{Think About it:}

Based on what you have learned for pavements so far, answer the following questions. If you don't know how to respond, take your best guess.

Question \#3: If it is determined that the strength of the subgrade is weak, what are the two options available to the designer?

Question \#4: When facing tight vertical clearances (e.g. a bridge over the road you are designing), which pavement type is the better choice (asphalt or concrete), and why?

(b) Questions 2-4

Figure 5.1 Sample quiz questions 
Another option available to the designer is to strengthen the soil with chemical soil stabilization. Question \#4, shown in Figure 5.1b, tries to get the students to think toward the future when designing pavement. Question \#4 asks when facing tight vertical clearances, such as a bridge, which pavement type may be the better pavement to consider. Although it may be possible to use a strong and relatively thin crosssection with a flexible pavement, throughout the life of the pavement it may not be the better choice due repaving operations. Although a portion of the original pavement is milled down prior to applying a new asphalt layer, often times more asphalt is placed than is milled. This makes the pavement cross section thicker and minimizes the clearance available for trucks passing under the vertical obstruction with each repaving operation. 


\subsection{Results}

Overall, the guest lecture was well-received and enjoyed by the CE 361 class and the presenter maintained the students' attention throughout a majority of the lecture. The second quiz was distributed to the class, and after the completion of the lecture, students were instructed to take the second quiz. Results from both Quiz 1 and Quiz 2 are shown in Table 5.1. The first two columns show the totals for Quiz 1 and Quiz 2 from left to right respectively. Overall, only 2 of the 28 quizzes decreased in score. A majority of the students' scores increased, with only a few scores remaining constant. The average score for Quiz 1 was 6.82 (median 7) out of a possible 13 points, while the average score for Quiz 2 was 9.36 with a median of 10 and a standard deviation of 3.18. 
Table 5.1 Pre-post quiz results

\begin{tabular}{|c|c|c|c|c|c|c|c|c|c|c|c|c|c|}
\hline \multicolumn{1}{|c|}{ Total Score } & \multicolumn{19}{|c|}{ Quiz Difference (Quiz2-Quiz1) } \\
\hline Quiz 1 & Quiz 2 & Total & 1a & 1b & 1c & 1d & 1e & 1f & $\mathbf{1 g}$ & $\mathbf{1 h}$ & $\mathbf{2}$ & $\mathbf{3}$ & $\mathbf{4}$ \\
\hline 8 & 11 & 3 & 0 & -1 & 0 & 0 & 0 & 0 & 0 & 0 & 1 & 2 & 1 \\
\hline 10 & 10 & 0 & 0 & 0 & 0 & 0 & -1 & 0 & 0 & 0 & 1 & 0 & 0 \\
\hline 10 & 12 & 2 & 0 & 0 & 0 & 0 & 0 & 0 & 0 & 0 & 1 & 1 & 0 \\
\hline 3 & 5 & 2 & 0 & 0 & 0 & 1 & 1 & 0 & 0 & 0 & 0 & 0 & 0 \\
\hline 9.5 & 13 & 3.5 & 0 & 0 & 0 & 0 & 0 & 0 & 0 & 1 & 0 & 1.5 & 1 \\
\hline 1.5 & 5 & 3.5 & 0 & 0 & 1 & 1 & 0 & 0 & 0 & 0 & 0 & 0 & 1.5 \\
\hline 0 & 2 & 2 & 0 & 0 & 0 & 0 & 0 & 0 & 0 & 0 & 1 & 1 & 0 \\
\hline 7 & 9 & 2 & 0 & 1 & 0 & 0 & 0 & 0 & 0 & 0 & 0 & 0 & 1 \\
\hline 4.5 & 10 & 5.5 & 0 & 0 & 0 & 0 & 0 & 0 & 0.5 & 1 & 1 & 1 & 2 \\
\hline 7 & 8 & 1 & -1 & 0 & 0 & 0 & 0 & 0 & 1 & -1 & 1 & 0 & 1 \\
\hline 6 & 8 & 2 & 0 & 0 & 0 & 0 & 0 & 0 & -1 & 0 & 1 & 2 & 0 \\
\hline 7 & 7 & 0 & 0 & 0 & 0 & 0 & 0 & 0 & 0 & 0 & 1 & 0 & -1 \\
\hline 7.5 & 12 & 4.5 & 0 & 0 & 0 & 1 & -1 & 0 & 1 & 0 & 1 & 1.5 & 1 \\
\hline 7 & 6 & -1 & -1 & -1 & 0 & 0 & 0 & 0 & 0 & 0 & 1 & -1 & 1 \\
\hline 3 & 8 & 5 & 0 & 0 & 0 & 0 & 0 & 1 & 1 & 0 & 1 & 1 & 1 \\
\hline 6 & 9 & 3 & 0 & 0 & 0 & 0 & 0 & 0 & 0 & 0 & 1 & 1 & 1 \\
\hline 8 & 11 & 3 & 0 & 0 & 0 & 0 & 0 & 0 & 0 & 0 & 1 & 1 & 1 \\
\hline 11 & 13 & 2 & 0 & 0 & 0 & 0 & 0 & 0 & 0 & 0 & 0 & 1 & 1 \\
\hline 3 & 12 & 9 & 1 & 0 & 0 & 1 & 1 & 1 & 1 & 1 & 1 & 2 & 0 \\
\hline 9 & 10 & 1 & 0 & 0 & 0 & 0 & -1 & 0 & -1 & 0 & 1 & 2 & 0 \\
\hline 10 & 13 & 3 & 0 & 0 & 0 & 0 & 0 & 0 & 0 & 0 & 1 & 1 & 1 \\
\hline 3 & 13 & 10 & 0 & 0 & 1 & 1 & 1 & 1 & 1 & 1 & 0 & 2 & 2 \\
\hline 8 & 9 & 1 & 0 & 0 & 0 & 0 & 0 & 0 & 0 & 0 & 1 & 0 & 0 \\
\hline 5 & 6 & 1 & 0 & 0 & 0 & 1 & 0 & 0 & 0 & 0 & 0 & -1 & 1 \\
\hline 9 & 13 & 4 & 0 & 0 & 0 & 0 & 0 & 0 & 0 & 0 & 1 & 1 & 2 \\
\hline 12 & 12 & 0 & 0 & 0 & 0 & 0 & -1 & 0 & 0 & 0 & 0 & 1 & 0 \\
\hline 6 & 3 & -3 & -1 & 0 & -1 & -1 & 0 & -1 & 0 & 0 & 1 & 0 & 0 \\
\hline 10 & 12 & 2 & 0 & 0 & 0 & 0 & -1 & 0 & 1 & 0 & 0 & 1 & 1 \\
\hline \multicolumn{2}{|c|}{ Mean } & 2.54 & -0.07 & -0.04 & 0.04 & 0.18 & -0.07 & 0.07 & 0.16 & 0.11 & 0.68 & 0.79 & 0.70 \\
\hline Median & 2 & 0 & 0 & 0 & 0 & 0 & 0 & 0 & 0 & 1 & 1 & 1 \\
\hline Standard Deviation & 2.69 & 0.38 & 0.33 & 0.33 & 0.48 & 0.54 & 0.38 & 0.53 & 0.42 & 0.48 & 0.87 & 0.74 \\
\hline
\end{tabular}

The last 12 columns in Table 5.1 show a comparative analysis between Quiz 1 and Quiz 2. The numbers shown in each column are calculated from subtracting the score of Quiz 1 from the score of Quiz 2, or Quiz2-Quiz1. In this way, positive values indicate a positive change, showing that the student's score increased in Quiz 2 and that the lecture better prepared them to answer questions on the quiz. 
The third column of Table 5.1 shows the total score difference between Quiz 1 and Quiz 2. A quick glance indicates that most scores improved, while a small number of scores remained the same and only two scores decreased in Quiz 2. The remaining columns show the point differences between each individual question on the quizzes. It is clear from analyzing the results that Question 1, parts a-h did not see much improvement in Quiz 2. Question 1, part d may have seen the most improvement, as indicated by the mean of 0.18 , which indicates that $18 \%$ of the students' scores increased for that particular question. However, Questions 2, 3, and 4 saw a median increase of 1 point in nearly $70 \%$ of the respondents, and overall the median total score increased by 2 points. Figure 5.2 shows a histogram of the total score differences between both quizzes. It can be seen that although 5 respondents' scores remained the same or decreased, the other 23 respondents performed better on the second quiz, with some scoring more than 4 points higher on the second quiz.

A histogram for each question can be seen in Figure 5.3, where the point change from Quiz 1 to Quiz 2 and frequency is shown. Figure 5.3a shows the overall point changes on Question 1 (parts a-h). In general, the results show a normal distribution centered on zero with a slight tendency to the right. However, the majority of the responses indicate no change between Quiz 1 and Quiz 2, and the positive changes are mostly cancelled out by the negative changes. However, the results for Question 2 indicate much more positive results, as seen in Figure 5.3b. Although 9 respondents' scores remained the same on Question 2, the 19 other respondents got Question 2 correct. 


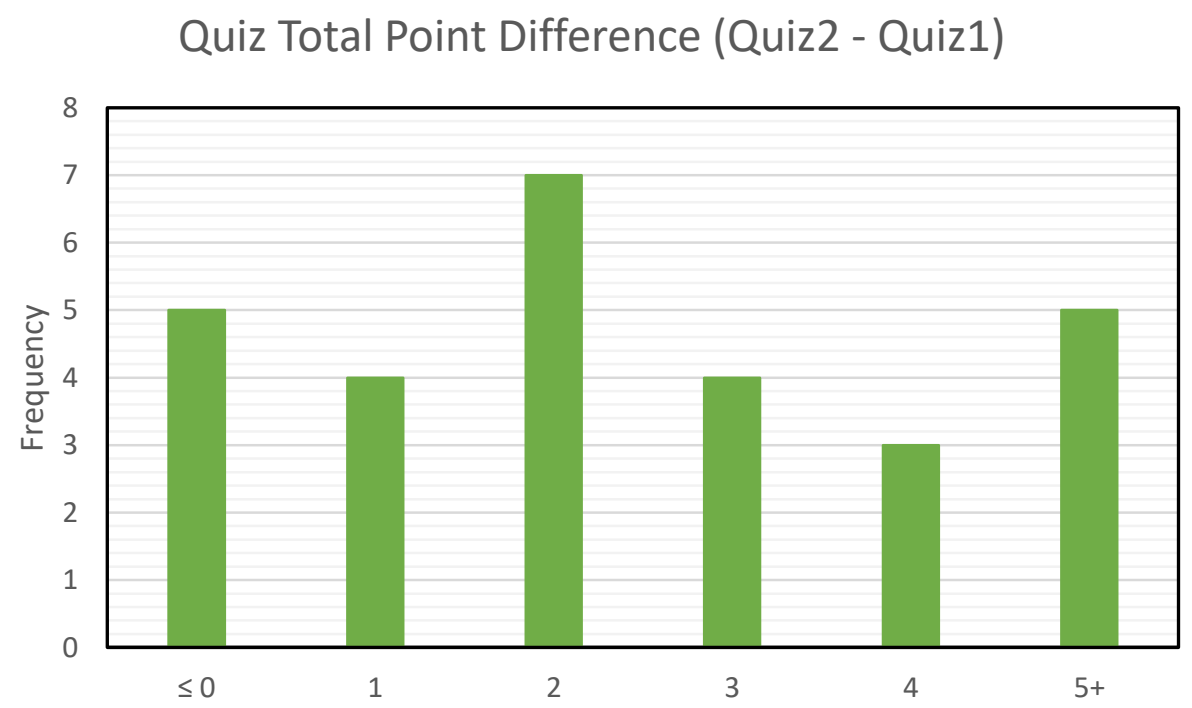

Figure 5.2 Pre-post quiz results

Question 3 and Question 4 have almost identical histogram plots, as seen in Figure 5.3c and Figure 5.3d. Both plots show histograms centered on a positive point difference of one point while some respondents scored positive two points. Also seen in both figures is that almost as many respondents made no changes or decreased in points. However, overall in both cases, more students increased scores. 
Q1 Point Difference (Quiz2 - Quiz1)

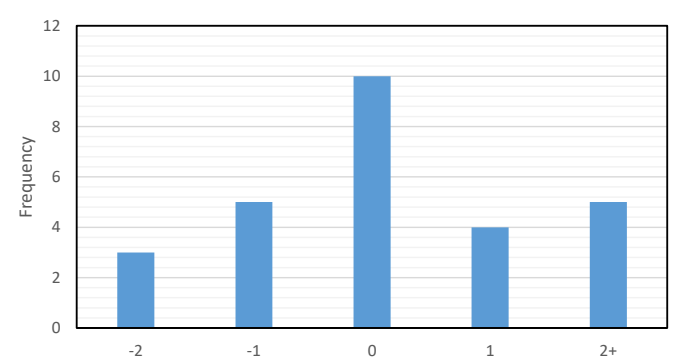

(a) Results for question 1

Q3 Point Difference (Quiz2 - Quiz1)

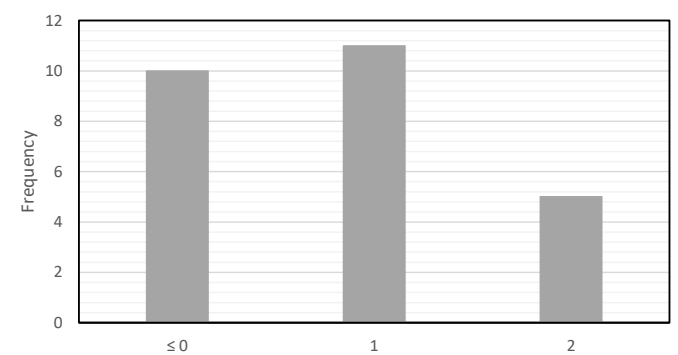

(c) Results for question 3
Q2 Point Difference (Quiz2 - Quiz1)

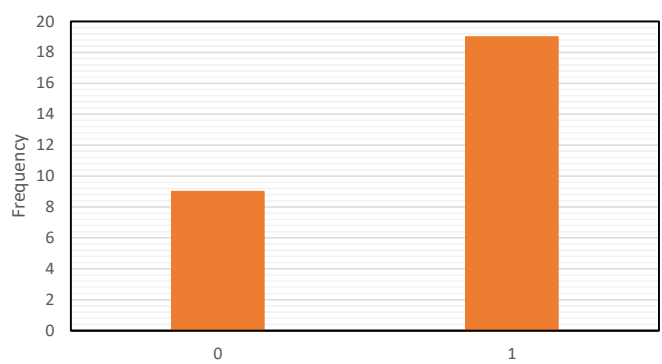

(b) Results for question 2

Q4 Point Difference (Quiz2 - Quiz1)

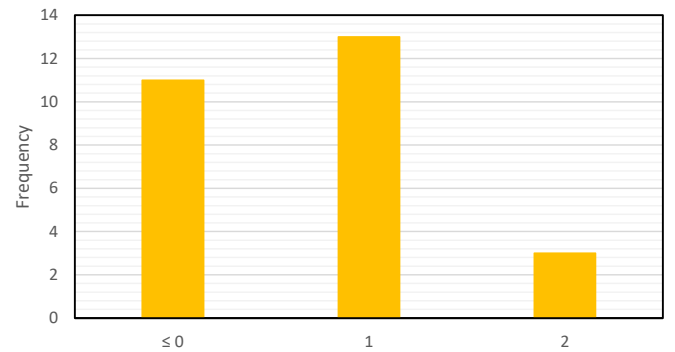

(d) Results for question 4

Figure 5.3 Individual question results

After the second quiz, students were given a survey to indicate how the time-lapse photography impacted the lecture and their learning. The survey can be seen in Figure 5.4a, and results of the survey are shown in Figure 5.4b. The survey asks questions such as "the introduction of time-lapse photography helped me learn better than from the book." The survey is listed as Question \#5 in Quiz \#2, and the six questions can be seen in Figure 5.4a, Question 5a is at the top of the figure, while Question 5f is in the last row of the figure. Responses to the survey questions are revealed preferences and are ordered from 'Strongly Disagree' to 'Strongly Agree'. 
Question \#5: Mark your responses to the degree you agree with the following statements:

The introduction of time-lapse photography in lecture:

\begin{tabular}{|l|l|l|l|l|l|}
\hline Time-lapse Photography: & $\begin{array}{l}\text { Strongly } \\
\text { Disagree }\end{array}$ & Disagree & $\begin{array}{l}\text { No } \\
\text { Opinion }\end{array}$ & Agree & $\begin{array}{l}\text { Strongly } \\
\text { Agree }\end{array}$ \\
\hline $\begin{array}{l}\text { Helped me with the big-picture } \\
\text { understanding of how a roadway is } \\
\text { constructed }\end{array}$ & & & & & \\
\hline Got me more interested in the topics & & & & & \\
\hline $\begin{array}{l}\text { Helped me learn better than from the } \\
\text { book }\end{array}$ & & & & & \\
\hline $\begin{array}{l}\text { Made me more comfortable with the } \\
\text { material }\end{array}$ & & & & & \\
\hline $\begin{array}{l}\text { Cleared up a misunderstanding or } \\
\text { confusion I had }\end{array}$ & & & & & \\
\hline $\begin{array}{l}\text { Gave me an appreciation for the } \\
\text { magnitude and scale of the material } \\
\text { used, and the manpower necessary for } \\
\text { projects }\end{array}$ & & & & & \\
\hline
\end{tabular}

(a) Question \#5

\section{Question 5 Frequencies}
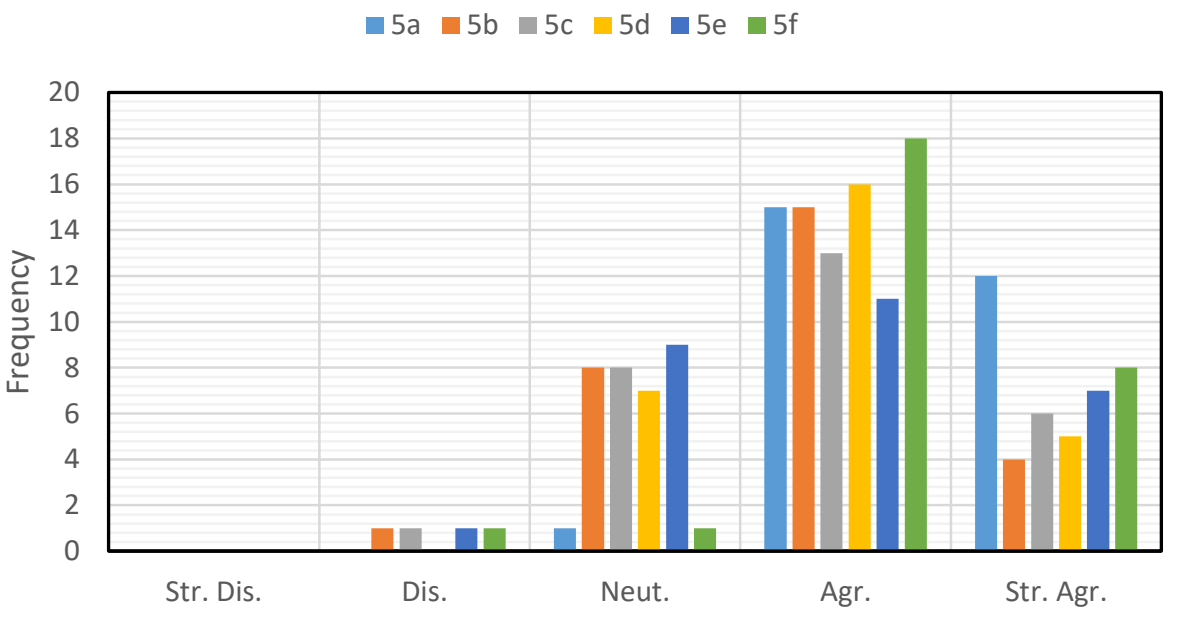

(b) Results to question \#5

Figure 5.4 Qualitative analysis 
A histogram of the responses to all six questions can be seen in Figure 5.4b. Note that no responses indicated 'strongly disagree' for any of the questions. Further, the respondents who indicated 'disagree' were for the following questions: 'the introduction of time-lapse photography to the lecture:' 'got me more interested in the topics', 'helped me learn better than from the book', 'cleared up a misunderstanding or confusion I had', and 'gave me an appreciation for the magnitude and scale of the material used, and the manpower necessary for such projects.' The response 'disagree' does not necessarily indicate negative results for questions such as 'cleared up a misunderstanding I had' as some students may not have had a misunderstanding to clear up.

Although it is the goal of the project team to develop material to help students learn better than simply from reading the book, all students and learning styles differ. The four major learning styles are: Visual, aural/auditory, reading/writing, and kinesthetic. The time-lapse photography learning sessions are well-suited for visual and kinesthetic learners and can be adapted for aural/auditory learners. However, as indicated by the results of Figure $5.4 b$, reading/writing learners may not gain as much benefit from such educational material.

Figure $5.4 b$ shows that overall, students agreed with each of the questions in the survey, and there were more positive than neutral or negative responses. This sends a positive message to the project team regarding the potential benefits of implementing time-lapse photography in educational classroom settings for students, contractors, or inspectors. 


\section{CHAPTER 6. BRIDGE DEMOLITION AND MEDIA CONTENT}

\subsection{Introduction}

The life-cycle of any project begins with project conception and eventually ends with retirement, re-use, or deconstruction and disposal. However, as it is a life-cycle, the entry to the end-of-life phase of one project often initiates the conception phase of a project to take its place. This chapter highlights two separate bridges that were determined to be unfit for service and were ultimately decommissioned. Both bridges were listed on the national historic bridge registry, and both bridges were removed using implosive charges. One of the requirements for INDOT, being listed on the national historic bridge registry, is that the retirement of the bridge must be well documented. Officials from INDOT tasked the project team with helping INDOT fulfill that requirement.

Figure 6.1 shows a map and an overview of a bridge over the Wabash River that was put out of service in June of 2016 and was officially retired on July 12 by means of implosive charges. Figure $6.1 b$ shows eastbound Sagamore Parkway Bridge in January 2016 before any construction. Figure $6.1 c$ shows the newer westbound bridge, which will remain intact throughout the duration of the project. Also in Figure $6.1 c$ is the temporary causeway to access the piers in the river. This will be used throughout the 
duration of the construction of the new structure, which is described in greater detail in Chapter 1.

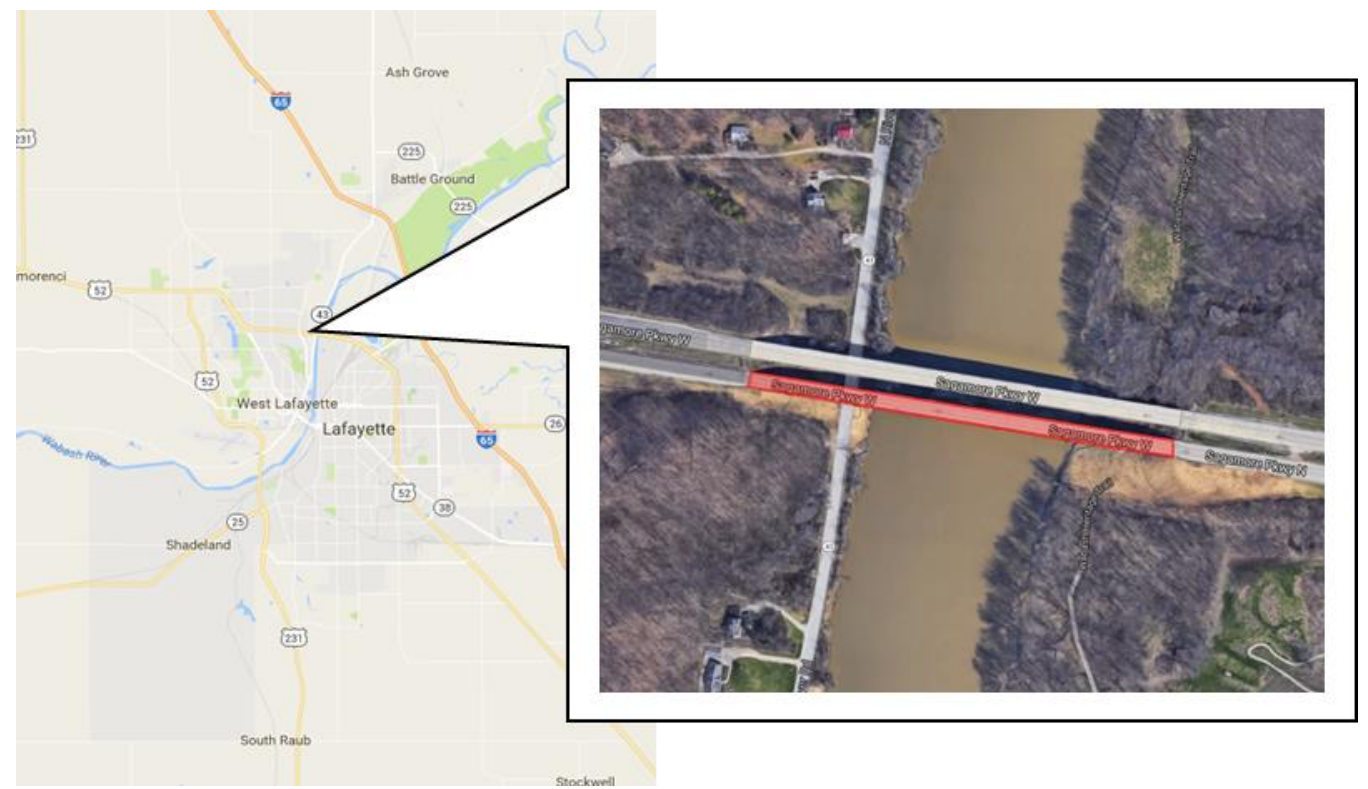

(a) Sagamore Parkway bridge over the Wabash River in Lafayette, Indiana

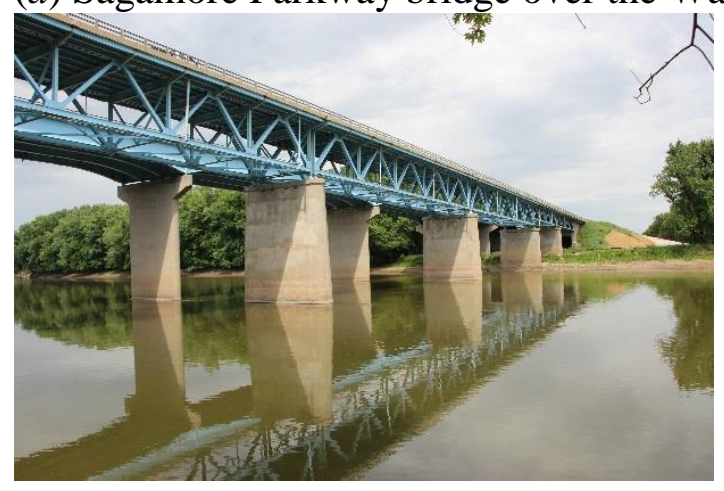

(b) Bridge before demolition

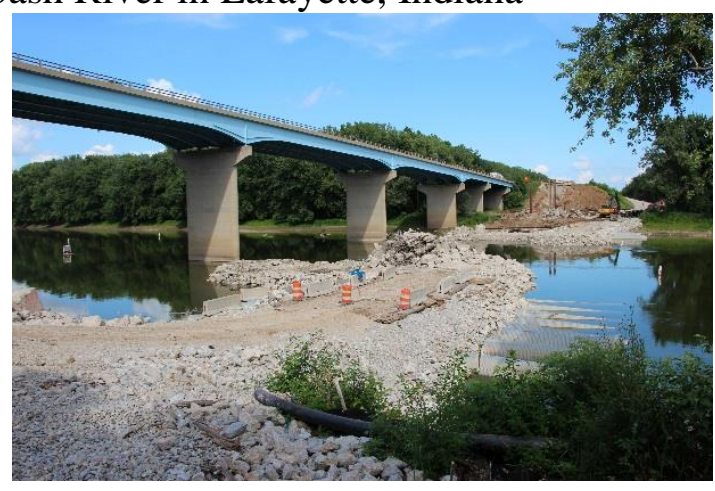

(c) Bridge fully removed

Figure 6.1 Sagamore Parkway bridge demolition overview 
The single-lane two-span camelback steel through truss bridge shown in Figure $6.2 b$ is located in Cedar Grove, Indiana near Cincinnati, Ohio. The bridge served as the only bridge for State Road over the Whitewater River before the alignment of the road was shifted to where it is today. The bridge was officially closed to traffic in 1999, but remained in place until it became a serious safety concern to the public. Although many other alternatives to demolishing the bridge were considered, the final decision to use a controlled demolition to remove the structure was recommended. The Old State Road \#1 Bridge was officially brought down by implosive charges on February 17, 2016. Figure $6.2 c$ shows a picture of the bridge piers during the bridge removal process. The piers were later removed and the river returned to its natural state.

This chapter will use high-speed time-lapse images before, during, and after the implosive charges were set to show several basic engineering principles. The images shown in the following figures were obtained by taking individual frames utilizing a GoPro video camera. This chapter will also demonstrate how multimedia can be used in the public realm to generate interest and positive feedback toward the featured projects. 


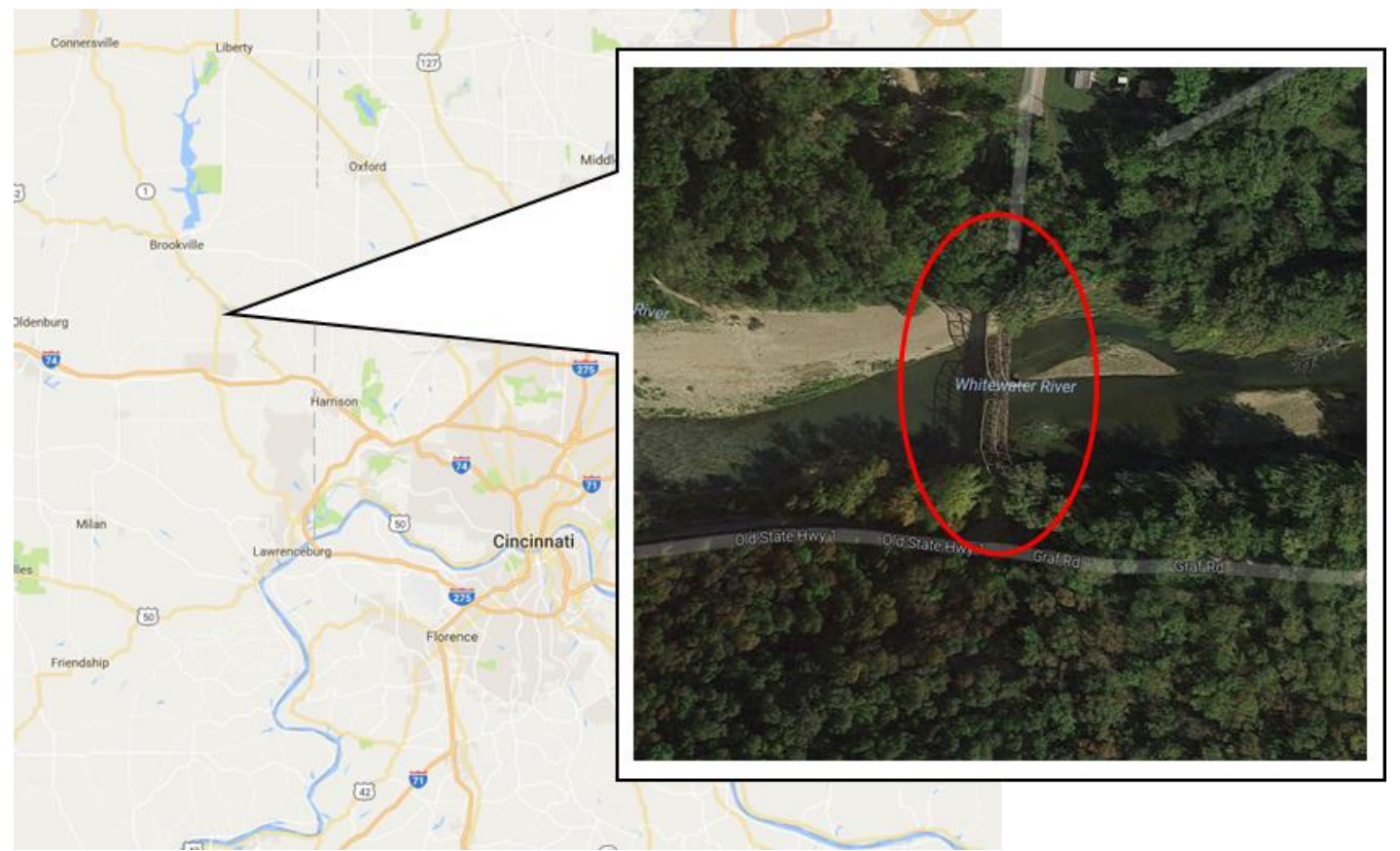

(a) Old State Road 1 Bridge over the Whitewater River in Cedar Grove

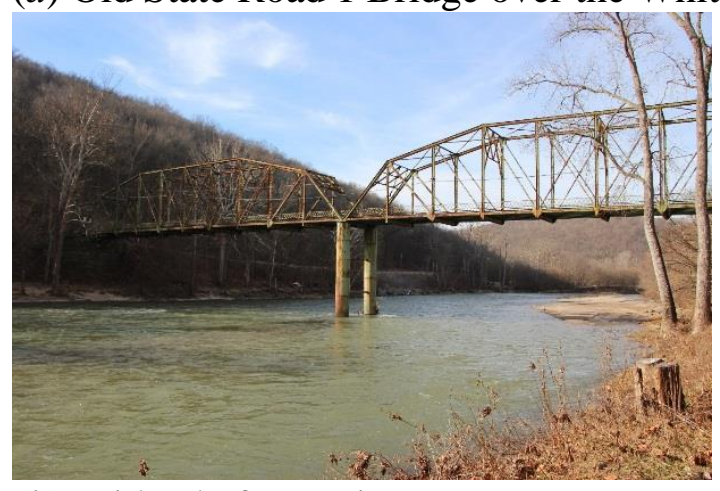

(b) Bridge before retirement

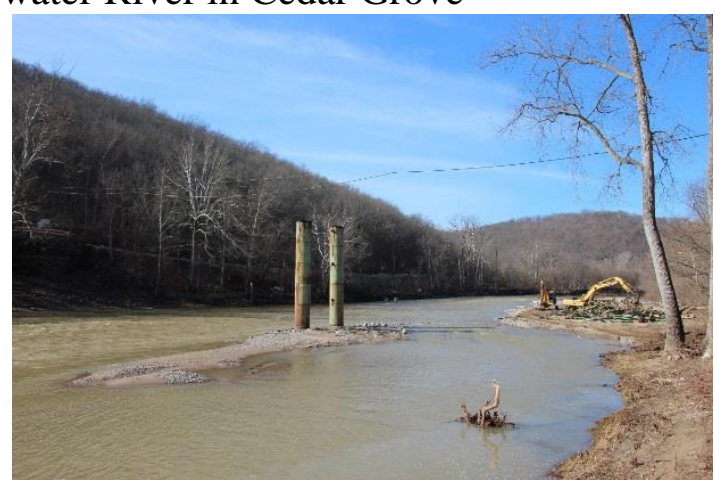

(c) Bridge during removal

Figure 6.2 Old State Road 1 bridge demolition overview 


\subsection{Sagamore Parkway US 52 Bridge Demolition}

The Sagamore Parkway bridge across the Wabash River between West Lafayette and Lafayette spanned over 900 feet and was no simple bridge to remove. The nearly $\$ 13,400,000$ project contract was awarded to Superior Construction, and construction began in May 2016 (9). The project includes removing the existing bridge and building a new structure with similar alignment to replace it. The new structure features a concrete bulb-tee design and is planned to span nearly 940 feet with eight spans. The structure will include two standard 12-foot travel lanes, 6-foot left shoulders, 11-foot right shoulders, and a 10-foot pedestrian walkway. The bridge is expected to open to traffic in the summer of 2018, and the total project has a completion date of June 2019. The contractors are currently on schedule, as construction started in May of 2016. Maintenance of traffic switch removing traffic from the eastbound bridge occurred on June 10, 2016. The old structure was demolished by means of implosive charges on July 12, 2016, which was the date originally targeted in the contract before construction began. Figure 6.3 shows multiple images taken by a GoPro camera at the site during the time of the implosion. Figure $6.3 a$ shows the bridge with charges in place after the concrete bridge deck was removed and before the charges were fired.

The locations of the implosive shaped charges and the approximate bridge sections can be seen in Figure 6.3b. The red dotted line indicates the cuts that will be made after the implosive charges are detonated. The callouts indicate individual sections of the bridge that will separate upon implosion and impact with the ground. The moment the shaped charges were detonated is shown in Figure 6.3c, while Figure 
6.3d shows the bridge as it falls immediately after detonation. Note how sections i-ii, vvi, and vii-viii each stayed together, while the connections between i and the section to the left as well as vi-vii sheared first as there was no support. Similarly, in part $d$ of the figure, shearing can be seen between the ii-iii connection as well as the iv-v and the viii and right-most piece on the pier.

Immediately upon impact, the bridge breaks up into individual pieces, as seen in Figure 6.3e. Note how sections i-ii, v-vi, and vii-viii all break into individual pieces. In this controlled explosive demolition, members of the bridge were cut to specific depths that were predetermined by explosive demolition experts. As shown in Figure $6.3 f$, the bridge was brought down safely, effectively, and in a controlled manner. To watch the GoPro footage of the demolition of the Sagamore Parkway bridge demolition, use the following link: https://www.youtube.com/watch?v=TuE81bvXisE

The afore-mentioned video was distributed to WLFI News Channel 18 on July 12, 2016. Shortly after distributing the video to WLFI, the project team was asked to be a featured story for the July 13 news. News Channel 18 wanted to know what the project team does and how the videos they produce, such as the Sagamore Parkway bridge demolition video, can be used. Figure 6.4 shows images taken from the story shown on July 13. Figure $6.4 a$ shows the segment title, "Students Study Wabash Bridge Demolition." Figure $6.4 b$ and Figure $6.4 c$ shows project team members Wayne Bunnell and Drake Krohn, respectively. The video produced by WLFI can be accessed from the following link: https://www.youtube.com/watch?v=MHn94rSu-F4 


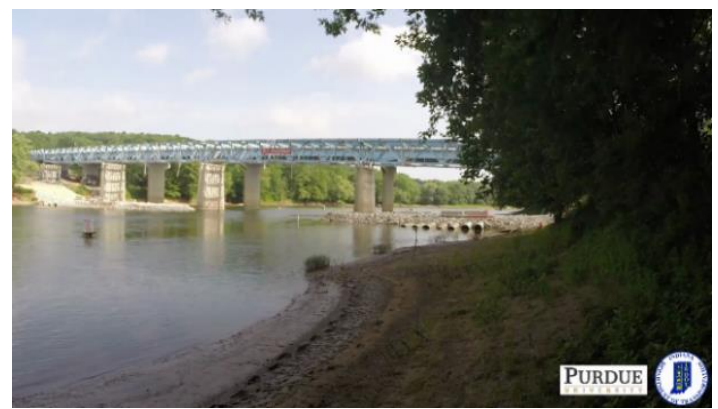

(a) Bridge before charges are set

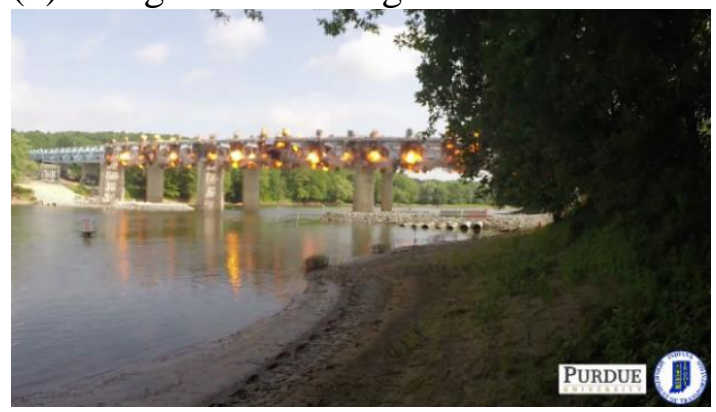

(c) Bridge during implosion

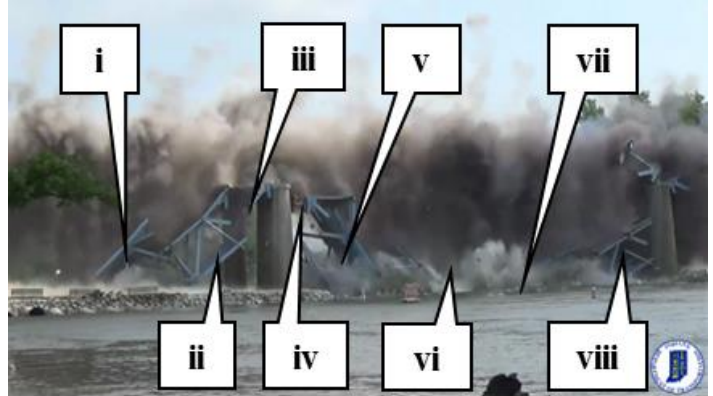

(e) Bridge has broken into individual sections

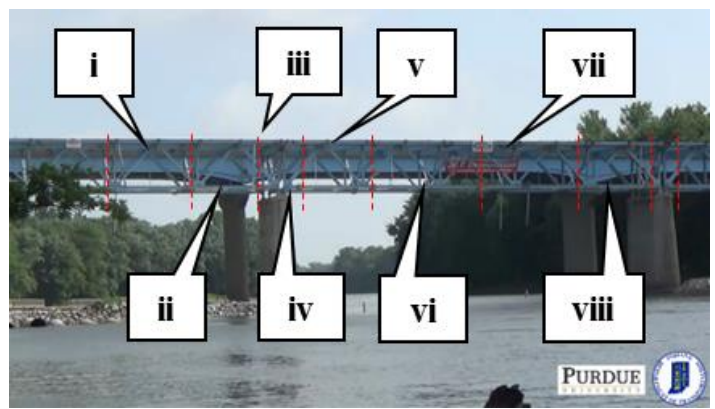

(b) Charge locations and bridge sections

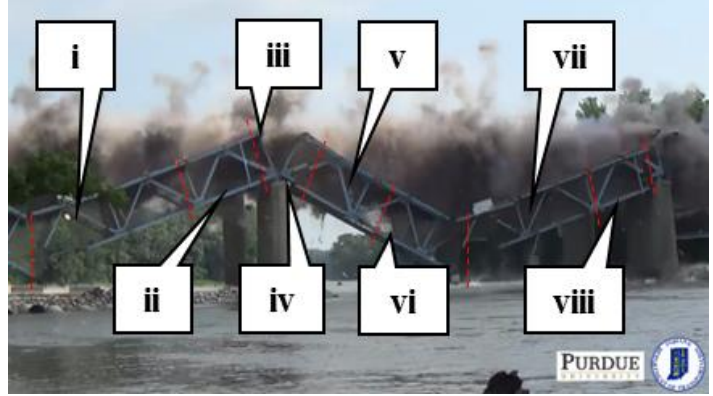

(d) Individual sections of bridge as collapse occurs

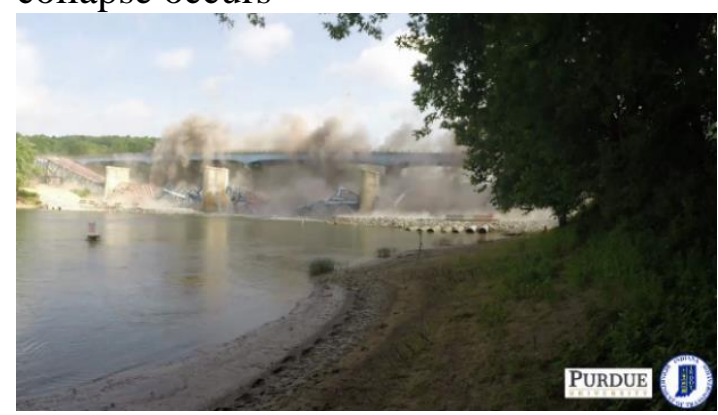

(f) Bridge after implosion

Figure 6.3 Sagamore Parkway US 52 bridge implosion 


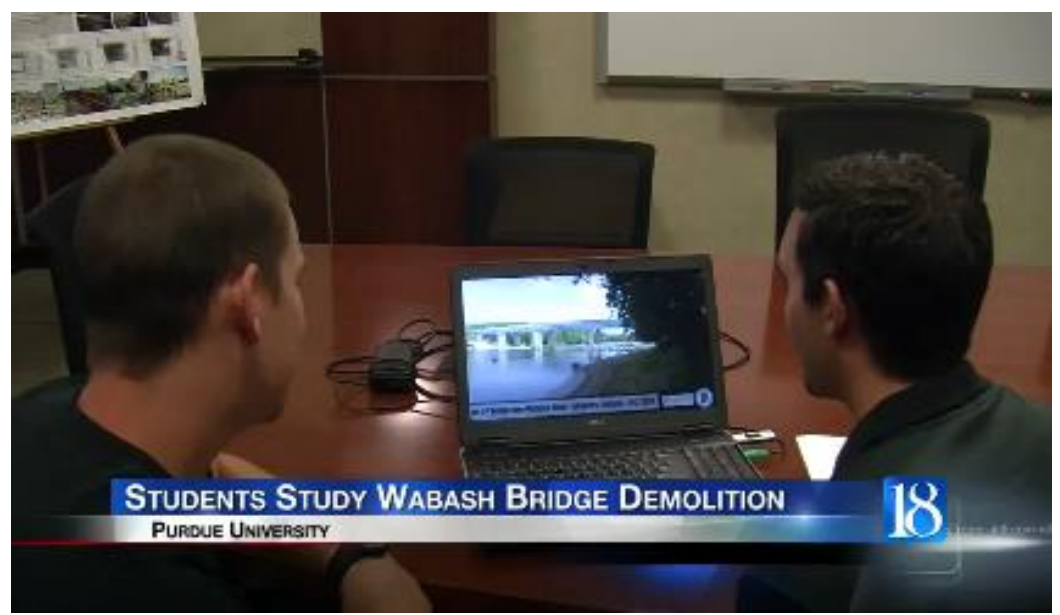

(a) Project aired by News Channel 18

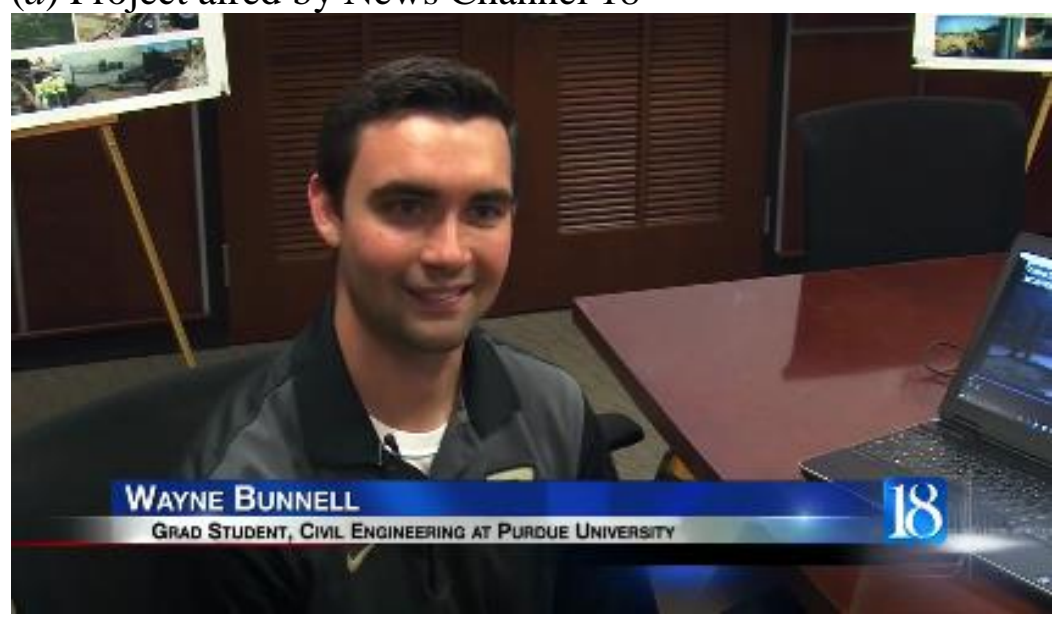

(b) Wayne Bunnell

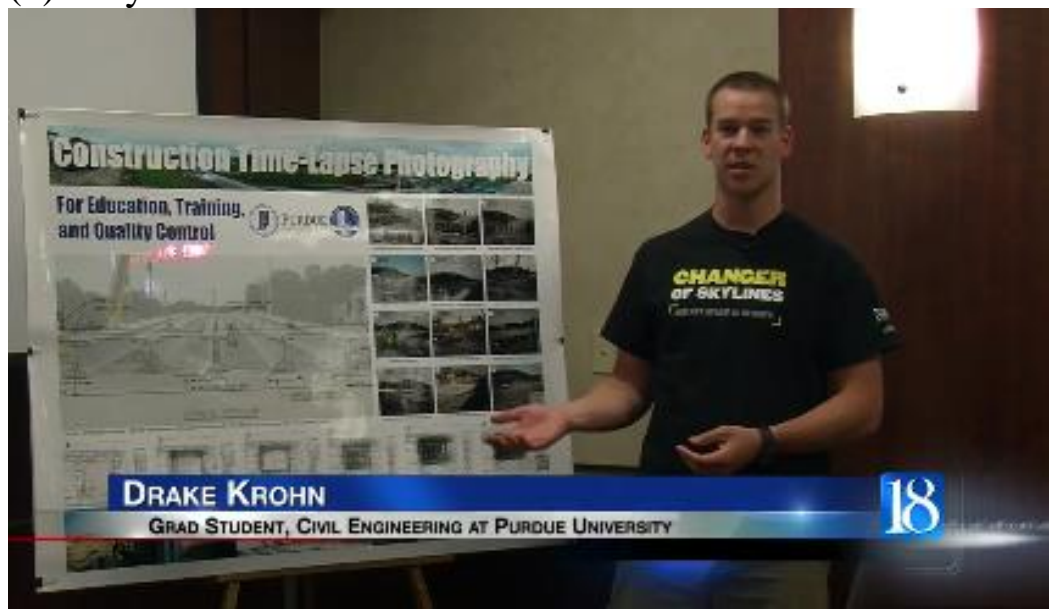

(c) Drake Krohn

Figure 6.4 News Channel 18 interview on bridge demolition 


\subsection{Whitewater River Bridge Demolition}

The second bridge demolition project regards the bridge that spanned nearly 370 feet over the Whitewater River in Cedar Grove, Indiana. Built in 1896, and listed in the National Historic Bridge Registry, the one-lane, two-span, camelback through steel truss bridge over the Whitewater River was demolished on February 17, 2016 by means of implosive shaped charges (10). This bridge served local traffic for many years, and was officially closed to all traffic on September 3, 1999. Deemed a safety hazard by INDOT, and given an official safety rating of 0 out of a possible 9 , the decision was made to retire and completely remove the bridge. Although many other alternatives to demolishing the bridge were considered, such as renovation to a pedestrian bridge, the final decision recommended was to use a controlled demolition to remove the structure, as it was the quickest, most cost-effective, and safest alternative.

The demolition and removal of the Old State Road 1 steel through truss bridge shown in Figure 6.5 can be accessed from the Purdue University Research Repository (PURR) at the following link: http://dx.doi.org/10.4231/R7348H97. The project team installed GoPro video cameras to view high-speed images of the implosion. Additionally, the project team installed time-lapse cameras to monitor the removal process of the old structure. In order to have a fully controlled bridge demolition, the bridge was pre-cut to a specific depth and with a specified cut pattern. Incendiary shaped charges were used to complete the cuts in a controlled, instantaneous, and safe manner. 
Figure $6.5 a$ shows the bridge prior to implosion, which corresponds to time 00:24 in the YouTube video found on PURR. As seen in part $a$, the bridge has charges set at specific locations on the bridge. Figure $6.5 b$ shows the bridge during implosion, corresponding with 00:25 in the YouTube video. At 00:27 in the video, the bridge comes to rest after the implosion, as seen in Figure $6.5 c$.

The bridge was cut it 4 strategic locations, which are shown in Figure $6.5 d$. The left-most cut severs the bridge from the South bridge approach. The cut left of the pier separates the truss from its center support and allows section $\mathrm{i}$ to fall straight down. The cut to the right of the pier severs the northern truss structure from its center support. The right-most cut breaks the truss into two separate pieces, ii and iii. The planned pieces of truss and fall patterns are shown in Figure 6.5e. Section i will fall straight down, as it will instantaneously lose all vertical and horizontal support. Section ii will likewise fall straight down, as its vertical supports are also severed. Section iii will lose vertical support from section ii, but a constant vertical force will be applied at the North bridge abutment, shown at the right side of the photo. This will cause the entire section to rotate with a positive moment about that point as the bridge falls.

Figure $6.5 f$ shows the bridge as it is falling, and as seen in the figure, the individual bridge sections fell as planned. A slow-motion of the bridge implosion can be seen at 00:31 in the YouTube video on PURR. There is a charge that initiates the shaped charges at the four cut locations. The charges are detonated sequentially from North to South, or right to left on the screen. This is evidenced in the way the bridge falls. As seen in Figure 6.5f, sections ii and iii seem to fall slightly faster than section i. A review of the slow-motion video at 00:36 shows that this is indeed the case. Full 
rotation of section iii does not occur until 00:38 in the video, at which point the South end of section ii strikes the ground, and the bridge shears at the fourth cut location, allowing section iii to rotate with a positive moment about the point of contact between the truss and the North abutment.

The rest of the YouTube video shows the cleanup process of the bridge. Note that the bridge implosion occurred around 10:00 AM on February 17, and the construction crew had removed the structure from the river the same day. Full removal, cleanup, and disposal of the bridge structure and its supports were completed by March 2, two weeks after the bridge implosion. 


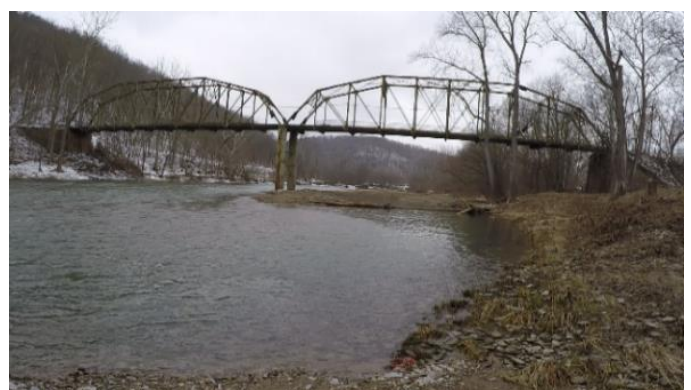

(a) Bridge before charges are set

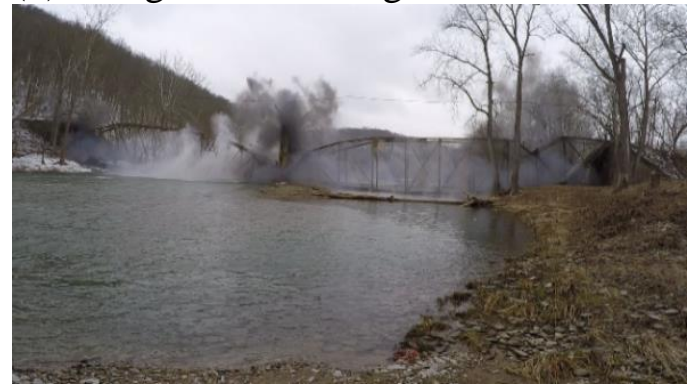

(c) Immediately after implosion

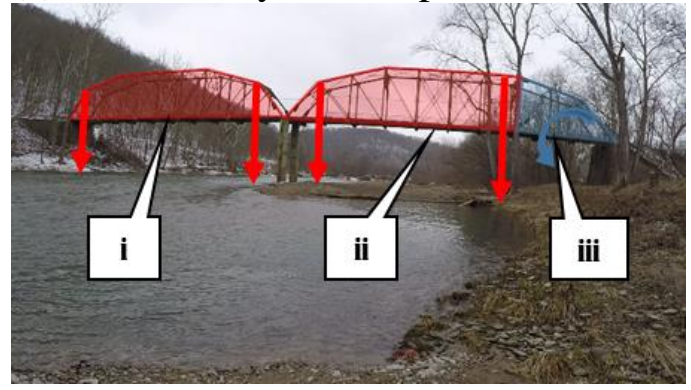

(e) Individual sections of bridge as collapse occurs

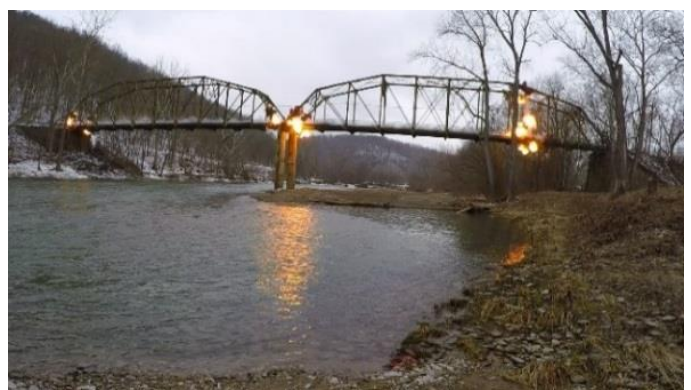

(b) Bridge during implosion

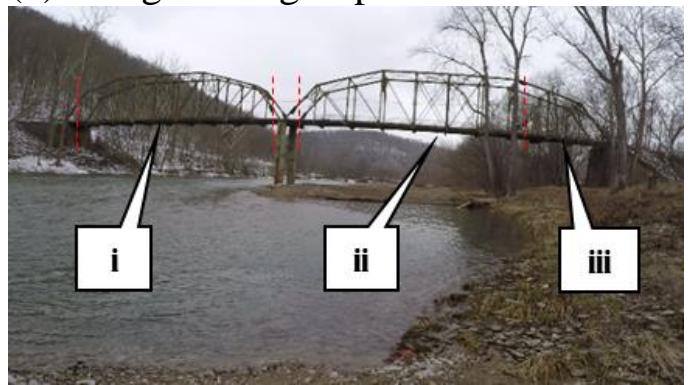

(d) Charge locations and bridge sections

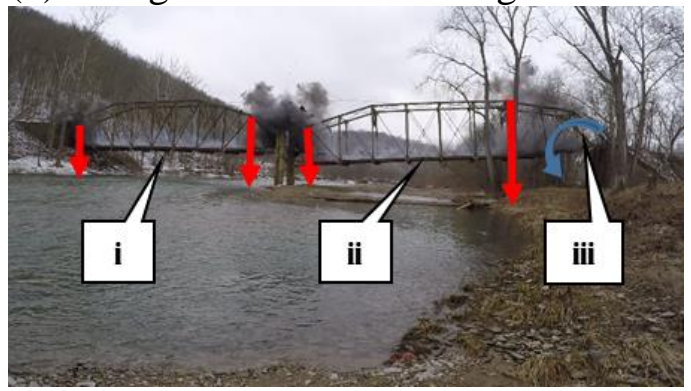

(f) Bridge has broken into individual sections

Figure 6.5 Demolition of Old State Road 1 Bridge over the Whitewater River 


\subsection{Discussion}

The general principles between the demolition processes shown in both examples are the same. Both bridges were cut prior to the detonation of shaped charges. Both bridges were brought down instantaneously by the additional force provided by the shaped charges. Individual sections were created as the bridges began to fall.

One primary difference between the two bridges is the sheer size of the bridges. The Sagamore Parkway Bridge is nearly three times as long and well over twice as wide as the Old State Road 1 Bridge. Although the demolition process is quite similar, the way the bridges fell, broke apart, and were removed from the river differed significantly. While the Old State Road 1 Bridge generally fell maintaining a horizontal orientation, the Sagamore Parkway bridge fell with more rotation and was broken up into many more sections. As seen in the PURR YouTube video, the Old State Road 1 Bridge was removed with relatively little heavy machinery whereas the Sagamore Parkway Bridge was removed from the Wabash River by crane. Although the demolition process of no two bridges is alike, one theme resonates between both demolitions featured in this chapter, and with all bridge demolitions. Safety is the top priority, and great care must be taken to ensure that the bridge is taken down in a manner that is safe for the construction crew, safe for the environment, and safe for the public. 


\section{CHAPTER 7. TRAINING MATERIALS UTILIZED BY INDOT}

\subsection{Introduction}

As with any business, training for newly-hired individuals and continuingeducation for existing staff continues to be a challenging need in a world that is always changing. INDOT's construction inspection team is no different, and consistent newhire training is challenging. Currently, INDOT trains construction inspectors during the off-peak construction season, the winter months. Throughout the winter months, inspectors must attend Highway Technician (HT) School. While in HT School, inspectors are taught various aspects of construction activities through traditional lecture or discussion-based educational techniques. Additionally, INDOT requires all new inspectors to take inspection qualification tests for each inspection area.

Although each of the guidelines for proper construction of field infrastructure are described in the INDOT Standard Specifications book, it is not written with the intent of education and training. Samples of the 1200 page document can be seen in Figure 1.1, and language from the Standard Specifications book is specifically pulled out and highlighted in Chapter 2 and Chapter 3. It is clear from the language in the Standard Specifications book that the intended audience was not newly-hired construction inspectors, but rather a team of legal experts. 
A newly-hired inspector will often receive on-site training with an experienced inspector. However, many construction inspectors are hired immediately before construction season begins. Therefore, many new inspectors have not had some of this agency-specific training. In order to remedy this unfortunate circumstance and to encourage better construction practices by contractors, the project team has developed educational training modules for contractors and inspectors. These modules use images and video content from the time-lapse cameras to 'bring the field to the office' and give active viewers virtual field experience. Although there is no substitute to on-site field experience, there is benefit to adding content developed with time-lapse photography to current training procedures.

\subsection{MSE Wall Construction Guidelines}

Throughout all of the construction projects monitored on the US 31 project within Carmel and Westfield, the project team captured the construction of many different MSE retaining walls. Under the guidance of key INDOT representatives, specifically Rob Goldner, the project team identified several MSE wall construction practices, both good and bad, that were observed while creating, viewing, and presenting the time-lapse videos.

See Figure 7.1 for sample slides from the PowerPoint created for INDOT titled "MSE Wall Construction: Guidelines for Inspectors and Contractors." Figure 7.1a shows the title slide for the presentation. The image used in the title slide is the East face of the MSE wall featured in Chapter 3. In the background of the image on the title slide is the bridge on US 31 over $169^{\text {th }}$ Street, featured in Chapter 2. 


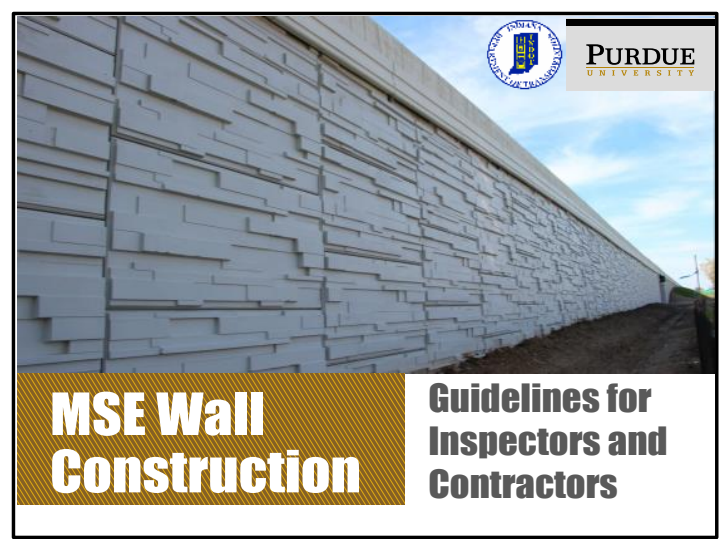

(a) MSE wall construction tutorial

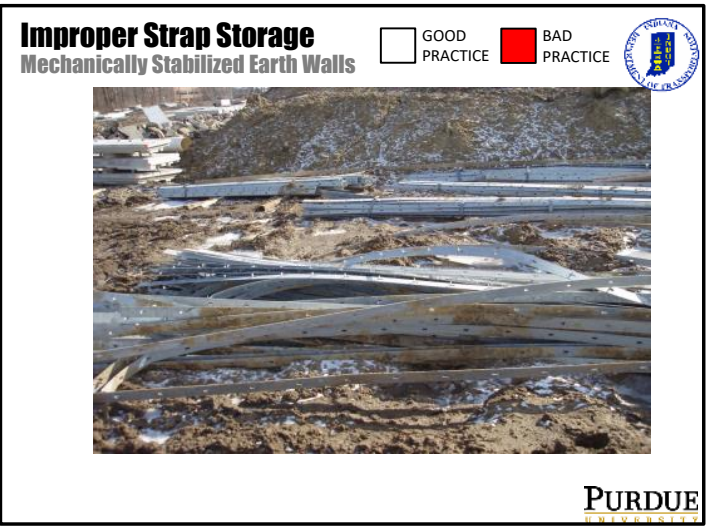

(c) Bad practice for reinforcement straps

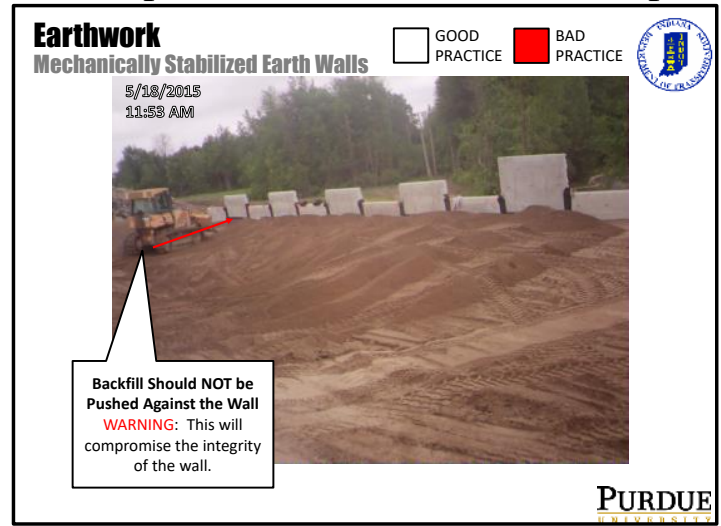

(e) Poor practice for MSE earthwork

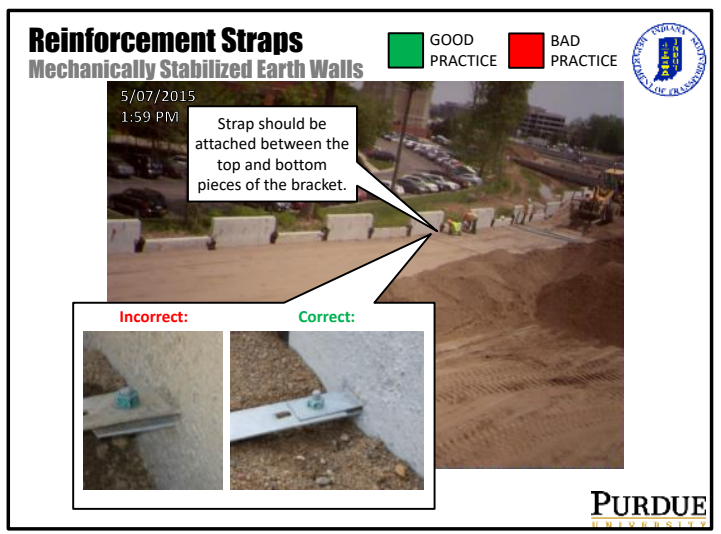

(b) Good and bad practices shown

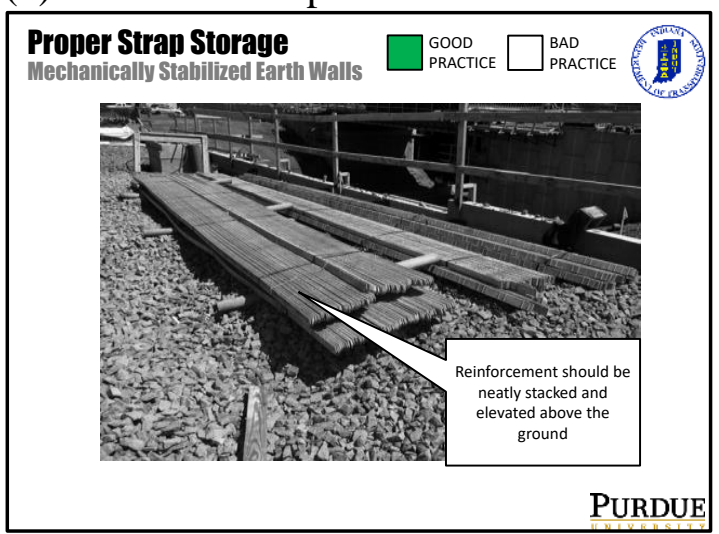

(d) Good practice for strap storage

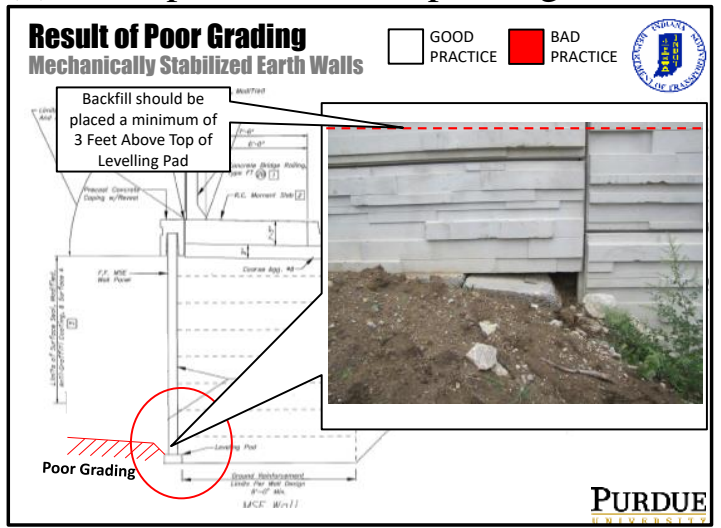

$(f)$ Results of poor practices

Figure 7.1 MSE wall construction guidelines for inspectors and contractors 
The goal of the presentation shown in Figure 7.1 is to provide the viewer with many images and figures depicting several common practices related to MSE wall construction, both good and bad. By the end of the instructional material, viewers should be able to identify several common mistakes made by contractors and how to avoid them. Galvanized soil reinforcement straps are shown in Figure 7.1b. This slide indicates where reinforcement straps should be placed on the panels. The slide shows the correct attachment procedure as well as procedures to avoid.

Figure 7.1c shows an image of stockpiling galvanized soil reinforcement straps incorrectly on the site. It is clear in this image that the straps are not neatly stacked, nor are they off the ground. Note that in this slide the 'bad practice' square is highlighted with a red box. This indicates to the reader that this kind of practice is one that should be looked for and avoided. Conversely, Figure 7.1d shows a much more well-managed storage of reinforcement straps. Note how the straps are stacked neatly, out of the way, and are elevated above the ground. This is the proper way to store reinforcement straps, as indicated on the top of the slide by highlighting the 'good practice' square with a green box.

Ensuring that contractors perform proper earthwork and compaction is a key factor in the successful construction of a mechanically stabilized earth retaining wall. The PowerPoint training module features sections dedicated to showing both proper and improper earthwork and compaction methods. Figure 7.1e is a sample from the earthwork section of the training module. As discussed in Chapter 3, backfill material should never be pushed up to the wall as shown in the image. The slide shows this is poor practice and should be avoided. Instead, the backfill should be spread closer to the 
wall by pushing the soil parallel along the length of the wall. Soil directly behind the concrete panel should be placed by hand in order to avoid pushing the panel out of level or damaging the reinforcement strap connectors.

The final sample slide shown in Figure 7.1f shows how poor grading near the MSE wall could affect the wall. It indicates that this is poor practice in the upper right, and shows an image of a wall that experienced problems by improper grading near the wall. The sloped piece of concrete under the panel next to the hole in the wall is the leveling pad, which should never be visible after construction and completion of the wall. The plan drawing shows the kind of grading that will lead to the deterioration depicted in the callout picture. Poor grading shown in the plan drawing does not allow for proper drainage. Grading such as this forces water to form a channel along the wallto-embankment interface instead of moving water away from the wall. In order to properly preserve the integrity of the wall, backfill for the embankment must be placed a minimum of 3 feet above the top of the leveling pad.

\subsection{Underdrain Construction Guidelines}

Similar to the MSE wall construction tutorial PowerPoint, the project team was tasked with creating a tutorial for the construction of underdrains. Figure 7.2 shows a sample of six slides from the presentation submitted to INDOT. Part $a$ shows the title slide of the training module titled 'Underdrain Construction: Guidelines for Contractors and Inspectors.' Figure 7.2b shows a slide that describes the standard trench dimensions and an example of a machine that digs such trenches. Inspectors are urged to verify the trench depth and dimensions frequently after verifying what it specifically called out in the construction plans. 
A typical underdrain detail is shown in the slide in Figure $7.2 c$ which describes their purpose and how underdrains work to facilitate drainage within the pavement. As with any drainage structure, the goal is to move water from one point to another. In the case of underdrains, their purpose is to remove water from within the soil under the pavement surface. Figure $7.2 d$ indicates the two most common ways for water to be discharged from the underdrains. Figure 7.2e shows a typical problem encountered when outletting the underdrain to the embankment, erosion. As indicated in the slide, in order to minimize the erosion impact from the underdrain outlet, one should consider placing the outlet as far down the embankment as possible. When outletting a pipe to the embankment, it is necessary to ensure that no foreign objects, such as animals or plants, enter the drainage pipe. In order to combat this, INDOT has required the installation of rodent screens on all underdrain outlet pipes, as seen in Figure 7.2f.

Overall, the goal of these instructional guideline tutorials is to provide several examples of what inspectors would commonly encounter while on the construction site and provide guidance as to which procedures are approved by INDOT. Although there is no substitute to in-field experience, visual training tutorials such as those showcased in this chapter have the potential to arm entry-level inspectors with the necessary knowledge in a short amount of time. This is especially useful to the entry-level inspector with little field experience that will not have the opportunity to attend in-depth training prior to the construction season. These tutorials can also be shown to contractors before a project to communicate the expectations of the agency before construction begins. 


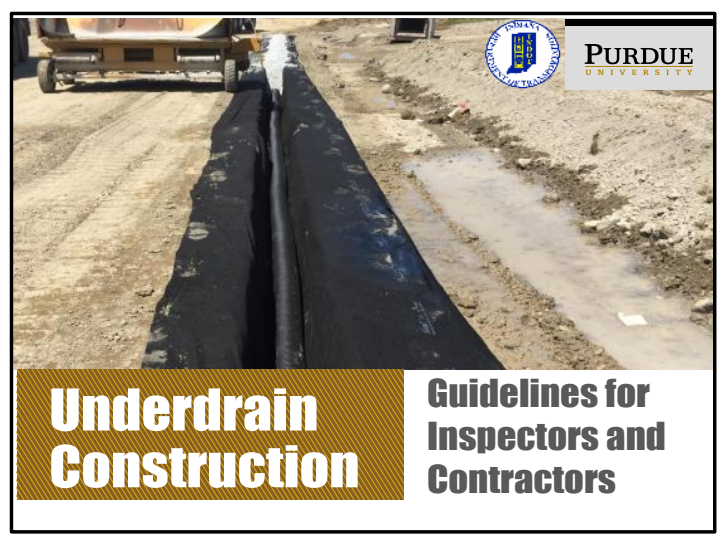

(a) Underdrain construction tutorial

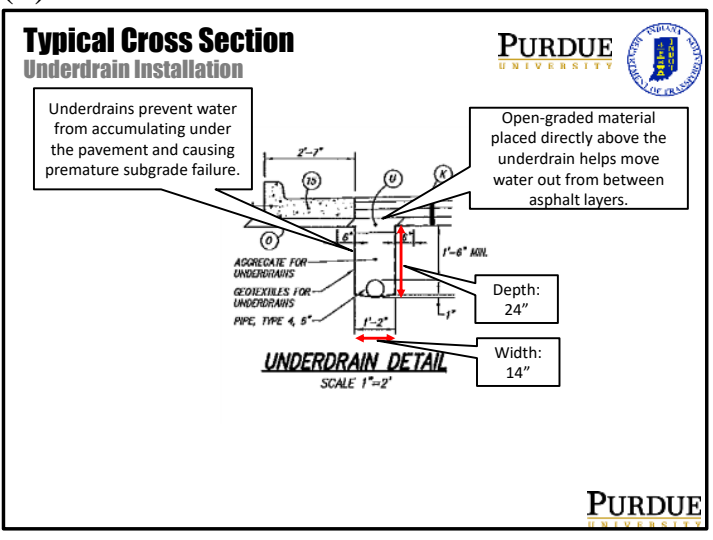

(c) Typical cross section of underdrains

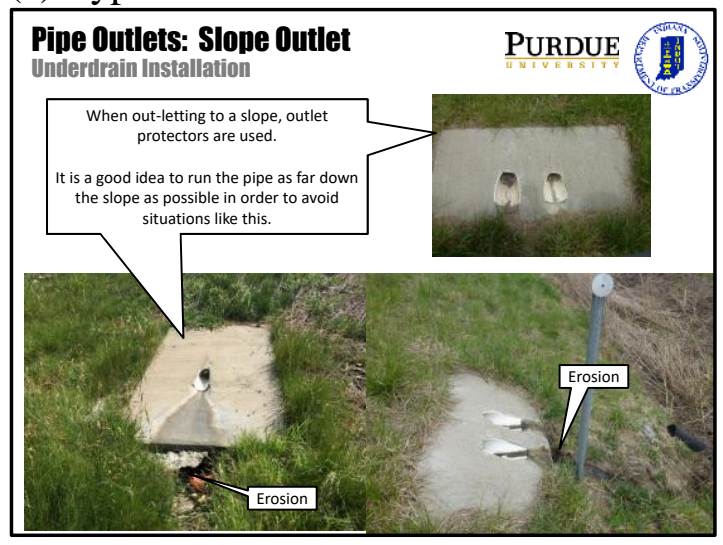

(e) Erosion considerations at slope

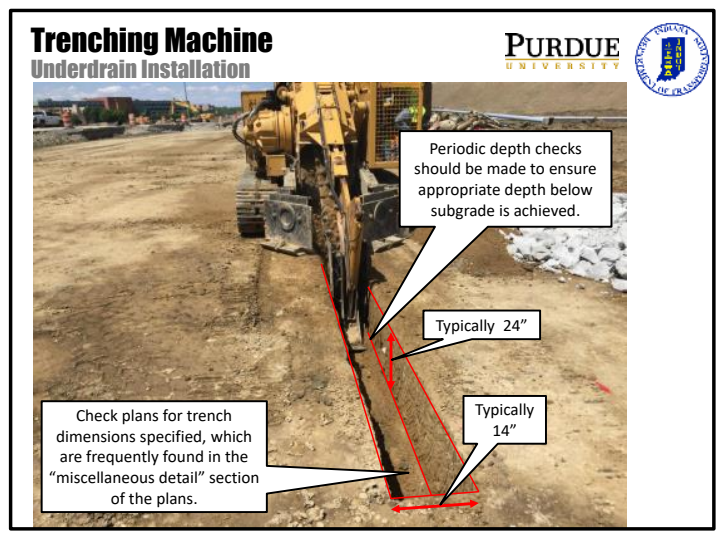

(b) Trench dimensions and notes

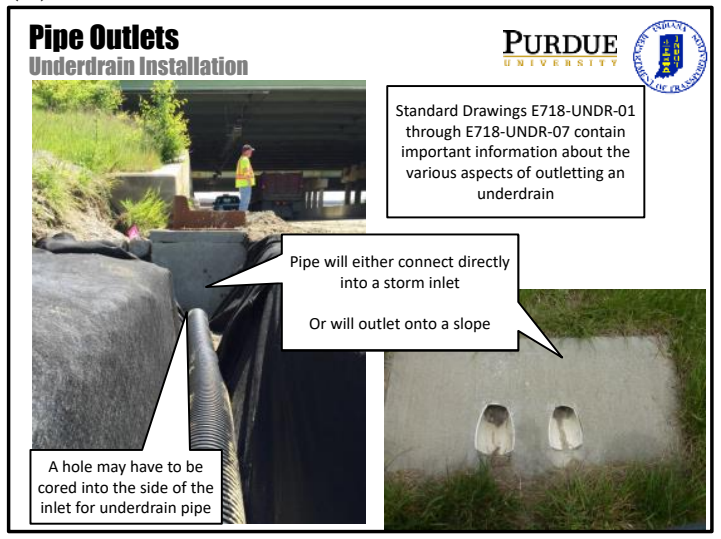

(d) Outletting pipes for drainage

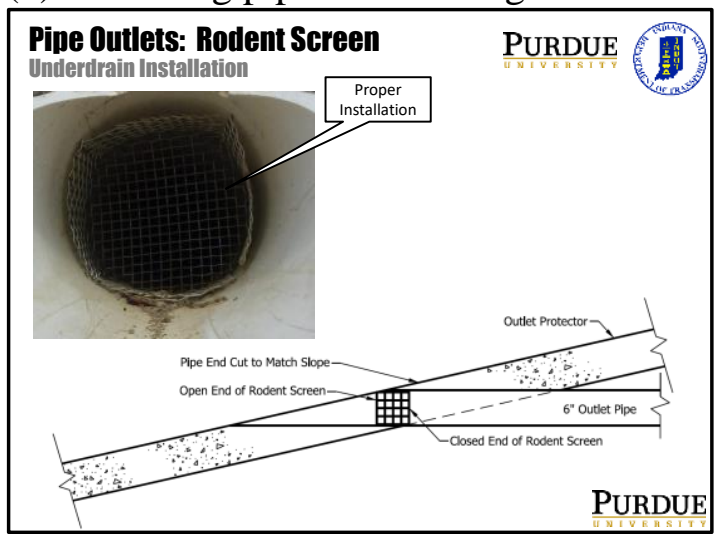

(f) Rodent screens

Figure 7.2 Underdrain construction guidelines for inspectors and contractors 


\subsection{Implementation of Training Modules by INDOT}

INDOT has implemented the training modules featured above in various ways, with plans for future uses as well. Currently, on contracts that contain operations that have training video modules produced by the project team, INDOT Project Engineers (PE) require that both INDOT Highway Technician (HT) inspectors and consulting Certified Tech inspectors view these training modules prior to beginning the work. This ensures that inspectors from both INDOT and consultants are aware of the typical situations encountered while performing such work. This also ensures that the expectations of INDOT are more transparent. For example, Elsadig Ibrahim, a Construction Engineer and PE at the INDOT Greenfield District recently had his entire inspection team view the mechanically stabilized earth retaining wall construction tutorial featured above in Section 7.2. Additionally, other training materials, such as ADA curb ramp installation are also in use. Videos such as the ADA curb ramp tutorial will be especially useful to project engineers with local planning agency (LPA) contracts.

In addition to current uses, INDOT has future plans for creating more educational and training material for construction inspectors and contractors. The most near-term goal is to use the educational training modules in the winter Highway Technician schools to supplement the standard course material. Future winter HT schools will implement the training material created by the project team, as they are relevant to the material being taught during that winter.

As more training videos are produced, INDOT plans to utilize a variety of the training modules as a requirement for "recertification" for the Certified Techs. In this 
way, INDOT can ensure that all inspectors are continually learning and gaining education regarding proper inspection and construction techniques. This "recertification" will be similar to a licensed engineer meeting a required number of continuing education hours in order to maintain the engineer's license. In addition to the training materials already created, INDOT hopes to produce virtual inspection training modules. These training modules will show time-lapse videos of specific portions of the construction of common field infrastructure. The videos will show both good and bad construction practices and inspectors will be required to identify as many construction issues as they can. 


\section{CHAPTER 8. CONCLUSIONS}

\subsection{Time-Lapse Technology}

The use of time-lapse photography to observe and document construction processes could provide new and innovative possibilities from numerous perspectives. The documentation can be used to create short video modules to educate and train inspectors, contractors, and engineers. Time-lapse of both 'big picture' (Table 2.1) and detailed construction elements (Table 2.2) can provide important training material to supplement specifications and design drawings. Such overview videos, used in conjunction with PowerPoint slides that have critical images from the time-lapse cameras and corresponding plan details provide excellent supplemental material for either self-study or discussion-based training. Some examples integrating time-lapse photos and plans were shown in Figure 1.7 and Figure 2.2. Several examples of integrating specification language from particular sections of the INDOT standard specifications manual were included throughout the case study in Chapter 2 . Furthermore, there is some benefit for complex operations to combining animation and multiple camera views. An example of illustrating a relatively complex operation involving staging and placing multiple beams is shown in Table $2.2 \mathrm{iv}$. 
Contractors and designers can benefit from the use of these educational modules to train staff on proper construction techniques for various projects. In addition, the images provide an opportunity to leverage current technologies in order to more effectively allocate the time of construction inspectors and project managers. Managers can use the photographic documentation as a digital timeline of the current construction project.

\subsection{Case Studies}

The case studies shown in Chapter 2, 3, and 4 featured the construction of a bridge overpass, a mechanically stabilized earth retaining wall, and the construction of two roundabouts, respectively. These case studies utilized time-lapse images to step through the construction process one image at a time. While Chapter 2 and Chapter 3 referenced relevant INDOT Standard Specifications, Chapter 4 compared and contrasted the construction processes of building concrete and asphalt roundabouts. These step-by-step examples can be shown to entry-level engineers, inspectors, and even contractors to give them a sense of project size, duration, and scope.

\subsection{Education in the Classroom}

Time-lapse images were utilized in the classroom to introduce pavement design to the Introduction to Transportation Engineering CE361 class. Students were given a quiz prior to the lecture, presented the lecture, and were given an identical quiz after the lecture. The scores between the pre and post lecture quizzes were compared with the expectation of seeing improvement in the second quiz as a result of introducing timelapse photography to the curriculum. Overall, the quiz scores did increase in the second quiz, showing promise for time-lapse photography in an academic setting. 


\subsection{Media and Marketing}

Two separate bridge demolitions were recorded with high-resolution GoPro cameras and the individual frames during implosion were analyzed. The project team identified the cut locations and instances where engineering principles are exemplified throughout the implosion and demolition process. Additionally, marketing and media footage was created and distributed by the project team to promote civil engineering, Purdue University, and INDOT. Through showing videos of interest to the public, good publicity can be obtained while also educating the public regarding various construction activities.

\subsection{Training for the Field}

INDOT is currently utilizing the training materials that were featured in Chapter 7 to educate their field inspectors. The training modules that have been created are now required viewing content for inspectors prior to the onset of a job requiring such work. Additionally, INDOT has plans for the future use of the training material such as implementation at winter Highway Technician School. Once enough training materials are created, INDOT will require that Highway Technicians and Certified Techs view a number of the training modules every year as continuing education. Finally, INDOT would like to create virtual inspection training modules for inspectors that can be used in a similar fashion. 


\subsection{Conclusions}

Time-lapse photography has been implemented on construction sites to obtain documentation of several common construction projects. These time-lapse videos have been used to identify both proper and improper construction techniques, to educate students in the classroom, to train professionals in the field, and to create promotional media for public viewing. The Indiana Department of Transportation has already implemented some of the educational training modules that were created for INDOT and contractor inspectors, with future plans for expansion and creation of additional training materials created from time-lapse photography. 


\section{REFERENCES}




\section{REFERENCES}

(1) Indiana Department of Transportation, "Indiana Department of Transportation Standard Specifications 2016," October, 2016 [Online]. Available: http://www.in.gov/dot/div/contracts/standards/book/sep15/2016Master.pdf

(2) Indiana Department of Transportation, "General Instructions to Field Employees," 25 October, 2016 [Online]. Available:

http://www.in.gov/dot/div/contracts/standards/GIFE/GIFEMaster.pdf

(3) Lavrenz, S.M., D. M. Bullock, "Opportunities for Enhancing Construction Education and Student Internships Using Multimedia Tools," Indiana Department of Transportation and Purdue University, West Lafayette, 2015.

(4) Mekker, M.M., M. McNamara, S.M. Remias, H. Li, J. McGregor, and D.M. Bullock, "Evaluation of Temporary Construction Point Traffic Detectors for Construction Zone Traffic Monitoring," 2015 ITS America Annual Meeting \& Expo, Pittsburgh, PA. June 2015.

(5) Lavrenz, S. M., T. L. Morris, D. M. Bullock, N. Riggs, "South Split Reconstruction Time-Lapse Composite," Purdue University, 2014 [Online]. Available: https://purr.purdue.edu/publications/1722

(6) Bullock, D. M., A. M. Hainen, A. Sydelko, D. Burford, M. Witt, "Demolition of Power Plant, ENAD, and Construction of Active Learning Center," Purdue University, 29 July, 2015 [Online]. Available: https://purr.purdue.edu/enadalc

(7) Indiana Department of Transportation, "The New US 31 Hamilton County," 25 October, 2016 [Online]. Available: http://us31hamiltoncounty.in.gov/ 
(8) South Bend Tribune, "South Bend Debuts New 'Smart Streets' Roundabouts," 8 September, 2016 [Online]. Available:

http://www.southbendtribune.com/news/local/south-bend-debuts-new-smartstreets-roundabouts/article_5c560c50-75ca-11e6-a96e-0fa98f4c5a05.html

(9) Indiana Department of Transportation, "Wabash River Bridge Replacement," October, 2016 [Online]. Available: http://www.in.gov/indot/3431.htm

(10) Indiana Department of Transportation, "Des. Nos.1172481, Bridge removal project located on old S.R. 1 over the Whitewater River, 0.5 miles south of U.S. 52 in Cedar Grove, Franklin County, Indiana," 22 June, 2011 [Online]. Available: http://www.franklincountyguide.com/files/indot\%20letter.pdf 
APPENDIX 


\section{APPENDIX}

\section{PURDUE UNIVERSITY RESEARCH REPOSITORY PUBLICATIONS}

1. Bartlett and Michigan Streets Roundabout Construction Time-Lapse http://dx.doi.org/10.4231/R7S46PXT

2. Bridge Approach Construction Time-Lapse http://dx.doi.org/10.4231/R78W3B9D

3. Bridge Beam Placement US 31 and 169th Street http://dx.doi.org/10.4231/R7542KK0

4. Bridge Deck Concrete Placement US 31 and 191st Street http://dx.doi.org/10.4231/R71C1TV8

5. Bridge Deck Construction Time-Lapse http://dx.doi.org/10.4231/R7WM1BCC

6. Bridge Deck Hydrodemolition and Rehabilitation http://dx.doi.org/10.4231/R7RV0KP3

7. Bridge in a Minute http://dx.doi.org/10.4231/R7N58JBD

8. Construction Time-Lapse of Mechanically Stabilized Earth Walls http://dx.doi.org/10.4231/R7BK199R 
9. Flexible Pavement Layering http://dx.doi.org/10.4231/R7HD7SN4

10. Honors College and Residences Construction Time-Lapse http://dx.doi.org/10.4231/R7JQ0Z0F

11. MSE Wall Construction Time-Lapse http://dx.doi.org/10.4231/R7CN71WB

12. Old Indiana State Road 1 Bridge Demolition, February 17, 2016 http://dx.doi.org/10.4231/R7348H97

13. Roundabout in a Minute http://dx.doi.org/10.4231/R77W6951

14. Sagamore Bridge Crossover Construction http://dx.doi.org/10.4231/R7445JFM

15. Sagamore Parkway Bridge Demolition and Cleanup http://dx.doi.org/10.4231/R70C4SRB

16. Sidewalk Construction 116th Street and US 31 http://dx.doi.org/10.4231/R7VM498F

17. Slip-Form Safety Barrier Construction http://dx.doi.org/10.4231/R7QZ27XK

18. Truck Apron Construction US 31 and 106th Street http://dx.doi.org/10.4231/R7M61H71

19. Underdrain Installation Time-Lapse http://dx.doi.org/10.4231/R7GF0RGV 
20. Wilmeth Active Learning Center Building Construction Time-Lapse, August 2014-September 2016

http://dx.doi.org/10.4231/R75B00D1 